Florida International University

FIU Digital Commons

FIU Electronic Theses and Dissertations

University Graduate School

$11-14-2016$

\title{
Going Beyond the Analysis of Common Contaminants: Target, Suspect, and Non-Target Analysis of Complex Environmental Matrices by High-Resolution Mass Spectrometry
}

Anna Katarina Huba

Florida International University, ahuba001@fiu.edu

DOI: $10.25148 /$ etd.FIDC001186

Follow this and additional works at: https://digitalcommons.fiu.edu/etd

Part of the Analytical Chemistry Commons, and the Environmental Chemistry Commons

\section{Recommended Citation}

Huba, Anna Katarina, "Going Beyond the Analysis of Common Contaminants: Target, Suspect, and Non-Target Analysis of Complex Environmental Matrices by High-Resolution Mass Spectrometry" (2016). FIU Electronic Theses and Dissertations. 3048.

https://digitalcommons.fiu.edu/etd/3048 


\title{
FLORIDA INTERNATIONAL UNIVERSITY \\ Miami, Florida
}

\section{GOING BEYOND THE ANALYSIS OF COMMON CONTAMINANTS: TARGET, SUSPECT, AND NON-TARGET ANALYSIS OF COMPLEX ENVIRONMENTAL MATRICES BY HIGH-RESOLUTION MASS SPECTROMETRY}

\author{
A dissertation submitted in partial fulfillment of \\ the requirements for the degree of \\ DOCTOR OF PHILOSOPHY \\ in \\ CHEMISTRY \\ by \\ Anna Katarina Huba
}


To: Dean Michael R. Heithaus

College of Arts, Sciences and Education

This dissertation, written by Anna Katarina Huba, and entitled Going Beyond the Analysis of Common Contaminants: Target, Suspect, and Non-Target Analysis of Complex Environmental Matrices by High-Resolution Mass Spectrometry, having been approved in respect to style and intellectual content, is referred to you for judgment.

We have read this dissertation and recommend that it be approved.

\section{Rudolf Jaffe}

Yong Cai

Berrin Tansel

Stanislaw Wnuk

Piero R. Gardinali, Major Professor

Date of Defense: November 14, 2016

The dissertation of Anna Katarina Huba is approved.

Dean Michael R. Heithaus

College of Arts, Sciences and Education

Andrés G. Gil

Vice President for Research and Economic Development and Dean of the University Graduate School

Florida International University, 2016 
(C) Copyright 2016 by Anna Katarina Huba

All rights reserved. 


\section{DEDICATION}

I dedicate this dissertation to my sister Kristina Huba and my dad Andrea Huba, without whose love and support this dissertation and journey would not have been possible. 


\section{ACKNOWLEDGMENTS}

I would like to start by expressing my sincere gratitude to my major professor, Dr.

Piero R. Gardinali, for all of his advice, patience, and understanding for my many travel requests. I would also thank all of my committee members, Dr. Rudolf Jaffe, Dr. Yong Cai, Dr. Berrin Tansel, and Dr. Stanislaw Wnuk, for their time, advice, and suggestions given during our few meetings. Special thanks to Dr. Jaffe for also being available to support my job applications by always being willing to write the requested recommendation letters. I would also like to thank SERC, the chemistry department, and the FIU graduate school (DEA fellowship), for supporting my studies.

Special thanks go to Ingrid whose caring nature, advice, and friendship have helped me survive my last few months at FIU, and to my good friends Kathia and Karina without whom lab just hasn't been the same. Next I would like to thank the whole EARL group (Nubia, Jenny, Cesar, Adolfo, Rafael, Jian, Margarita, Gabriela, Alina, Carlos, Sudha, and Gilbert) for the valuable input and advice, but also for the much needed coffee and sweets breaks!

The biggest thank you goes to my family, my sister Kristina without whose unconditional love and support I would not have made it through this journey, to my dad Andrea, my aunt Bea, and my grandparents Jozef and Maria, for their love, advice and support throughout my life. Last but not least, thank you to all my friends all over the world (Diana, Zsofia, Drew, Fiorenza, Stefania, and Yan-Carlo), who despite the short or long distances have always been there for me and supported me in any way they could. 


\begin{abstract}
OF THE DISSERTATION
GOING BEYOND THE ANALYSIS OF COMMON CONTAMINANTS: TARGET, SUSPECT, AND NON-TARGET ANALYSIS OF COMPLEX ENVIRONMENTAL MATRICES BY HIGH-RESOLUTION MASS SPECTROMETRY
\end{abstract}

by

Anna Katarina Huba

Florida International University, 2016

Miami, Florida

Professor Piero R. Gardinali, Major Professor

The advancements in the field of analytical chemistry, and especially mass spectrometry, have been redefining the field of contaminant detection. While more traditional analysis was sufficient to screen for a small number of well-known compounds, new techniques such as high-resolution mass spectrometry, have enabled a fairly comprehensive screening for previously unknown contaminants. This is enormously beneficial with respect to the analysis of water, air, or soil quality in a society that continuously introduces novel anthropogenic compounds into the environment. This dissertation, thus, focused on the analysis of the uncharacterized portion of compounds in two types of complex environmental matrices (i.e., crude oil and wastewater).

First, targeted and non-targeted analyses were used in order to characterize a crude oil weathering series. Traditional techniques were used for the analysis of wellknown oil components and led to the confirmation of biodegradation and photodegradation trends. An ultrahigh-resolution mass spectrometric analysis was carried out in conjunction with several visualization plots in order to search for unknown 
compounds. While the study successfully detected a drastic increase in oxygenated components (likely ketones, quinones, and carboxylic acids), it also revealed severe limitations in the state of the art non-targeted crude oil analysis. Some of these limitations were explored in an in-depth atmospheric pressure ionization study of model petroleum compounds, and the dependence of ionization efficiency on numerous factors (e.g., size, heteroatom content, and methylation level) was shown. Since disregarding these intrinsic limitations leads to severely biased conclusions, these results provide crucial information for future crude oil characterization studies. Lastly, suspected and non-targeted analyses were used to evaluate contamination levels in wastewater-impacted interrelated water samples. A significant number of persistent compounds were tentatively identified, which represents an area of environmental concern that needs to be addressed further.

Overall, this dissertation successfully applied non-targeted (in addition to targeted) analysis in order to screen for non-characterized compounds in crude oil and wastewater affected water samples. By doing so, the great potential of the growing field of non-targeted screening in order to expand the range of contaminants to include previously unknown and emerging compounds was highlighted. 


\section{TABLE OF CONTENTS}

CHAPTER

PAGE

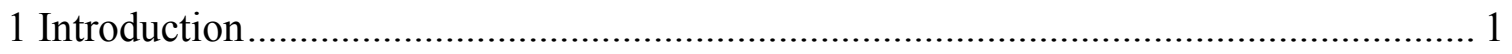

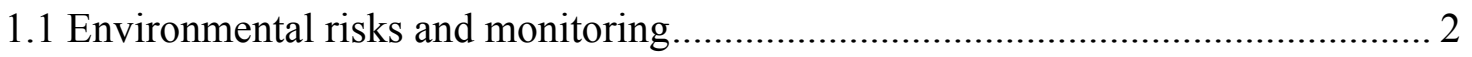

1.1.1 Crude oil: risks, composition, and analysis .............................................. 3

1.1.2 Wastewater: environmental risks ........................................................ 4

1.1.2.1 Water recycling ................................................................... 5

1.2 Target, suspect, and non-target screening ..................................................... 6

1.3 Objectives of the dissertation.......................................................................... 8

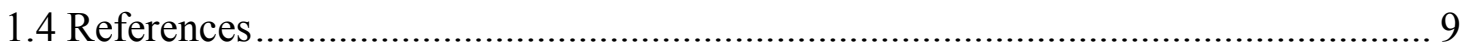

2 Characterization of a crude oil weathering series by ultrahigh-resolution mass spectrometry using multiple ionization modes....................................................... 13

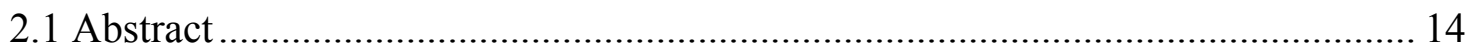

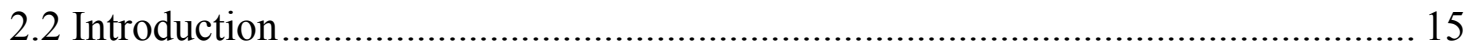

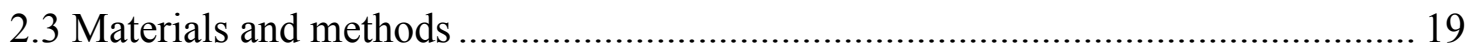

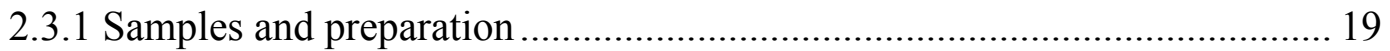

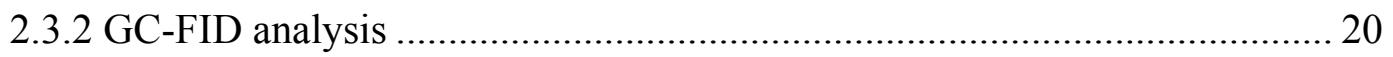

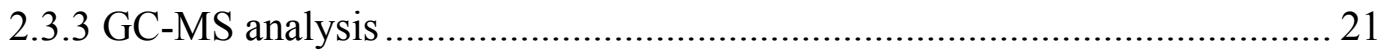

2.3.4 Ultrahigh-resolution mass spectrometric analysis ................................ 21

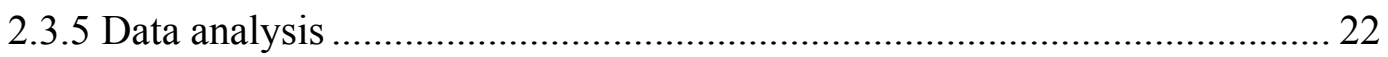

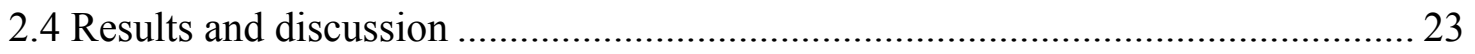

2.4.1 GC-FID and GC-MS analysis, and weathering studies .......................... 23

2.4.2 Ultrahigh-resolution mass spectrometric analysis ................................. 24

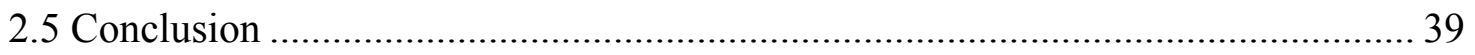

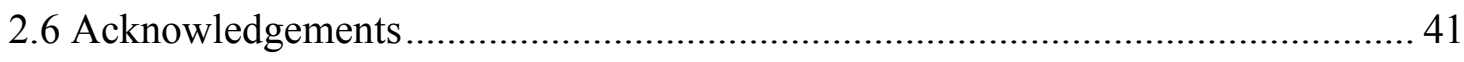

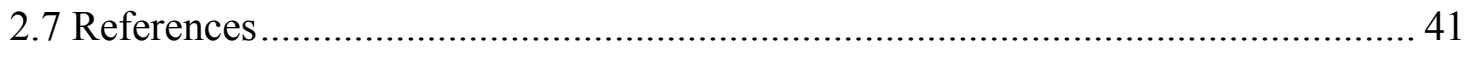

3 Understanding the atmospheric pressure ionization of petroleum components: The effect of size, structure, and presence of heteroatoms ........................................ 46

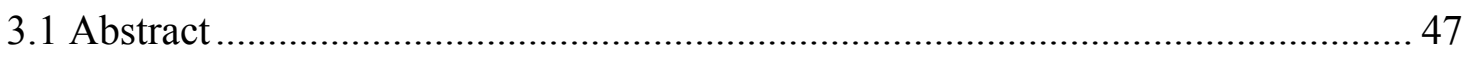

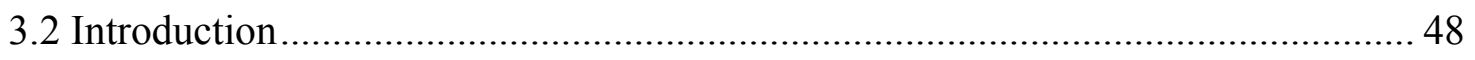

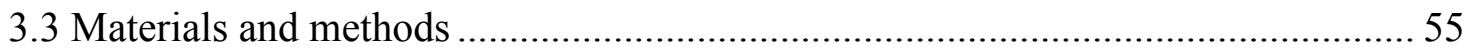




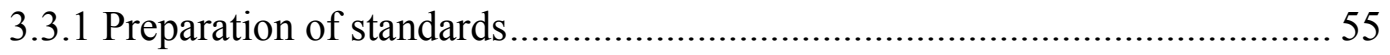

3.3.2 High-resolution mass spectrometric analysis............................................. 55

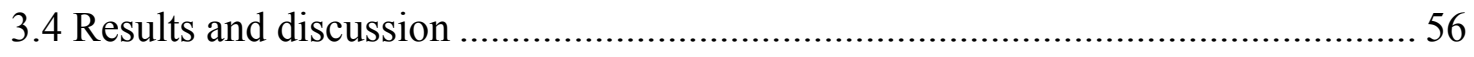

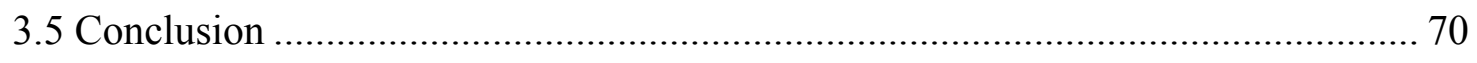

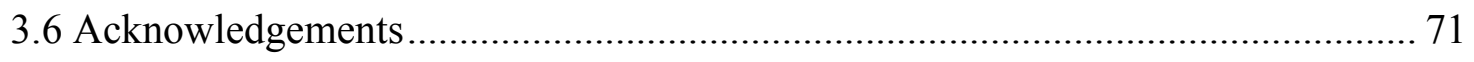

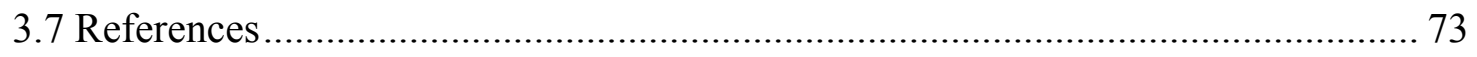

4 Occurrence of suspect and non-target contaminants in a typical system impacted by treated domestic wastewater................................................................................ 78

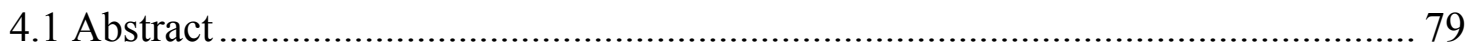

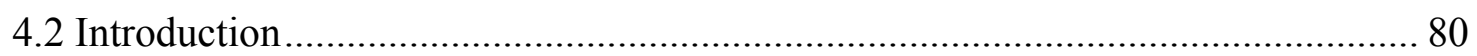

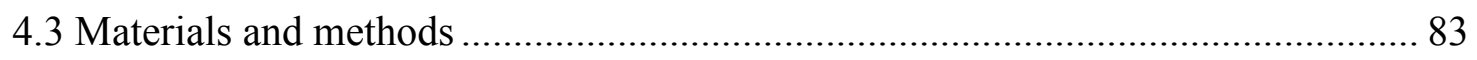

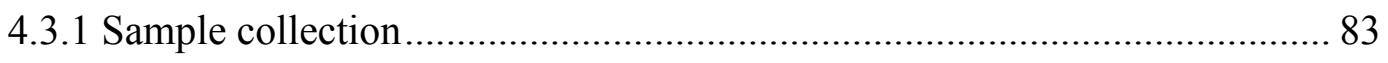

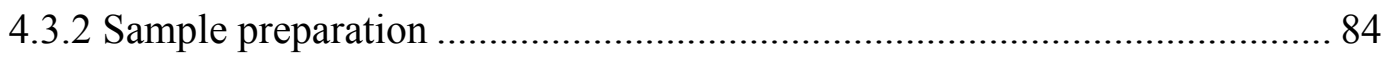

4.3.3 High-resolution mass spectrometric analysis.............................................. 85

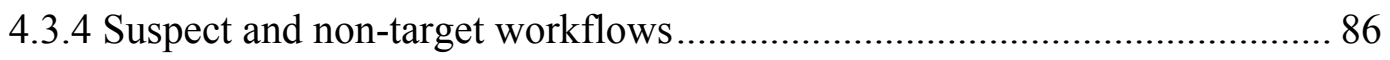

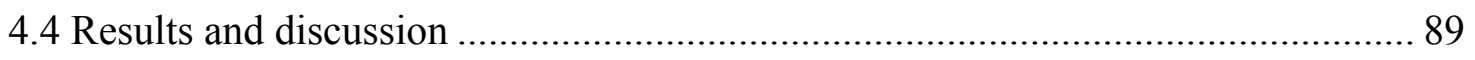

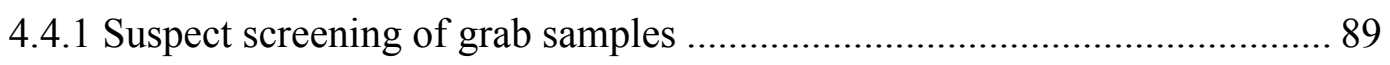

4.4.2 Non-target screening of grab samples..................................................... 92

4.4.3 Comparison of passive and grab sampling: suspected and non-targeted

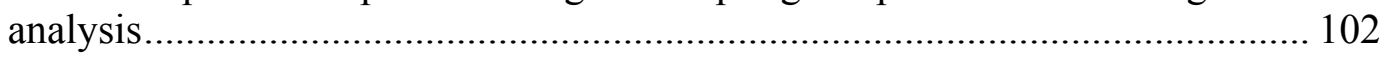

4.4.4 Persistence, fate, and transformation of contaminants through the water

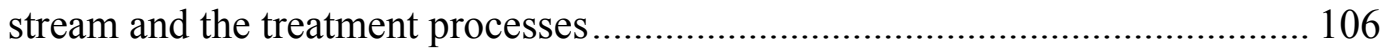

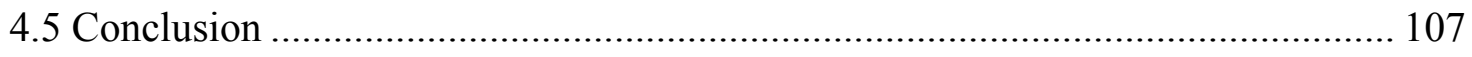

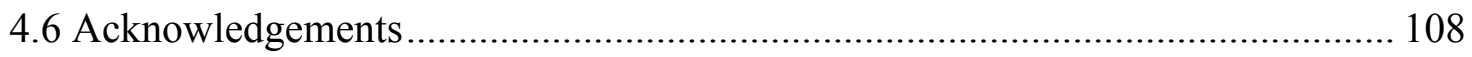

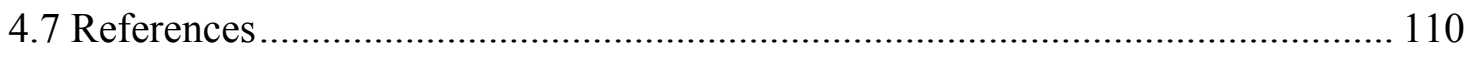

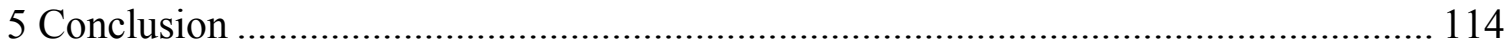

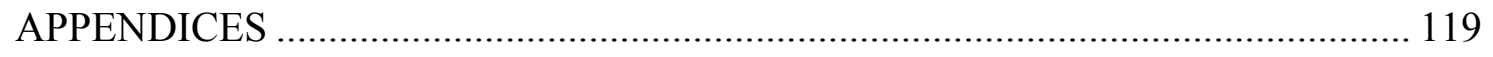

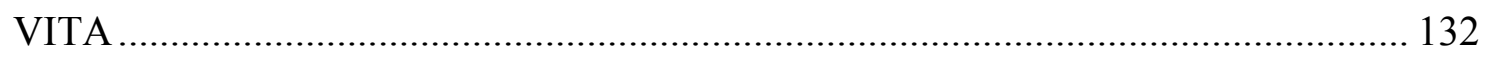




\section{LIST OF FIGURES}

FIGURE

PAGE

2.1 GC-FID chromatograms of the weathering series (Massachusets, CTC, Juniper, and Elmer's Island mat), highlighting the decrease of overall signal, as well as the disappearance of low molecular weight compounds and the formation of the UCM ..... 25

2.2 Ratios of the concentration of chrysene/benz(a)anthracene (top) and nC18/phytane (bottom) ratios for the weathering series, showing an increase in photodegradation and biodegradation, respectively. The top ratio was obtained from GC-MS data, while the bottom ratio used GC-FID data

$2.3(-)$ ESI spectra of the oil weathering series, highlighting the three distinct areas of major changes, and a relative increase of higher molecular weight compounds with weathering.

2.4 (-) APPI spectra of the oil weathering series, with the zoomed in spectra shown on the right emphasizing the shift towards higher molecular weight.

2.5 (+) DESI spectrum of unweathered Massachusetts oil, showing the successful use of an ambient technique to analyze crude oil

2.6 Class distributions for (+) APPI (top) and (+) ESI (bottom) for samples of the weathering series (Massachusetts, CTC, Juniper, Elmer's Island mat). Full arrows depict a consistent trend over the whole weathering series, while dashed arrows depict trends in which the Elmer's Island mat is an exception. Compounds showing as protonated ions are denoted by the $(\mathrm{H})$, others are radical ions.

2.7 Heteroatom class distributions for (-) APPI (top) and (-) ESI (bottom) of the weathering series (Massachusetts, CTC, Juniper, Elmer's Island mat). Full arrows depict a consistent trend over the whole weathering series, while dashed arrows depict trends in which the Elmer's Island mat is an exception. Compounds showing as protonated ions are denoted by the $(\mathrm{H})$, others are radical ions

2.8 Kendrick Mass Defect (KMD) vs. Nominal Kendrick Mass contour plots for oxygen containing hydrocarbons (left) and hydrocarbons (right) obtained using (-) APPI conditions....

2.9 DBE vs. carbon number for the $\mathrm{O}_{1}-\mathrm{O}_{3}$ containing hydrocarbons detected in the weathering series in $(+)$ APPI mode.

2.10 Van Krevelen plots of source (Massachusetts) and weathered (Juniper) oils obtained in $(+)$ APPI mode, showing the relative increase of aromatic and unsaturated oxidation products. 
2.11 (-) APPI spectrum of the Elmer's Island mat fortified with several individual model compounds used to test ionization efficiency, and Kendrick mass defect plot of the $\mathrm{O}_{1}$ and $\mathrm{O}_{2}$ classes of the same sample showing the corresponding detection and correct assignment of the model compounds.

3.1 Graph illustrating the total relative ionization efficiencies of the major compound classes that were ionized in at least one ionization source. Each compound was run in quadruplicate, all values portrayed represent averages, with the error bars representing the relative percent error.

3.2 Comparison of the average relative molar intensities of the radical versus the protonated ion in (a) APPI and (b) APCI positive mode.

3.3 Relative total molar intensities in APPI and APCI positive mode, showing (a) the effect of size $(2$ ring $\mathrm{PAH}=$ naphthalene, 3 ring $\mathrm{PAH}=$ mixture of anthracene/phenanthrene, 4 ring PAH = mixture of chrysene/benz(a)anthracene, and 5 ring $\mathrm{PAH}=$ dibenzo(a,h)anthracene), and (b) the effect of methylation on the ionization efficiencies of PAHs. Average molar intensities are depicted, with error bars showing the relative percent error.

3.4 Relative total molar intensities in APPI and APCI positive mode, showing (a) the effect of size (2 ring $\mathrm{PAH}=$ benzothiophene, 3 ring $\mathrm{PAH}=$ dibenzothiophene, and 4 ring $\mathrm{PAH}=$ naphthodibenzothiophene) and (b) the effect of methylation on the ionization efficiencies of a sulfur containing PAH. Average molar intensities are depicted, with error bars showing the relative percent error.

3.5 Comparison of two 4-ring isomeric PAHs (benzo(a)anthracene and chrysene), showing significant differences in ionization efficiency and formation of the protonated ionic species (depicted by the shaded area). The compounds were both run in quadruplicate with the relative molar intensity representing the average value and the error bars the relative percent error

3.6 Total relative molar intensities depicting the ionization efficiencies of heteroatom containing PAHs in the positive ionization mode. Relative molar intensities are an average of quadruplicate runs, and error bars represent the relative percent error

3.7 Comparison of ionization efficiencies of four PAHs analyzed in quadruplicate in individual solutions and in a PAH mixture, illustrating the extent of ionization suppression in (a) APPI, (b) APCI, and (c) ESI. Relative molar intensities and error bars represent the average value and the relative percent error, respectively. 
4.1 Scheme depicting the linked water system with the grab (UP, EFF, EMZ, DWI, and TDW) and POCIS (UP, EMZ, DWI, and TDW) sampling points

4.2 Suspect screening workflow created in Compound Discoverer 2.0, including peak-picking, retention time alignment, background subtraction, and matching of the detected $\mathrm{m} / \mathrm{z}$ values to a previously uploaded "suspects" list.

4.3 Non-target screening workflow created in Compound Discoverer 2.0, including peak-picking, retention time alignment, background subtraction, elemental composition prediction (which includes an isotopic pattern match), ChemSpider search, and mzCloud fragmentation pattern search.

4.4 Distribution of the contaminant classes for all grab sampling locations analyzed using the suspect screening workflow

4.5 Kendrick mass defect plot showing the distribution of components within the four sampling sites. The two areas unique to the effluent are highlighted by black ovals, while the red encircled area highlights the components that were tentatively identified by the non-target screening workflow.

4.6 Kendrick mass defect plots of the negative mode data for the four sampling points. Homologous series (examples depicted by red diamonds) are highlighted and are clearly present in both the effuent and the treated drinking water samples. Kendrick mass defect plot showing the distribution of components within the four sampling sites

4.7 Mass defect plot defined by the ethoxylate repeat $\left(\mathrm{C}_{2} \mathrm{H}_{4} \mathrm{O}\right)$, clearly illustrating the numerous polyethoxylated series that dominate the negative mode data of the effluent sampling site (red diamonds are examples of specific series, while the "grid" depicts numerous other homologous series differing by 44 mass units and thus an ethoxylate unit).

4.8 Mass defect plot defined by the substitution of a hydrogen with a chlorine $(\mathrm{H} / \mathrm{Cl})$, showing the distribution of components within the four sampling sites. Areas unique to the effluent sampling site are highlighted by red ovals, while the area marked by the black oval represents components mainly present in the other (surface) water samples.

4.9 Graph illustrating the major compounds tentatively identified by the non-target screening workflow in the grab samples, and their distribution within the four sampling sites

4.10 Comparison of number and distribution of components in the drinking water intake sampling site for the grab versus passive sampling methods. 
4.11 Comparison of number and distribution of components in the drinking water intake sampling site for the grab versus passive sampling methods................................ 105

4.12 Evaluation of recalcitrance of the tentatively identified compounds: compounds persistent through the river stream $(\mathrm{EMZ} \rightarrow \mathrm{DWI})$, and all the way through the drinking water (EMZ $\rightarrow$ TDW) are shown............................................... 109 


\section{LIST OF ABBREVIATIONS AND ACRONYMS}

ABBREVIATION

APCI

APLI

APPI

CEC

DBE

DCM

DEET

DESI

DWH

DWI

ESI

EFF

EMZ

GC

GCxGC

TOF

FID

FT

FT-MS

HCD

HESI
FULL NAME

Atmospheric Pressure Chemical Ionization

Atmospheric Pressure Laser Ionization

Atmospheric Pressure Photoionization Contaminants of Emerging Concern

Double Bond Equivalent

Dichloromethane

N,N-Diethyl-meta-toluamide

Desorption Electrospray Ionization

Deepwater Horizon

Drinking Water Intake

Electrospray Ionization

Effluent

Effluent Mixing Zone

Gas Chromatography

Two-Dimensional Gas Chromatography

Time of Flight

Flame ionization detector

Fourier Transform

Fourier Transform Mass Spectrometry

Higher-Energy Collisional Dissociation

Heated Electrospray Ionization 
HPLC

HRMS

IUPAC

ICR

KMD

KNM

LC

LDI

LLE

MS

MS/MS

MC-252

$\mathrm{m} / \mathrm{z}$

PAHs

POCIS

ppm

SERC

SIM

SPE

TDW

TWA

UCM

UV
High Performance Liquid Chromatography

High-Resolution Mass Spectrometry

International Union of Pure and Applied Chemistry

Ion Cyclotron Resonance

Kendrick Mass Defect

Kendrick Nominal Mass

Liquid Chromatography

Laser Desorption Ionization

Liquid-liquid extraction

Mass Spectrometry

Tandem Mass Spectrometry

Mississippi Canyon Block 252

mass over charge ratio

Polycyclic Aromatic Hydrocarbons

Polar Organic Chemical Integrative Sampler

Parts per million

Southeast Environmental Research Center

Selective ion monitoring

Solid Phase Extraction

Treated Drinking Water

Time Weighted Average

Unresolved Complex Mixture

Ultra Violet 
CHAPTER 1

Introduction 


\subsection{Environmental risks and monitoring}

The unceasingly growing human population (Ong, 2016) introduces a vast number of natural and anthropological compounds into the environment. The incessant growth is, furthermore, resulting in the scarcity of several natural resources (e.g., crude oil and freshwater) (Garcia, 2016; Owen et al., 2010; Brandt, 2008), leading humanity to explore potentially risky alternatives. The use of less accessible oil reservoirs, as well as unconventional sources of crude oil and gas has, for example, gained significant popularity (Hart, 2014); however, challenging extraction and refining techniques, combined with the lack of detailed studies and knowledge, lead to potentially great environmental concern (Brandt, 2008; Farrell and Brandt, 2006). Another human practice that has gained in popularity in recent years is water "recycling". One has to keep in mind that even though our planet is covered mostly by water, only about $3 \%$ of the total is freshwater; moreover, out of all the freshwater, the portion that is accessible to support and sustain life is only about $1 \%(\mathrm{Ong}, 2016)$. The lack of fresh and potable water has led to the increasing need of water recycling, which sparks concerns about the persistence of certain contaminants (Aguera and Lambropoulou, 2015; Levine and Asano, 2004). These compounds can, moreover, undergo several degradation reactions leading to a great variety and number of contaminants, all potentially hazardous (Farré et al., 2008). It becomes clear that all of these human practices put a lot of stress on the delicate balance of natural ecosystems (Farrell and Brandt, 2006; Levine and Asano, 2004). Therefore, agencies that are concerned with the wellbeing of our environment establish strict guidelines for water, soil, and air quality, including the testing for potentially hazardous 
contaminants. However, as a result of the continuously growing and evolving society, the contaminants introduced and present constantly change, and the monitoring of previously well-known contaminants, may not be sufficient for a future time point. It is thus imperative to have the possibility of monitoring the environment for new and emerging contaminants, which are not commonly monitored for, and not (yet) regulated.

\subsubsection{Crude oil: risks, composition, and analysis}

As previously mentioned, crude oil is one of the natural resources whose finite supply is cause of concern, because even though alternative sources of energy have been explored, humanity still heavily relies on energy derived from petroleum (Tollefson and Monastersky, 2012). A significant amount of risk comes with the constant extraction, transport, and refinement of crude oil; accidental crude oil releases are, thus, almost inevitable, and pose a severe threat to pristine ecosystems (Wang et al., 2013b). A recent such example is the Deepwater Horizon (DWH) accident, which released a turbulent mixture of gas and oil into the Gulf of Mexico (Aeppli et al., 2012; Camilli et al., 2012; McNutt et al., 2012). The monitoring of the fate of the oil represents one of the major goals following an oil spill. Crude oil is composed of thousands of compounds, which can be divided into four general classes: saturated hydrocarbons, aromatic compounds, resins, and asphaltenes (Mansuy et al., 1997; Speight, 2004a). The compositional complexity represents one of the primary challenges when dealing with petroleum. Moreover, once the crude oil is in the environment, weathering processes (e.g., dissolution, dispersion, bio/photodegradation (Aeppli et al., 2012; Wang et al., 2013a)) further increase the complexity. The characterization of known and uncharacterized 
fractions of crude oil is, thus, an important area of environmental research. Conventional petroleum characterization mainly uses gas chromatography flame ionization detection (GC-FID) and gas chromatography mass spectrometry (GC-MS) (Maki et al., 2001) to characterize known and common components such as aliphatics and polycyclic aromatic hydrocarbons (PAHs). However, limitations with coelution and inability of analyzing polar, nonvolatile, or thermally labile compounds, prevent such techniques from looking at high-boiling and polar compounds that are often prevalent in heavy and weathered oils (Wang et al., 2013; Burns, 1993; Charrie-Duhaut et al., 2000). In order to investigate the latter, one thus needs to use alternative methods of analysis, which allow for the detection of polar and non-volatile compounds, and provide the high-resolution needed to resolve the thousands of peaks present in the spectra of such a complex matrix (McKenna et al., 2013). High-resolution mass spectrometry coupled to several different ionization sources and separation techniques, is therefore usually the method of choice.

\subsubsection{Wastewater: environmental risks}

Another important area of environmental concern is related to the release of (treated) wastewater into the water cycle. The introduced wastewater, adds additional contaminants to a water system that is already affected by human practices such as agriculture and farming (Deblonde et al., 2011). Globally, the introduced contaminants are of a great variety, and include: human and veterinary drugs, personal care products, pesticides, surfactants, hormones, plasticizers, and fire retardants (Maruya et al., 2016; Odendaal et al., 2015). With the advancements of analytical techniques, pollutants can now be readily detected at trace levels (i.e., concentrations in the ng/L range (Odendaal et 
al., 2015)), which allows one to become aware of a much larger range of contaminants present, that might not be present on routine monitoring list. While some of these compounds, such as pesticides, can have a direct toxic behavior on aquatic life even at low concentrations (Relyea, 2009), other issues are the persistence, accumulation and biomagnification (Fono et al., 2006; Guo and Krasner, 2009). Although most of these unknown contaminants are present at concentrations levels much below established toxicity levels, the long-term effect of these novel contaminants are often not studied and not known (Odendaal et al., 2015). These newly detected, widely unregulated and unmonitored compounds (Diamond et al., 2011) fall under the broad term of "contaminants of emerging concern", which are defined by the US Environmental Protection Agency (US-EPA) as "pollutants not currently included in routine monitoring programs" which "may be candidates for future regulation depending on their ecotoxicity and potential health effect and frequency of occurrence in environmental media" (EPA, 2015). These compounds can then, moreover, undergo diverse degradation processes, leading to the formation of transformation products, which can be of equal or higher concern with respect to their parent molecules (Farré et al., 2008).

\subsubsection{Water recycling}

Water recycling is an important way to obtain fresh and drinking water, and has gained significant importance and urgency in an era were water scarcity is a serious and growing issue (Miller, 2006). Reclaimed water is used for a variety of purposes, such as agriculture, irrigation, construction activities, artificial lakes, or even to make drinking water (Bixio et al., 2008; Ong, 2016). One of the principal concerns with this practice is 
that many contaminants are not removed during the wastewater treatment and are recalcitrant and ubiquitous (Fatta-Kassinos et al., 2011). Waste water treatment plants (WWTPs) collect and "clean up" urban and industrial wastewater, to a point where the water that is released back into the environment is as free of contaminants as possible. However, the treatments are often not enough to efficiently remove the more persistent compounds (Batt et al., 2016; Kümmerer, 2009; Verlicchi et al., 2012). In addition to the contaminants that are released into the water cycle through WWTPs, others are released directly into the surrounding surface waters (e.g., pesticides, veterinary pharmaceuticals). Therefore, some of these compounds will persist and transform during the procedures involved in the reclamation process, and one of the current major issues is that specific water quality guidelines or standards are missing. To obtain a broad picture of as many of the contaminants present (even at trace levels), a technique needs to be used which provides the sensitivity of trace analysis, and at the same time the resolution needed in order to resolve all the components of a complex matrix. In recent years, thus, highresolution mass spectrometry in combination with mainly liquid chromatography (and to a smaller extend GC) has been the analysis method of choice.

\subsection{Target, suspect, and non-target screening}

As previously mentioned, the most popular methods for monitoring contaminants in the environment include liquid (LC) and gas (GC) chromatography coupled to mass spectrometry (MS). When screening for a set of known compounds, which have available reference standards for the ultimate confirmation, one performs target analysis. Such analysis is very useful for quick and specific inquiries, and for quantification studies. 
However, the limited number of compounds analyzed severely narrows the number of compounds investigated, and the majority of contaminants present are ignored. To obtain a comprehensive picture, non-target analysis can be performed. Non-targeted analysis requires no "a priori" selection of contaminants, and theoretically detects any compound present above the method detection limit. Moreover, since no prior selection of compounds is needed, retrospective analysis is also possible. These features are enormously advantageous and necessary for the determination of new and emerging contaminants, or transformation products, as such are not yet included in target lists. Suspect screening is non-target analysis where some previous knowledge of the possible contaminants is present and these are thus included into extensive lists, which are then used for the screening of the contaminants.

Both suspect and non-target analysis largely rely on the power and development of high-resolution mass spectrometric instruments. Such techniques allow for the acquisition of full scan spectra while providing accurate-mass and high-resolution, two factors essential for non-targeted analysis. Instruments such as the Orbitrap or the Fourier Transform Ion Cyclotron Resonance (FT-ICR) mass spectrometers routinely provide resolutions of $>140,000$ and $>1,000,000$ FWHM, respectively, and mass accuracies of $<1$ ppm. Depending on the class of compounds of interest, these techniques can then be coupled to different separation techniques (e.g., GC, LC, and GCxGC) and different ionization sources (e.g., electrospray ionization, atmospheric pressure photoionization, and atmospheric pressure chemical ionization). Moreover, high-resolution is also essential when dealing with the analysis of complex matrices (such as crude oil and 
wastewater), to separate the thousands of peaks present, separate isobaric compounds, and obtain molecular formulae.

\subsection{Objectives of the dissertation}

The overall goal of this dissertation is to perform target, as well as suspect and non-target analysis in two complex environmental matrices (i.e., crude oil and wastewater affected water), to expand the range compounds investigated to uncharacterized and emerging contaminants.

First, target analysis will be employed to characterize a novel weathering series stemming from the Deepwater Horizon disaster. The results on known compound classes (i.e., aliphatics and aromatics) will be used to assess whether a weathering series is present, and what type of weathering processes affected the oil samples. Subsequently, high-resolution mass spectrometry will be used to perform non-targeted analysis and characterize the overall changes in the oil composition, as well as identify specific compound classes being formed within the uncharacterized portion of the crude oils.

Current limitations in "petroleomics" will be evidenced by a separate atmospheric pressure ionization study on select model petroleum compounds. Intrinsic benefits and drawbacks of three commonly employed atmospheric pressure ionization sources (i.e., electrospray ionization, atmospheric pressure photoionization, and atmospheric pressure chemical ionization) will be revealed. More specifically, ionization efficiencies, as well as specific factors affecting the latter, will be shown for a broad range of compounds.

Lastly, the use and benefits of suspect and non-target analysis towards the tentative identification of contaminants and transformation products in wastewater 
affected water samples will be shown, and the distribution and recalcitrance of the tentatively identified compounds will be evaluated. Moreover, the advantages of passive sampling will be evaluated with respect to grab sampling.

\section{$1.4 \quad$ References}

Aeppli C, Carmichael CA, Nelson RK, Lemkau KL, Graham WM, Redmond MC, et al. Oil Weathering after the Deepwater Horizon Disaster Led to the Formation of Oxygenated Residues. Environmental Science \& Technology 2012; 46: 8799-8807.

Agüera A, Lambropoulou D. New Challenges for the Analytical Evaluation of Reclaimed Water and Reuse Applications. In: Fatta-Kassinos D, Dionysiou DD, Kümmerer K, editors. Wastewater Reuse and Current Challenges. Springer International Publishing, Cham, 2016; 7-47.

Batt AL, Kincaid TM, Kostich MS, Lazorchak JM, Olsen AR. Evaluating the extent of pharmaceuticals in surface waters of the United States using a National-scale Rivers and Streams Assessment survey. Environmental Toxicology and Chemistry 2016; 35: 874881.

Bixio D, Thoeye C, Wintgens T, Ravazzini A, Miska V, Muston M, et al. Water reclamation and reuse: implementation and management issues. Desalination 2008; 218: 13-23.

Brandt AR. Converting Oil Shale to Liquid Fuels: Energy Inputs and Greenhouse Gas Emissions of the Shell in Situ Conversion Process. Environmental Science \& Technology 2008; 42: 7489-7495.

Burns KA. Evidence for the Importance of Including Hydrocarbon Oxidation-Products in Environmental Assessment Studies. Marine Pollution Bulletin 1993; 26: 77-85.

Camilli R, Di Iorio D, Bowen A, Reddy CM, Techet AH, Yoerger DR, et al. Acoustic measurement of the Deepwater Horizon Macondo well flow rate. Proceedings of the National Academy of Sciences of the United States of America 2012; 109: 20235-20239.

Charrie-Duhaut A, Lemoine S, Adam P, Connan J, Albrecht P. Abiotic oxidation of petroleum bitumens under natural conditions. Organic Geochemistry 2000; 31: 977-1003.

Deblonde T, Cossu-Leguille C, Hartemann P. Emerging pollutants in wastewater: A review of the literature. International Journal of Hygiene and Environmental Health 2011; 214: 442-448. 
Diamond JM, Latimer HA, Munkittrick KR, Thornton KW, Bartell SM, Kidd KA. Prioritizing contaminants of emerging concern for ecological screening assessments. Environmental Toxicology and Chemistry 2011; 30: 2385-2394.

EPA. Water: Contaminants of emerging concern. 2015. http://water.epa.gov/scitech/cec/

Farrell AE, Brandt AR. Risks of the oil transition. Environmental Research Letters 2006; 1: 014004 .

Farré Ml, Pérez S, Kantiani L, Barceló D. Fate and toxicity of emerging pollutants, their metabolites and transformation products in the aquatic environment. TrAC Trends in Analytical Chemistry 2008; 27: 991-1007.

Fatta-Kassinos D, Kalavrouziotis IK, Koukoulakis PH, Vasquez MI. The risks associated with wastewater reuse and xenobiotics in the agroecological environment. Science of The Total Environment 2011; 409: 3555-3563.

Fono LJ, Kolodziej EP, Sedlak DL. Attenuation of Wastewater-Derived Contaminants in an Effluent-Dominated River. Environmental Science \& Technology 2006; 40: 72577262.

Garcia X, Pargament D. Reusing wastewater to cope with water scarcity: Economic, social and environmental considerations for decision-making. Resources, Conservation and Recycling 2015; 101: 154-166.

Guo YC, Krasner SW. Occurrence of Primidone, Carbamazepine, Caffeine, and Precursors for N-Nitrosodimethylamine in Drinking Water Sources Impacted by Wastewater1. JAWRA Journal of the American Water Resources Association 2009; 45: 58-67.

Hart A. A review of technologies for transporting heavy crude oil and bitumen via pipelines. Journal of Petroleum Exploration and Production Technology 2014; 4: 327336.

Kümmerer K. The presence of pharmaceuticals in the environment due to human use present knowledge and future challenges. Journal of Environmental Management 2009; 90: 2354-2366.

Levine AD, Asano T. Peer Reviewed: Recovering Sustainable Water from Wastewater. Environmental Science \& Technology 2004; 38: 201A-208A.

Maki H, Sasaki T, Harayama S. Photo-oxidation of biodegraded crude oil and toxicity of the photo-oxidized products. Chemosphere 2001; 44: 1145-1151. 
Mansuy L, Philp RP, Allen J. Source identification of oil spills based on the isotopic composition of individual components in weathered oil samples. Environmental Science \& Technology 1997; 31: 3417-3425.

Maruya KA, Dodder NG, Sengupta A, Smith DJ, Lyons JM, Heil AT, et al. Multimedia screening of contaminants of emerging concern (CECS) in coastal urban watersheds in southern California (USA). Environmental Toxicology and Chemistry 2016; 35: 19861994.

McKenna AM, Nelson RK, Reddy CM, Savory JJ, Kaiser NK, Fitzsimmons JE, et al. Expansion of the Analytical Window for Oil Spill Characterization by Ultrahigh Resolution Mass Spectrometry: Beyond Gas Chromatography. Environmental Science \& Technology 2013; 47: 7530-7539.

McNutt MK, Camilli R, Crone TJ, Guthrie GD, Hsieh PA, Ryerson TB, et al. Review of flow rate estimates of the Deepwater Horizon oil spill. Proceedings of the National Academy of Sciences of the United States of America 2012; 109: 20260-20267.

Miller GW. Integrated concepts in water reuse: managing global water needs. Desalination 2006; 187: 65-75.

Odendaal C, Seaman MT, Kemp G, Patterton HE, Patterton H-G. An LC-MS/MS based survey of contaminants of emerging concern in drinking water in South Africa. South African Journal of Science 2015; 111: 01-06.

Ong CN. Water reuse, emerging contaminants and public health: state-of-the-art analysis. International Journal of Water Resources Development 2016; 32: 514-525.

Owen NA, Inderwildi OR, King DA. The status of conventional world oil reservesHype or cause for concern? Energy Policy 2010; 38: 4743-4749.

Relyea RA. A cocktail of contaminants: how mixtures of pesticides at low concentrations affect aquatic communities. Oecologia 2009; 159: 363-376.

Speight JG. Petroleum asphaltenes - Part 1 - Asphaltenes, resins and the structure of petroleum. Oil \& Gas Science and Technology-Revue D Ifp Energies Nouvelles 2004; 59: 467-477.

Tollefson J, Monastersky R. The global energy challenge: Awash with carbon. Nature 2012; 491: 654-655.

Verlicchi P, Al Aukidy M, Zambello E. Occurrence of pharmaceutical compounds in urban wastewater: Removal, mass load and environmental risk after a secondary treatment-A review. Science of The Total Environment 2012; 429: 123-155. 
Wang C, Chen B, Zhang B, He S, Zhao M. Fingerprint and weathering characteristics of crude oils after Dalian oil spill, China. Marine Pollution Bulletin 2013; 71: 64-68. 


\section{CHAPTER 2}

\section{Characterization of a crude oil weathering series by ultrahigh-resolution mass}

\section{spectrometry using multiple ionization modes}

This chapter was published in the journal Science of the Total Environment and adapted with permission from all participating authors.

Anna Katarina Huba, Piero R. Gardinali, Science of the Total Environment 563-564 (2016) 600-610. 


\subsection{Abstract}

Accidental crude oil releases, such as the Deepwater Horizon (DWH) accident are always a potential threat to pristine marine ecosystems. Since the toxicity of crude oil heavily depends on its variable composition, the comprehensive characterization of crude oil compounds as a function of weathering is an important area of research. Traditional gas chromatography-based characterization presents significant limitations, and the use of ultrahigh-resolution mass spectrometric (UHRMS) techniques (that allow for the assignment of molecular formulae) has been shown to be better equipped to address the complex nature of crude oils. This study used a Q Exactive Orbitrap mass spectrometer operated at a resolving power of 140,000 FWHM with both electrospray ionization (ESI) and atmospheric pressure photoionization (APPI) sources, in order to characterize a crude oil weathering series of the Macondo oil released during the $D W H$ incident (the source oil, two differently weathered surface slicks, and a beached residue). Preliminary gas chromatography mass spectrometry (GC-MS) and gas chromatography flame ionization detection (GC-FID) results suggested that the four oils comprised a true weathering series (including biodegradation and photodegradation in addition to other well-known processes such as dissolution and evaporation). UHRMS results showed a clear increase in oxygenated compounds with weathering, and further suggest a significant gain of acidic compounds, as well as the transformation of phenols to ketonic and quinonic compounds with weathering. A complementary study on a weathered oil sample amended with selected model compounds contributed additional insight into the functional group types that are accessible in each ionization technique. 


\subsection{Introduction}

In a society that is highly dependent on energy derived from petroleum, constant crude oil extraction and transportation lead to virtually unavoidable releases into the environment (Wang et al., 2013). On April 20, 2010, a turbulent mixture of gas and a light, sweet (Macondo type) crude oil was released into the Gulf of Mexico as a result of the Deepwater Horizon (DWH) drilling rig incident in the Mississippi Canyon Block 252 (MC252) (Aeppli et al., 2012; Camilli et al., 2012; McNutt et al., 2012). In the days following the accident, some of the escaped Macondo oil rose $1500 \mathrm{~m}$ to the surface of the ocean, creating oil slicks some of which ultimately reached the coast (Liu et al., 2012). In the event of crude oil discharges into marine environments, weathering processes such as dissolution, dispersion, emulsification, evaporation, biodegradation, and photo-oxidation (Aeppli et al., 2012; Wang et al., 2013) constantly modify the oil composition (Jordan and Payne, 1980; Wang et al., 2013). Weathering, thus, adds compositional complexity to what is already one of the most complex natural mixtures known to mankind (Hsu et al., 2011). The thousands of compounds present in crude oil can be divided into four main classes: saturated hydrocarbons (straight, branched, and cyclic alkanes), aromatic compounds (containing one or more rings), resins (relatively high molecular weight and polar compounds, which are soluble in the oil, and contain heteroatoms such as nitrogen, sulfur, and oxygen), and asphaltenes (highest molecular weight and most polar compounds, also containing heteroatoms such as nitrogen, oxygen and sulfur but unlike resins insoluble in the oil) (Garrett et al., 1998; Speight, 2004). These different compound types are affected differently by oil weathering as each of the weathering processes is selective towards specific compounds. For example, evaporation 
and emulsification deplete the oil of its volatile compounds, while water washing removes water-soluble compounds (Mansuy et al., 1997), and biodegradation affects primarily $\mathrm{n}$-alkanes followed by branched and cyclic hydrocarbons, closely followed by naphthenic compounds (Wang et al., 2013). Photo-oxidation has been shown to primarily modify select polycyclic aromatic hydrocarbons (PAHs), and in addition to other oxidation mechanisms (including biodegradation) to be responsible for the increase of the oxygen content in the remaining oil (McKenna et al., 2013; Prince et al., 2003). Since several constituents in crude oil have been associated with some degree of toxicity, the characterization of fresh and especially of the modified weathered crude oil is crucial in order to understand the potential environmental effects.

Conventional oil characterization by gas chromatography flame ionization detection (GC-FID), or gas chromatography mass spectrometry (GC-MS) (Maki et al., 2001), has been able to elucidate weathering related compositional changes of hydrocarbons and PAHs. However, coelution and the inability to analyze polar, nonvolatile, or thermally unstable compounds (Burns, 1993; Charrie-Duhaut et al., 2000; Garrett et al., 1998; McKenna et al., 2013; Wang et al., 2013), limit the amount and type of analytes that can be detected (McKenna et al., 2013). Consequently, both techniques tend to overlook the analysis of oxygenated hydrocarbons (Aeppli et al., 2012), which is particularly problematic for weathered oil that has a lower amount of low-boiling and non-polar compounds that are GC amenable, and has a higher amount of high-boiling and polar compounds (Aeppli et al., 2012). The characteristic oil "hump" or unresolved complex mixture (UCM), which is a raised baseline due to the coelution of numerous compounds and is observed in GC analysis and is most prominent in weathered oils, is an 
indication of the limitations of these previously described techniques (Gough and Rowland, 1990). In order to resolve a larger fraction of the components present in oil, more advanced techniques need to be used, such as two-dimensional gas chromatography mass spectrometry $(\mathrm{GC} \times \mathrm{GC}-\mathrm{MS})$ or Fourier transform mass spectrometry (FT-MS). GC $\times$ GC-MS somewhat expands the accessible analytical window and allows for isomer differentiation (McKenna et al., 2013); however, it is still limited to volatile compounds that are $\mathrm{GC}$ amenable (up to $\mathrm{C}_{45}$ ). FT-MS, on the other hand, provides the possibility to extend this range up to $\mathrm{C}_{100}$ (McKenna et al., 2013), and to analyze nonvolatile and/or highly polar compounds (Mapolelo et al., 2009; Qian et al., 2001a; Qian et al., 2001b). Moreover, FT-MS analysis provides ultrahigh-resolution (Kaiser et al., 2011; Podgorski et al., 2013), and mass accuracy of less than $1 \mathrm{ppm}$ (with internal calibration) (Savory et al., 2011), which leads to the possibility of assigning elemental compositions (Rodgers et al., 2005). The ability to couple several different ionization techniques to FT-MS is also crucial in the analysis of complex and diversified mixtures such as crude oil. Common sources that have been used are electrospray ionization (ESI) and atmospheric pressure photo ionization (APPI) (McKenna et al., 2013), but others such as atmospheric pressure chemical ionization (APCI) (Roussis and Fedora, 2002), and atmospheric pressure laser ionization (APLI) (Schrader et al., 2008) have also been employed. APPI is particularly useful to characterize nonpolar or slightly polar species, while ESI offers the advantage of accessing more polar species while avoiding interferences of the hydrocarbon matrix. As a result, comprehensive characterizations of weathered oils must be achieved by a combination of multiple techniques, aimed at accessing the maximum possible number of compounds. 
A big portion of the previous studies on the Macondo oil released during the $D W H$ accident have focused mainly on common analytes that are GC amenable, such as PAHs, alkanes, and hopane and sterane biomarkers (Aeppli et al., 2012; McKenna et al., 2013). Unsurprisingly, reports have shown that, with increased weathering, the oil was depleted of most of its saturated and aromatic compounds (Aeppli et al., 2012; Atlas and Hazen, 2011; Carmichael et al., 2012; Kostka et al., 2011; Lima et al., 2005; Liu et al., 2012). However, McKenna et al. (2013) estimated that in surface slicks only about $40 \%$ of the total mass of hydrocarbons could be analyzed by conventional GC-based techniques, while Reddy et al. (2012) estimated that for weathered Macondo oil traditional analytes only account for less than $25 \%$ of the oil mass. Moreover, an increase in oxygenated hydrocarbons with a concurrent decrease in saturated hydrocarbons and aromatics was reported in weathered oil deposited at the shoreline (Aeppli et al., 2012). Hall et al. (2013) further predicted by GC $\times$ GC-MS analysis that this oxygenated fraction is largely due to the oxidation of saturates, which has only recently been shown to be a significant process during oil weathering (Hall et al., 2013). FT-ICR analysis of oiled sands has shown a similar trend, more specifically detecting the possible formation of carboxylic acids, ketones, and alcohols (Ruddy et al., 2014), all being consistent with photo-oxidation and biodegradation transformation products. However, a significant portion of the currently available knowledge originates from $\mathrm{GC} \times \mathrm{GC}-\mathrm{MS}$ analysis, and thus only applies to a limited amount of compounds. Data currently available from ultrahigh-resolution mass spectrometry (UHRMS) is limited, which evidences a strong need to expand the knowledge on weathering products of the Macondo crude oil by FTMS techniques. This study, therefore, aims to characterize and identify compositional 
changes that occurred in a weathering series (fresh crude oil, two distinct oil slicks, and a beached oil mat) of the Macondo crude oil. UHRMS coupled with APPI and ESI in both positive and negative ionization mode are used in order to expand the range and type of compounds that can be detected.

\subsection{Materials and methods}

\subsubsection{Samples and preparation}

Four different field-collected oils were characterized in this study. The unweathered Macondo oil (denoted as Massachusetts oil from hereon) was collected by a production vessel on August 15, 2010 directly at the MC-252 wellhead, and transferred to the Massachusetts oil barge. Two weathered oils originating from two distinct surface slicks were skimmed from the Gulf of Mexico, and were collected by the USCG Cutter Juniper and Barge No. CTC02404 on July 19, 2010 and July 29, 2010, respectively (referred to as Juniper and CTC oil from now on). The last oil was buried in the shoreline of Elmer's Island (Louisiana), was exposed after hurricane Isaac, and was subsequently collected in August 2012 (denoted as Elmer's Island mat from hereon). A 20,000 ppm oil stock solution was then created for the four oils by dissolving approximately $1 \mathrm{~g}$ of crude oil in $50 \mathrm{~mL}$ of methylene chloride. The stock solutions were then diluted two-fold to a final concentration of 10,000 ppm for GC-FID and GC-MS analyses. GC-MS samples were spiked with $100 \mu \mathrm{L}$ of a PAH surrogate standard mixture (naphthalene-d8, acenaphtene-d10, phenanthrene-d10, and perylene-d12), as well as $100 \mu \mathrm{L}$ of a PAH internal standard mixture (fluorine-d10 and benzo(a)pyrene-d12). GC-FID samples, on the other hand, were spiked with $100 \mu \mathrm{L}$ of an aliphatic surrogate (n-dodecane-d26, n- 
eicosane-d42, n-triacontane-d62, p-terphenyl-d14) as well as $100 \mu \mathrm{l}$ of an aliphatic internal standard ( $5 \alpha$ androstane and n-hexadecane-d34). For UHRMS analysis $50 \mu \mathrm{L}$ of oil stock was left to air dry, and was subsequently reconstituted into 50:50 toluene/methanol to a final concentration of $2500,5000,5000$, and $10,000 \mathrm{ppm}$ for Massachusetts, CTC, Juniper, and Elmer's Island mat, respectively. The final solutions were spiked with $1 \%$ formic acid, and $1 \%$ ammonium hydroxide for positive and negative ionization mode, respectively. An internal standard (tetradecanoic 14,14,14-d3 acid, $11.6 \mathrm{ppm}$ ) was added to all UHRMS samples. The desorption electrospray ionization (DESI) analysis' sample preparation was minimal, and consisted in creating a thin oil film on a DESI slide. For the model compound study, Elmer's Island mat was spiked with ten standards covering a range of functional group types: phenol, 2ethylphenol, 4-isopropylphenol, coprostane, coprostan-3-one, cholesterol, tetradecanoic 14,14,14,-d3 acid (all at approximately $10 \mathrm{ppm})$, coprostan-3-ol (1 ppm), tetracosanol (2 ppm), and tetracosanoic acid (5 ppm). All the solvents used were Optima LC/MS grade and were purchased from Fisher Scientific (Fair Lawn, NJ, USA).

\subsubsection{GC-FID analysis}

GC-FID analysis was carried out on a Thermo Trace 1310 GC-FID, fitted with an

$\mathrm{Rxi}^{\circledR}-5 \mathrm{Sil}$ fused silica capillary column $(30 \mathrm{~m} \times 0.25 \mathrm{~mm} \times 0.25 \mu \mathrm{m})$. A sample volume of $2 \mu \mathrm{L}$ was injected (in splitless mode) into the instrument. The inlet temperature was held at $325^{\circ} \mathrm{C}$, and the carrier gas was set at a constant flow rate of $2.4 \mathrm{~mL} / \mathrm{min}$. The starting oven temperature was $40^{\circ} \mathrm{C}$, followed by an initial $7.5^{\circ} \mathrm{C} / \mathrm{min}$ ramp to $215^{\circ} \mathrm{C}$, and a second $10{ }^{\circ} \mathrm{C} / \mathrm{min}$ ramp to $320^{\circ} \mathrm{C}$, and then a final hold of $13 \mathrm{~min}$. 


\subsubsection{GC-MS analysis}

GC-MS analysis was carried out in electron impact mode $(70 \mathrm{eV})$ on a Thermo Finnigan Ultra trace TSQ Quantum XLC GC-MS operated in selected ion monitoring (SIM) mode. The GC-MS was fitted with an $\mathrm{Rxi}^{\circledR}$-5Sil fused silica capillary column (30 $\mathrm{m} \times 0.25 \mathrm{~mm} \times 0.25 \mu \mathrm{m})$, and helium was used as the carrier gas and set at a constant flow of $1.7 \mathrm{~mL} / \mathrm{min}$. A sample volume of $2 \mu \mathrm{L}$ was introduced (in splitless mode) into the injector which was held at $300{ }^{\circ} \mathrm{C}$. The initial oven temperature was $40{ }^{\circ} \mathrm{C}$, followed by a $7.5^{\circ} \mathrm{C} / \mathrm{min}$ ramp to $295^{\circ} \mathrm{C}$, and an eight minute hold.

\subsubsection{Ultrahigh-resolution mass spectrometric analysis}

Analysis was carried out on a Q Exactive Orbitrap (Thermo Scientific, NJ, USA) by direct infusion through a $500 \mu \mathrm{L}$ syringe (Thermo Scientific, NJ, USA) at a typical flow rate of $30 \mu \mathrm{L} / \mathrm{min}$. In addition to the acquisition of the sample, each infusion data file contained acquisitions of a mobile phase background, and a solvent background. Data were acquired in full scan mode over a mass range of $80-1200 \mathrm{~m} / \mathrm{z}$, and the instrument was operated at a resolution of 140,000 FWHM. The automatic gain control (AGC) target was set to $1 \times \mathrm{e}^{6}$, while the maximum injection time was set to $50 \mathrm{~ms}$. External mass calibration provided a mass accuracy of $5 \mathrm{ppm}$. The APPI ionization source (Thermo Scientific, NJ, USA) was equipped with a krypton UV gas discharge lamp (Syagen Technology, Inc, Tustin, CA) that produces $10-10.2 \mathrm{eV}$ photons $(120 \mathrm{~nm}) . \mathrm{N}_{2}$ sheath gas at 40 psi was used to facilitate the ionization, while the auxiliary port remained closed. The heated vaporizer region was held at $350{ }^{\circ} \mathrm{C}$, while the capillary temperature was set to $300{ }^{\circ} \mathrm{C}$, for both positive and negative mode. For the ESI analysis a heated 
electrospray (HESI) source (Thermo Scientific, NJ, USA) was used, and typical conditions for positive mode were a spray voltage of $5.20 \mathrm{kV}$, a heated vaporizer region at $300{ }^{\circ} \mathrm{C}$, capillary temperature of $300{ }^{\circ} \mathrm{C}$, and sheath and auxiliary gas at 40 and $5 \mathrm{psi}$, respectively. For negative mode, the typical conditions were a spray voltage of $4.50 \mathrm{kV}$, a heated vaporizer region at $300{ }^{\circ} \mathrm{C}$, capillary temperature of $200{ }^{\circ} \mathrm{C}$, and sheath and auxiliary gas at 35 and $30 \mathrm{psi}$, respectively. For DESI (Prosolia, IN, USA) analysis the source conditions included a $\mathrm{m} / \mathrm{z}$ range of $100-1200$, a spray voltage of $3.60 \mathrm{kV}$, capillary temperature of $300{ }^{\circ} \mathrm{C}$, and an auxiliary gas heater temperature of $0{ }^{\circ} \mathrm{C}$. Sheath gas flow rate was kept at $5 \mathrm{psi}$, while the sweep and auxiliary gas flow rates were kept at 0 psi.

\subsubsection{Data analysis}

Mass spectra were obtained by averaging a selected range of consecutively acquired infusion spectra. A background spectrum acquired in the same infusion run as the sample was subtracted to account for external contamination. Data processing was performed by using the Composer 1.0.6 software (Sierra Analytics, CA, USA), which relies on petroleum specific composition assignment algorithms. Criteria used for peak detection and molecular formula assignments included: a m/z range of $80-1000 \mathrm{Da}$, a match tolerance of $5 \mathrm{ppm}$ for formula assignments, a DBE range from -0.5 to 65 , and element ranges of $\mathrm{C} \leq 200, \mathrm{H} \leq 1000, \mathrm{O} \leq 5, \mathrm{~N} \leq 4, \mathrm{~S} \leq 2$. The setting for the minimum relative peak abundance accepted was sample specific in order to adjust for the variable nature of the samples. 


\subsection{Results and Discussion}

\subsubsection{GC-FID and GC-MS analysis, and weathering studies}

Initially, the characterization of the weathering series was performed by visual inspection of the chromatograms obtained by GC-FID analysis. The characteristic trend in depletion of volatile compounds (predominantly alkanes, and to a lesser amount aromatics) for the weathered oils was observed and is shown in Figure 2.1. A clear loss of all the front-end compounds (which represent the low molecular weight and thus volatile hydrocarbons and aromatics), and an appearance and increase of the characteristic oil UCM (which is due to hydrocarbon species that coelute in chromatographic analysis) is clearly noticeable when going from Massachusetts to the weathered oils (CTC, Juniper, and Elmer's Island mat). The specific order of the oils in the weathering series is shown by the disappearance of more and more alkanes, and an overall decrease in signal. Massachusetts is shown to be a relatively fresh oil, while out of the two surface slick oils Juniper appears to be more weathered than CTC (which agrees with previous studies on total PAH depletion (BP, 2014.), and the Elmer's Island mat is shown to be the most weathered.

Further characterization studies of the same oils (shown in Figure 2.2) were conducted in order to perform a more in-depth characterization of the weathering series based on processes other than dissolution and evaporation. GC-FID and GC-MS analyses and subsequent quantifications of specific alkanes and PAHs, respectively, showed results that reinforce the previously determined weathering order, showing an increase in both biodegradation as well as photodegradation going from Massachusetts, to CTC, to Juniper, to the Elmer's Island mat. Figure 2.2 illustrates these results, and shows plots of 
two degradation ratios (chrysene/benz(a)anthracene (Behymer and Hites, 1988; Lemkau et al., 2010; Plata et al., 2008; Yim et al., 2011) and n-C18/phytane (Lemkau et al., 2010; Wang et al., 1998; Wang et al., 1995b; Yim et al., 2011)) that have previously been used as good indicators of crude oil photodegradation and biodegradation, respectively. The ratio of chrysene/benz(a)anthracene increases for the weathering series, indicating an increase in photodegradation of the oils. On the other hand, the n-C18/phytane ratio decreases, which is an indication of increased biodegradation. This strongly suggests that this is a true weathering series (going from Massachusetts, to CTC, to Juniper, to the Elmer's Island mat), and likely includes both photodegradation and biodegradation, in addition to other weathering processes such as dissolution and evaporation. An interesting fact that is noticeable is that, based on the results here obtained, the degree of weathering does not appear to be strictly time or location dependent, but mainly associated to the oil's path and the environmental factors related with it (such as temperature, nutrients, salinity, $\mathrm{pH}$, sun incidence, and currents). Having a series of weathered oils is, therefore, essential in order to achieve a more comprehensive understanding of the dynamic changes that affect crude oil in a marine environment. This understanding is the fundamental basis to any oil toxicity estimations.

\subsubsection{Ultrahigh-resolution mass spectrometric analysis}

Since GC-FID and GC-MS analyses pose significant limitations in a comprehensive oil characterization, in order to expand the analytical window of compounds detected, ultrahigh-resolution mass spectrometric analysis of the four oils was performed by means of an Orbitrap Q Exactive instrument. The four oils were 
analyzed in both $( \pm)$ ESI as well as $( \pm)$ APPI, in order to target a broader range of compounds (polar and nonpolar). The potential of using DESI for crude oil analysis was also evaluated; this technique, being an ambient technique, significantly reduces the time and effort dedicated to sample preparation.

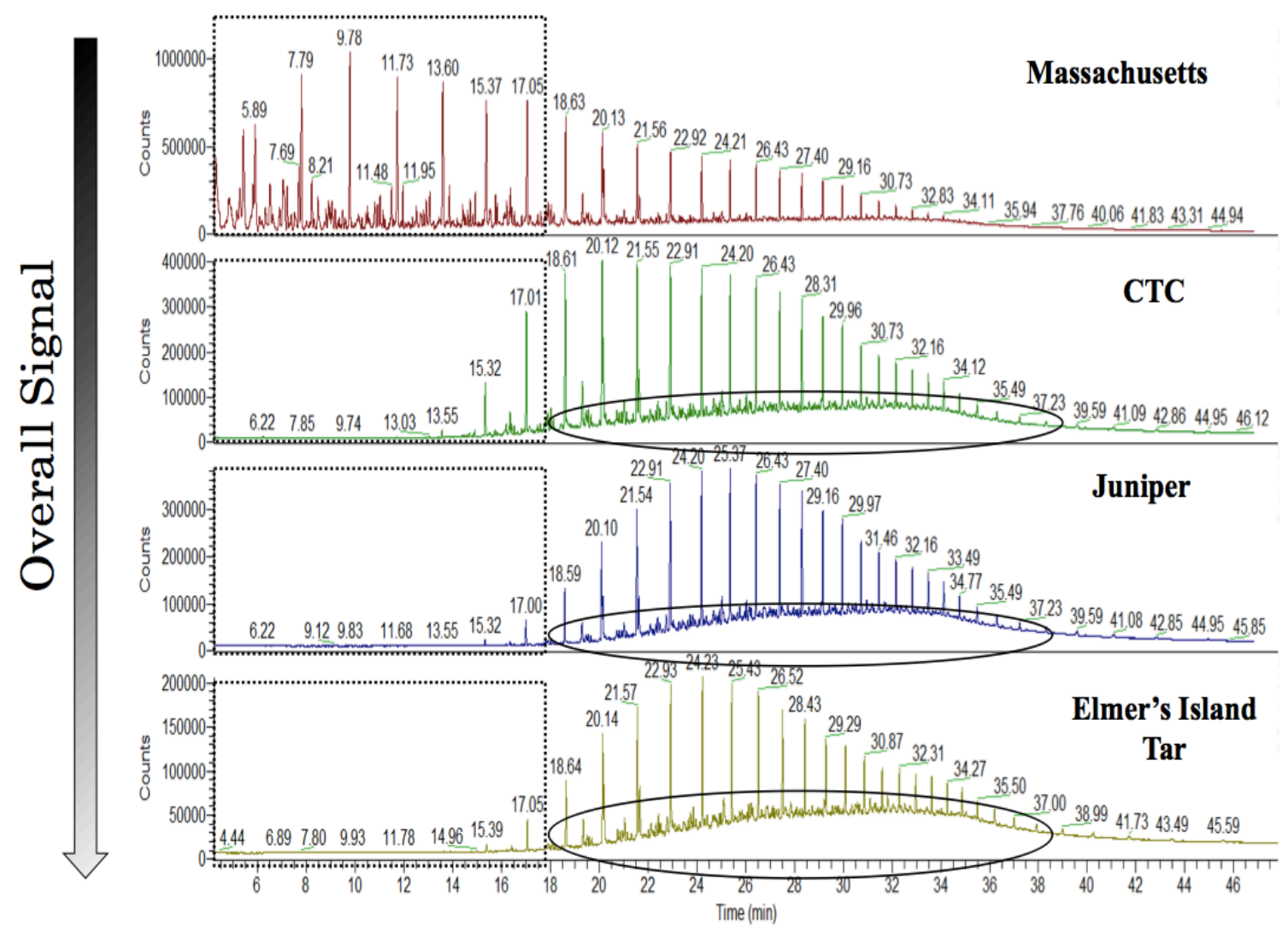

Figure 2.1 GC-FID chromatograms of the weathering series (Massachusetts, CTC, Juniper, and Elmer's Island mat), highlighting the decrease of overall signal, as well as the disappearance of low molecular weight compounds and the formation of the UCM. 

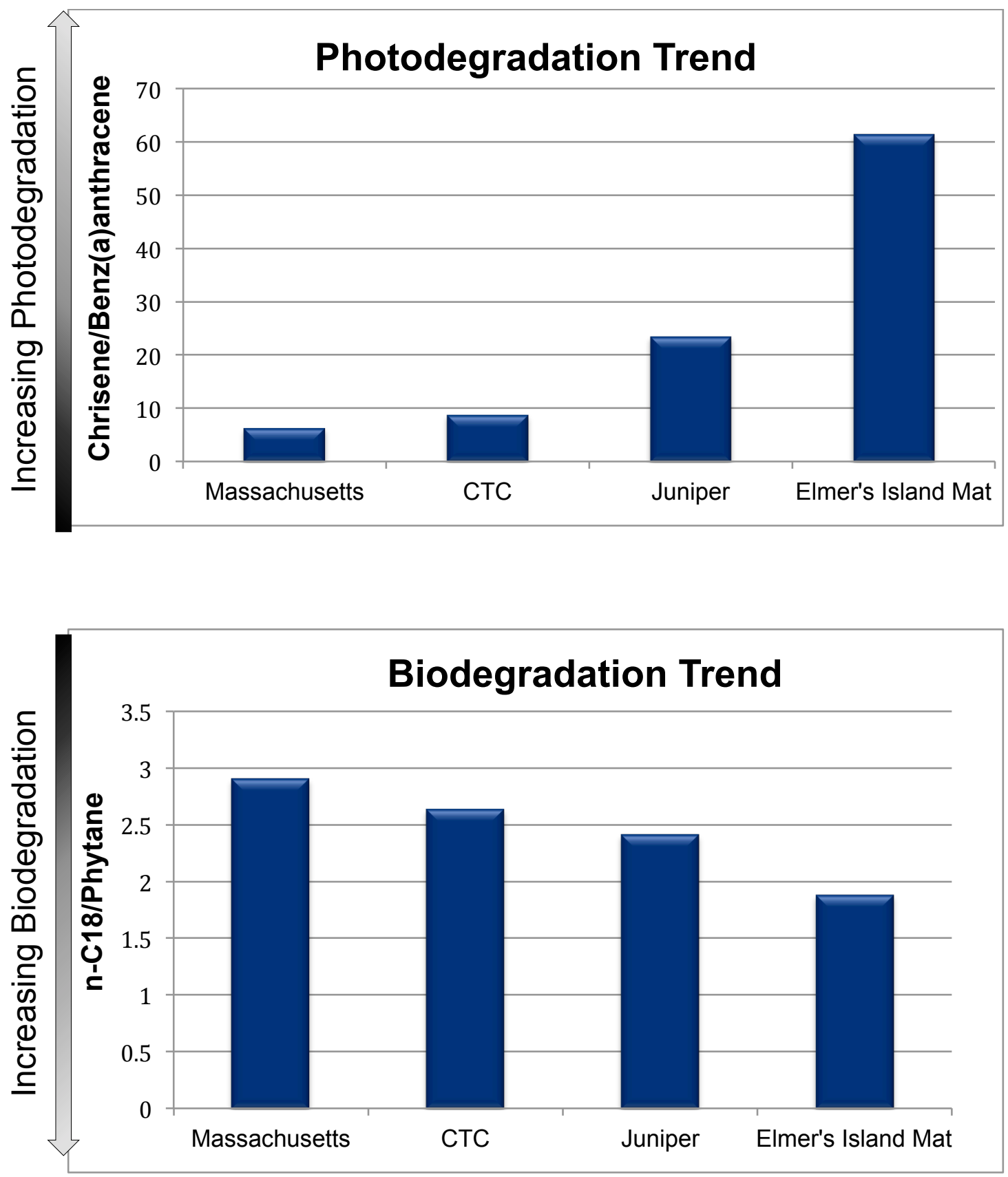

Figure 2.2 Ratios of the concentration of chrysene/benz(a)anthracene (top) and nC18/phytane (bottom) ratios for the weathering series, showing an increase in photodegradation and biodegradation, respectively. The top ratio was obtained from GCMS data, while the bottom ratio used GC-FID data. 
The resulting mass spectra for ESI and APPI ionization show significant changes, which can be seen particularly well in the negative mode spectra provided in Figure 2.3 and Figure 2.4 (positive mode spectra are provided in Appendix 1).Overall, a common trend independent of the ionization source or mode, is the relative increase in higher molecular weight compounds. The (-) ESI spectra shown in Figure 2.3, for example, clearly show this trend as the first section of the spectrum significantly decreases, while the second section increases with weathering. Moreover, a completely new series of compounds appears in the third section of the Elmer's Island mat spectrum, which illustrates the additional compositional complexity of beached oils (that may have incorporated exogenous materials). Compared to the ESI data shown in Figure 2.3, the () APPI data shown in Figure 2.4 show less dramatic changes, but also appear to present a slight shift towards higher molecular weight compounds, which is especially visible in the magnified spectra shown in the inserts. Furthermore, it can be seen that the APPI spectra appear to contain a much larger amount of individual masses. This evidences the more selective nature of the ESI ionization source towards more polar compounds, as it eliminates the background hydrocarbon interference that dominates the APPI spectrum. This is a good illustration of how these two ionization techniques are complementary and how a comprehensive crude oil characterization must use a combination of both. The positive ionization spectra obtained with the ESI and APPI sources also showed several differences and are provided in Appendix 1. The use of the desorption technique (DESI), also provided successful petroleum spectra (an example is shown in Figure 2.5). However, when comparing the spectra of the whole weathering series, no apparent 
significant changes were seen, and the subsequent, in depth, study of these oils thus focused on the ESI and APPI data.

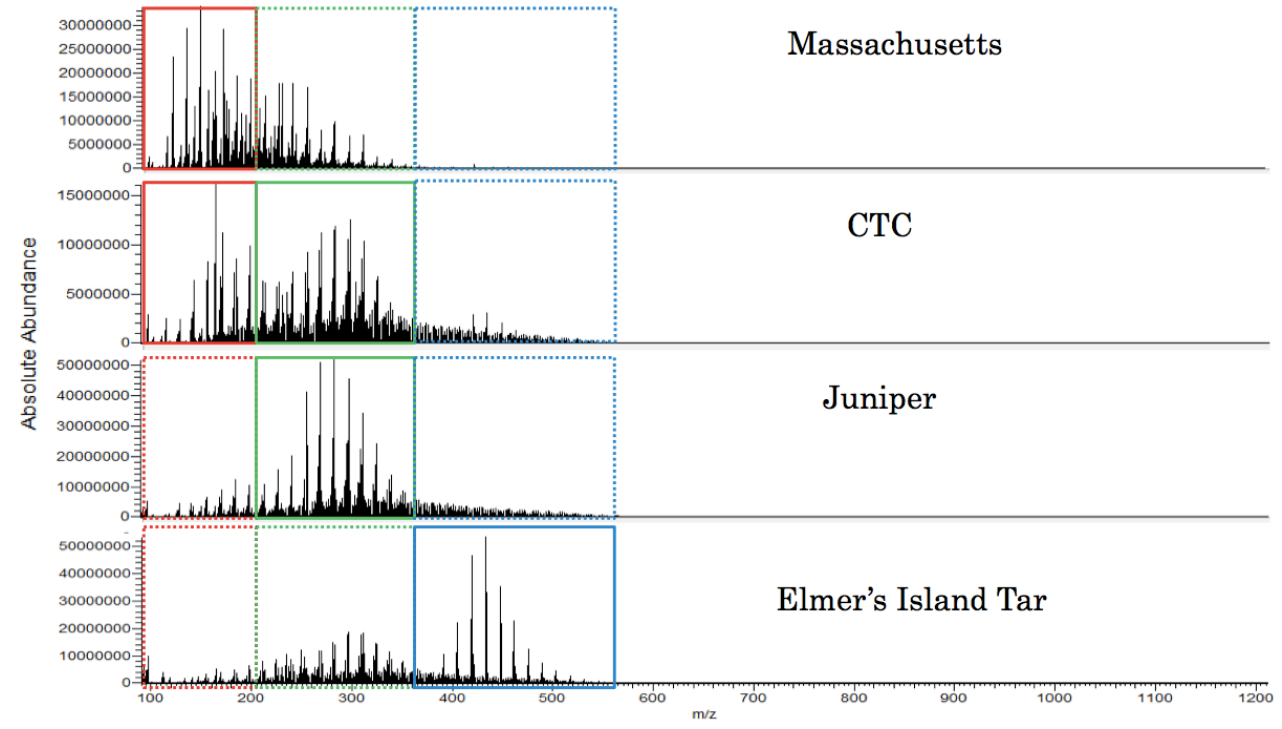

Figure 2.3 (-) ESI spectra of the oil weathering series, highlighting the three distinct areas of major changes, and a relative increase of higher molecular weight compounds with weathering.

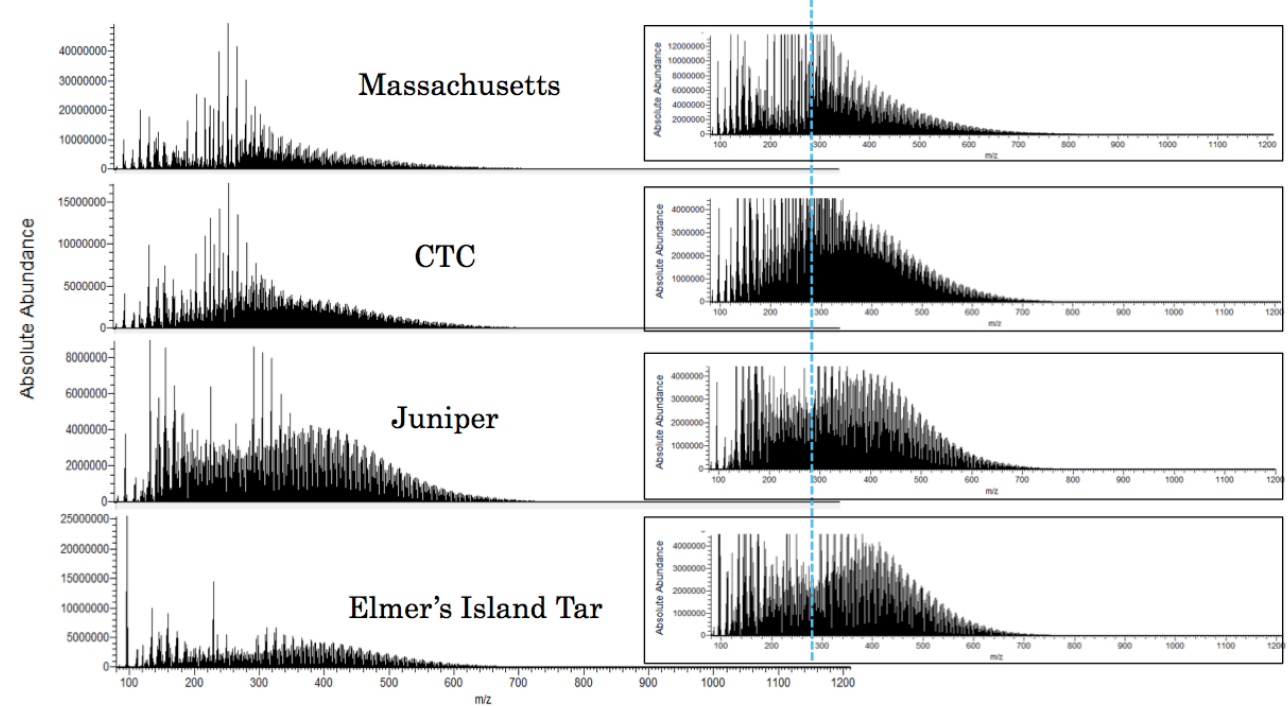

Figure 2.4 (-) APPI spectra of the oil weathering series, with the zoomed in spectra shown on the right emphasizing the shift towards higher molecular weight. 


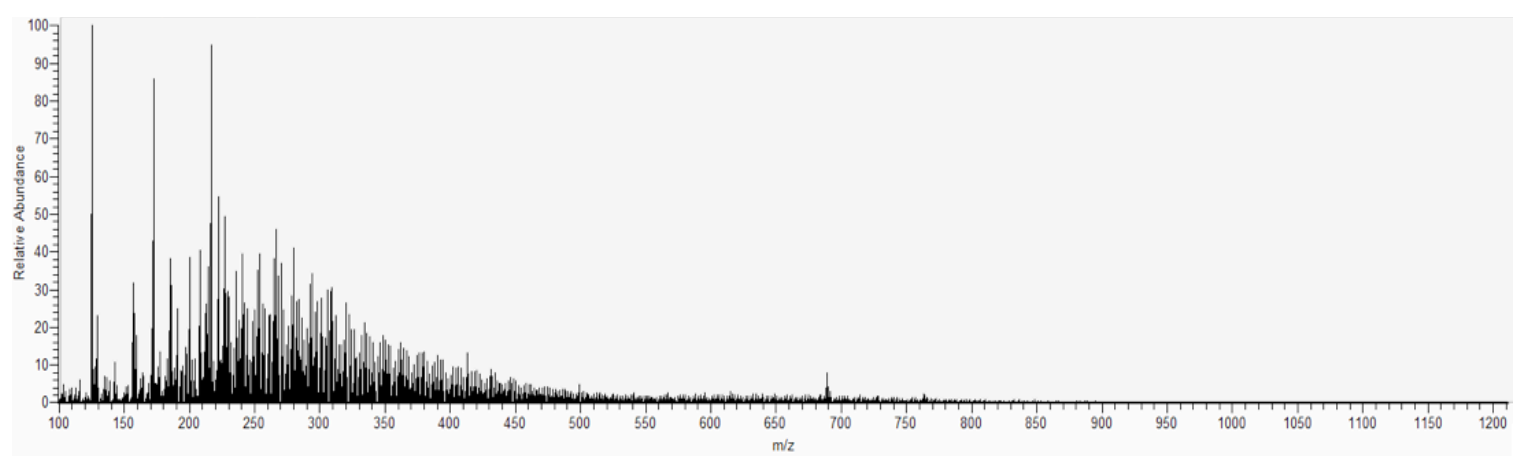

Figure 2.5 (+) DESI spectrum of unweathered Massachusetts oil, showing the successful use of an ambient technique to analyze crude oil.

In order to confirm these visually apparent changes, class distribution plots were created by categorizing all the assigned molecular formulae $\left(\mathrm{C}_{\mathrm{v}} \mathrm{H}_{\mathrm{w}} \mathrm{N}_{\mathrm{x}} \mathrm{O}_{\mathrm{y}} \mathrm{S}_{\mathrm{z}}\right)$ into specific heteroatom classes $\left(\mathrm{O}_{1}, \mathrm{O}_{2}, \mathrm{NO}, \mathrm{NO}_{2}\right.$, etc. $)$, and by plotting the relative abundance of each of these classes. These graphs are shown in Figure 2.6 and Figure 2.7, and show the presence of large compositional diversity among the four oils and the two ionization methods. Figure 2.6 depicts the differences between ESI and APPI in positive ionization mode. The most dominant class detected in $(+)$ APPI is the hydrocarbon class (protonated molecules are denoted by the $(\mathrm{H})) .(+)$ ESI, on the other hand, is dominated by nitrogen containing compounds, while the hydrocarbon portion is much smaller. Another interesting concept shown in these two plots is that while ESI ionization requires protonation, APPI provides the possibility to ionize other species by charge transfer owing to the presence of dopant molecules (toluene). This creates radical compound classes for the hydrocarbon, nitrogen, and oxygen classes that become fairly prominent. Figure 2.6 also shows a clear increase in oxygenated species $\left(\mathrm{O}_{1}, \mathrm{O}_{2}, \mathrm{O}_{3}\right)$, with a concurrent reduction in hydrocarbons as the weathering degree of the oils increases. 
Some of the classes of the Elmer's Island mat are an exception to this trend, which could be due to the differing nature of beached oils. The increase in oxidation with weathering that is observed corroborates data from other studies (Aeppli et al., 2012; Hall et al., 2013; Ruddy et al., 2014). Negative mode data (shown in Figure 2.7) extends the compositional coverage to highly oxygenated species $\left(\mathrm{O}_{4}\right.$ and $\left.\mathrm{O}_{5}\right)$. However, unlike for positive mode where all the oxygenated classes increased with weathering, in negative mode there seems to be a decrease in lower oxygenated species $\left(\mathrm{O}_{1}\right.$ for APPI, and $\mathrm{O}_{1}$ and $\mathrm{O}_{2}$ for ESI) with a concurrent increase in higher oxygenated species $\left(\mathrm{O}_{2}-\mathrm{O}_{5}\right.$ for APPI, and $\mathrm{O}_{3}-\mathrm{O}_{5}$ for $\left.\mathrm{ESI}\right)$.

In order to more clearly depict the changes in hydrocarbons and oxygenated compounds, Kendrick mass defect plots were created (Kendrick mass $=$ IUPAC mass $\times$ (14.00000/14.01565)). Such graphs plot the Kendrick Nominal Mass vs. the Kendrick Mass Defect (difference between the nominal and the exact Kendrick masses), and can be used in order to simplify the visualization of data originating from complex matrices, and to better visualize compositional changes. An example of such plots is given in Figure 2.8 for (-) APPI data, and shows a significant increase in oxygenated hydrocarbons $\left(\mathrm{O}_{1}\right.$ to $\left.\mathrm{O}_{5}\right)$, with an especially large increase in compounds in the mid-mass range $(\mathrm{m} / \mathrm{z} 300-$ 500) for weathered oils. This correlated to a reduction of the hydrocarbon component, which mainly lost its higher molecular weight (m/z 350 and up) compounds. 

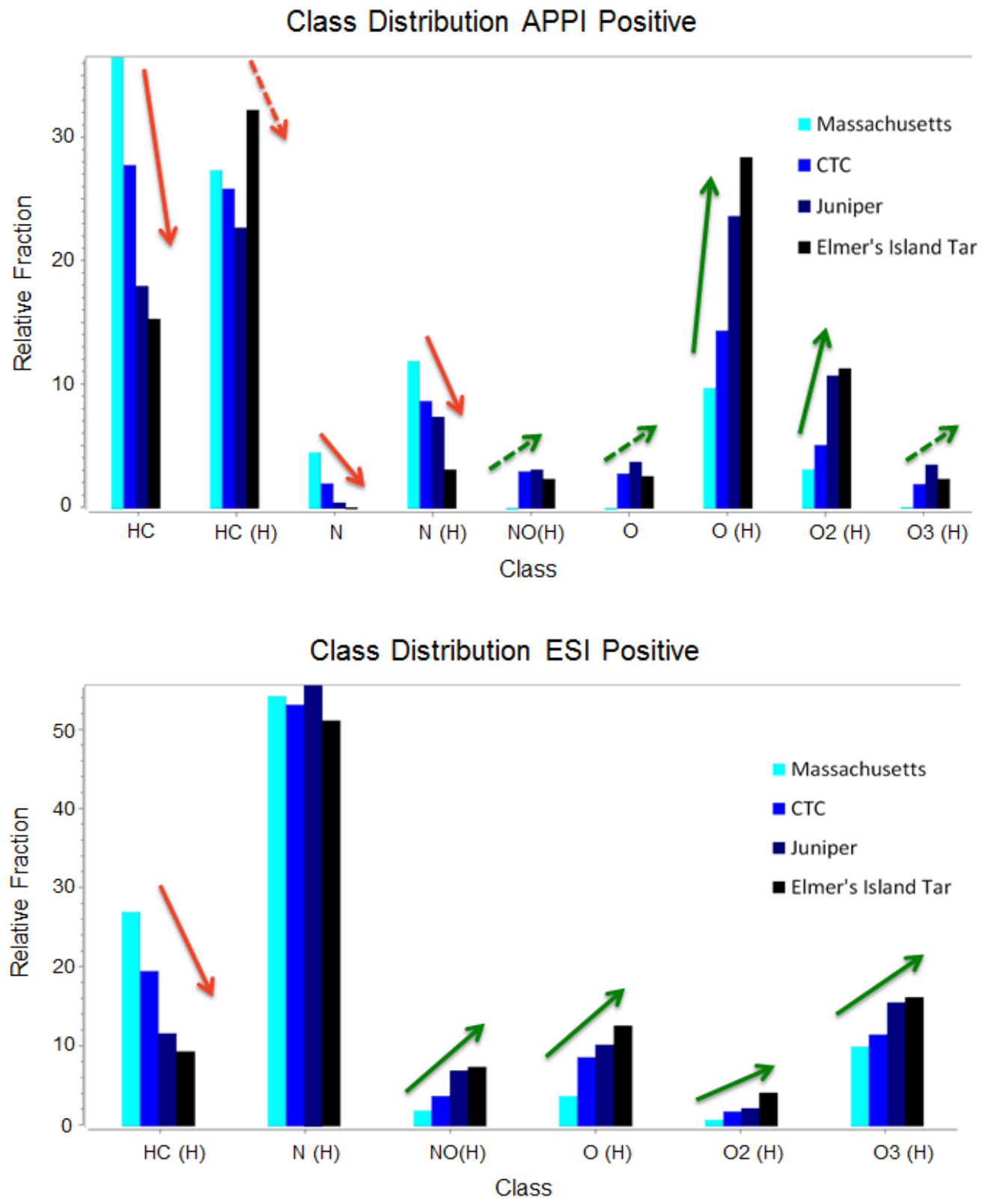

Figure 2.6 Class distributions for (+) APPI (top) and (+) ESI (bottom) for samples of the weathering series (Massachusetts, CTC, Juniper, Elmer's Island mat). Full arrows depict a consistent trend over the whole weathering series, while dashed arrows depict trends in which the Elmer's Island mat is an exception. Compounds showing as protonated ions are denoted by the $(\mathrm{H})$, others are radical ions. 

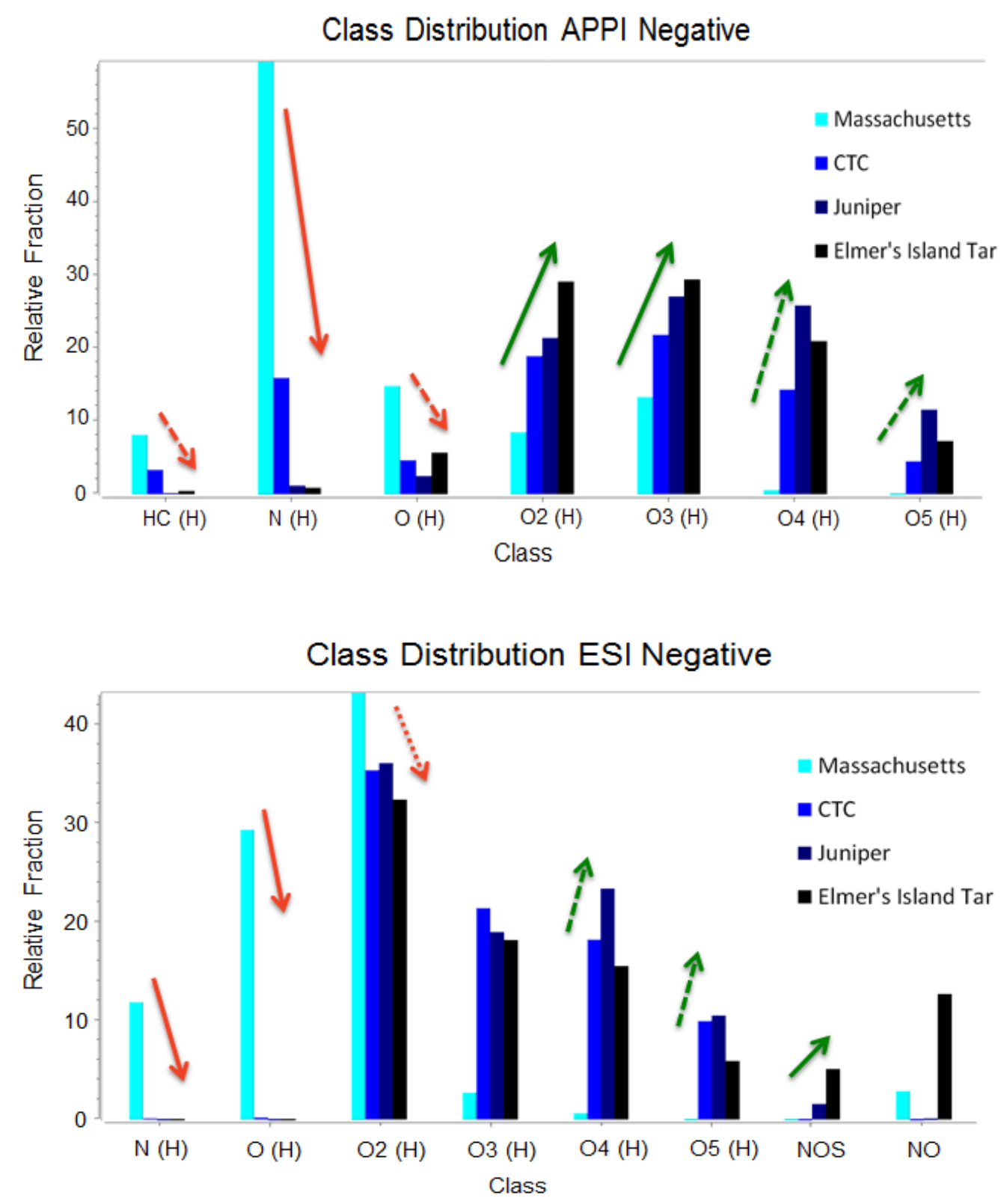

Figure 2.7 Heteroatom class distributions for (-) APPI (top) and (-) ESI (bottom) of the weathering series (Massachusetts, CTC, Juniper, Elmer's Island mat). Full arrows depict a consistent trend over the whole weathering series, while dashed arrows depict trends in which the Elmer's Island mat is an exception. Compounds showing as protonated ions are denoted by the $(\mathrm{H})$, others are radical ions. 
The results so far have shown an overall increase in oxygenated hydrocarbons (mostly in the mid to high molecular weight range), but have given little insight into the changes occurring within the specific oxygen classes. Double bond equivalent (DBE) plots were created by plotting the DBEs (number of rings and double bonds) versus the carbon number, in order to visualize changes happening in individual classes and get a better understanding on the saturation level of the compounds involved. The (+) APPI plots are shown in Figure 2.9 as an example of the results that were obtained. The appearance of oxygenated species that was previously observed with weathering is mostly confirmed by these plots; moreover, it becomes evident that for $(+)$ APPI mode the newly formed or enriched oxygenated compounds are mostly unsaturated or aromatic compounds (DBE 5-15) with 15-40 carbons. ESI and negative ionization mode results have shown similar ranges (Appendix 2 shows a comparison of (+) APPI and (+) ESI plots, while Appendix 3 shows (-) ESI results), and since PAHs are compounds that fall in that range, these results may suggest that PAHs and their derivatives could be a significant portion of the compounds that undergo oxidation during the weathering process.

This possibility is confirmed by the results of Figure 2.01, which shows a Van Krevelen diagram (that plots $\mathrm{H} / \mathrm{C}$ versus $\mathrm{O} / \mathrm{C}$ and indicates unsaturation and oxidation, respectively) for the unweathered Massachusetts oil (top) and the weathered Juniper oil (bottom) in (+) APPI mode. This plot depicts all the peaks that were assigned a molecular formula containing at least one oxygen, and evidences a drastic increase in the number and in the relative intensity of oxygenated compounds present in the weathered oil. The areas of major changes (shown by the red rectangles) contain compounds with a $\mathrm{H} / \mathrm{C}$ in 
the range of $0.5-1.5$. Completely saturated hydrocarbons would have a $\mathrm{H} / \mathrm{C}$ ratio of 2 , while completely aromatic species would have a $\mathrm{H} / \mathrm{C}$ of $<1$ (with benzene starting at 1 , and the $\mathrm{H} / \mathrm{C}$ decreasing with increasing number of rings, so that chrysene would have a $\mathrm{H} / \mathrm{C}$ of about 0.67$)$. The nature of the compounds whose detected ions are enhanced are therefore either completely aromatic in nature (when $\mathrm{H} / \mathrm{C}<1$ ), or contain some kind of unsaturation and aromaticity if they fall in the $\mathrm{H} / \mathrm{C}$ between 1 and 2 .

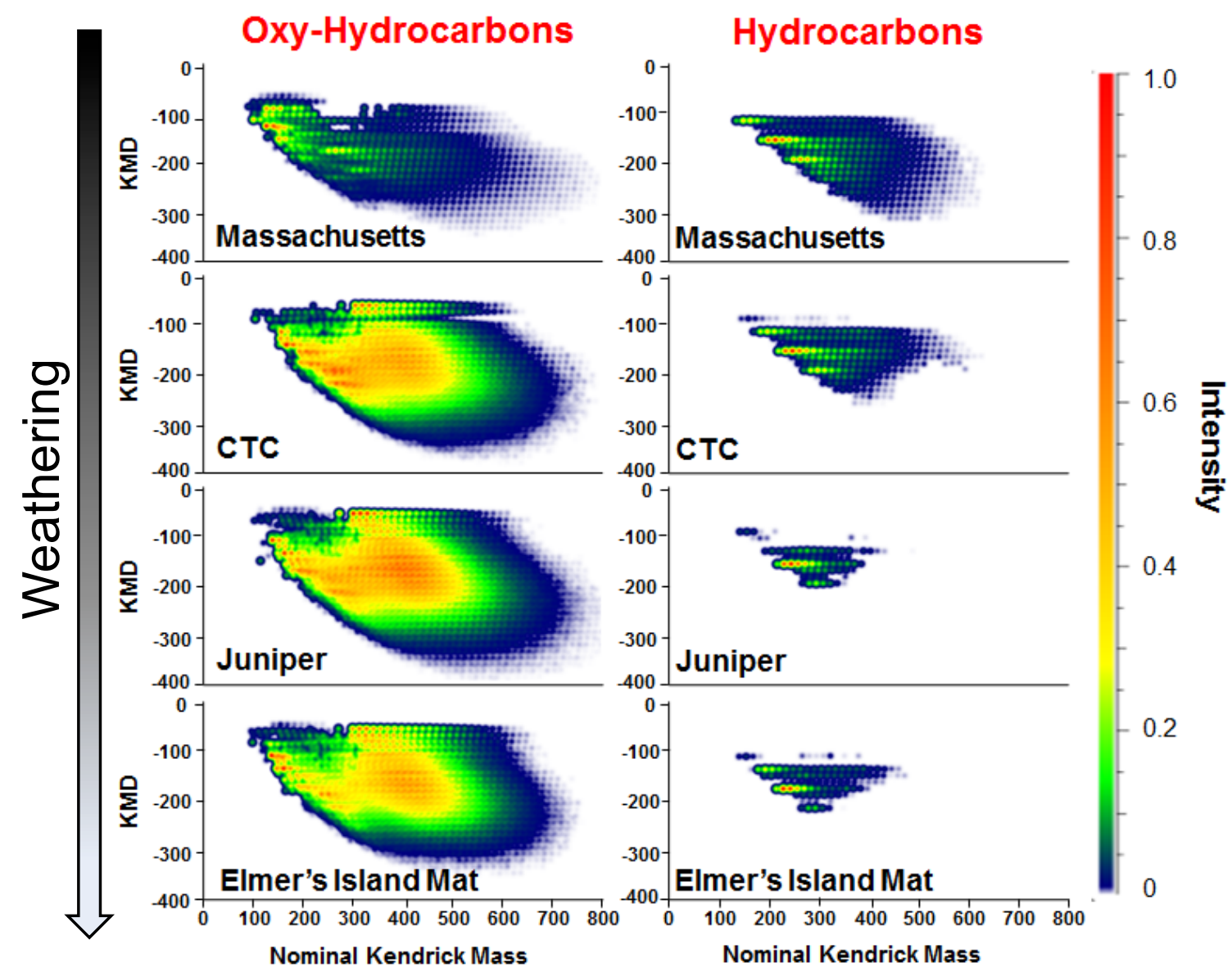

Figure 2.8 Kendrick Mass Defect (KMD) vs. Nominal Kendrick Mass contour plots for oxygen containing hydrocarbons (left) and hydrocarbons (right) obtained using (-) APPI conditions. 


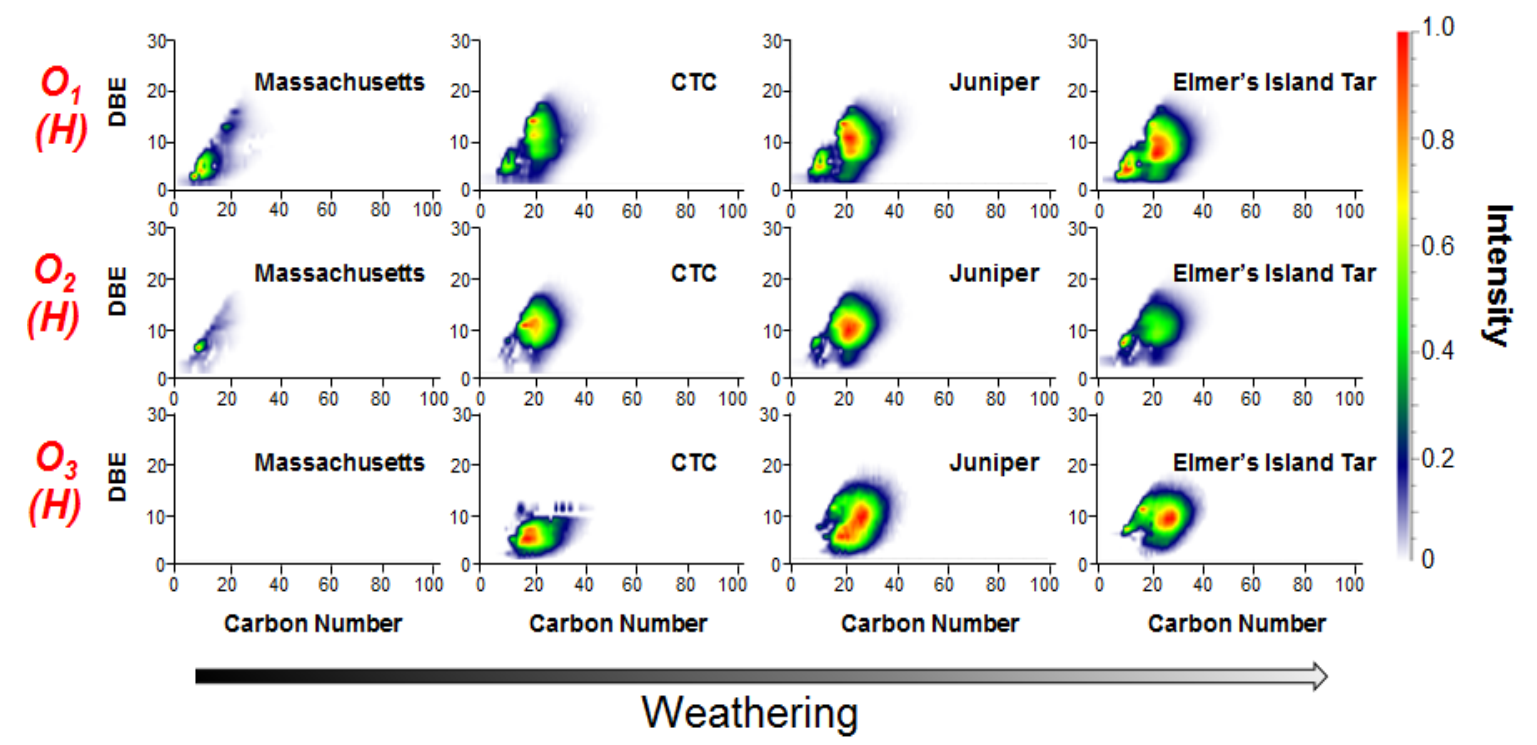

Figure 2.9 DBE vs. carbon number for the $\mathrm{O}_{1}-\mathrm{O}_{3}$ containing hydrocarbons detected in the weathering series in (+) APPI mode.

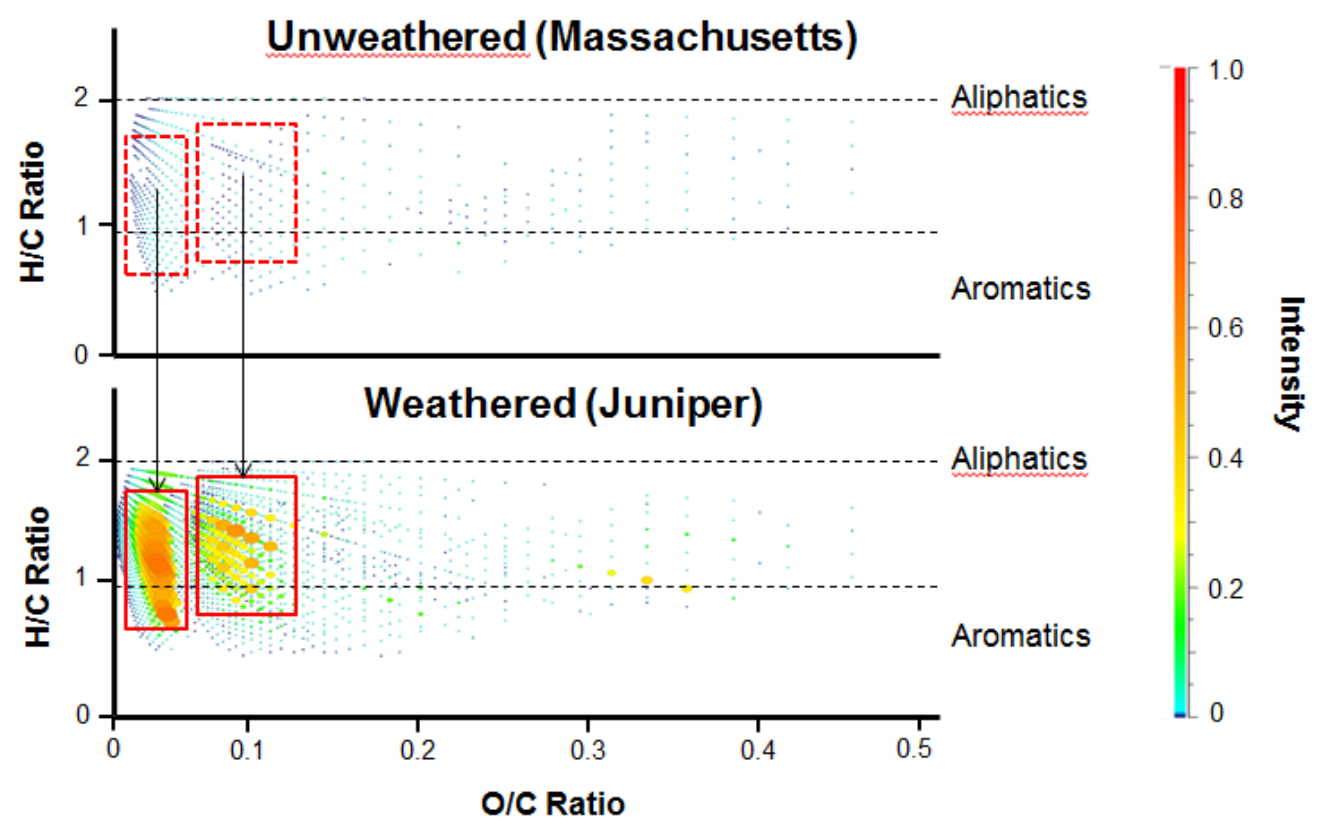

Figure 2.10 Van Krevelen plots of source (Massachusetts) and weathered (Juniper) oils obtained in $(+)$ APPI mode, showing the relative increase of aromatic and unsaturated oxidation products. 
All these different types of plots are essential in visualizing general trends in data sets containing thousands of assigned compounds. However, they do not provide unequivocal information on the functional group types of the molecules. Some information regarding what specific types of molecules are present can be inferred from ionization studies elucidating selective ionization mechanisms or preferential ionization of individual heteroatoms. Figure 2.6 and Figure 2.7, show how the relative abundances of the different oxygen classes vary based on the ionization source and mode, and suggest that different functional group types may be involved. For example, in negative ionization mode (Figure 2.7) for weathered oils there is a substantial prevalence of $\mathrm{O}_{2}$ species with respect to $\mathrm{O}_{1}$ species. This agrees with previous reports (Mapolelo et al., 2011; Mapolelo et al., 2009; Ruddy et al., 2014), and has been attributed to a preferential ionization of carboxylic acid species that can be easily deprotonated. For the unweathered oil this is not always true as in (-) APPI the $\mathrm{O}_{1}$ species represent a larger relative fraction compared to the $\mathrm{O}_{2}$ species. This could either mean that the $\mathrm{O}_{1}$ fraction (such as alcohols, phenols, ketones) is large enough to dominate a preferential ionization of acidic $\mathrm{O}_{2}$ species, or that there are singly oxygenated compounds mostly present in the unweathered oil that are similarly well ionized as the carboxylic acids. In positive ionization mode, on the other hand, there is a prevalence of $\mathrm{O}_{1}$ over $\mathrm{O}_{2}$ compounds (shown in Figure 2.6), which is most likely due to the preferential ionization of some $\mathrm{O}_{1}$ species (such as alcohols, phenols, or ketones) with respect to $\mathrm{O}_{2}$ compounds.

In order to gain a better understanding of the nature of specific oxygenated classes and the significance of these results, a systematic ionization study was conducted by spiking several compounds into an Elmer's Island mat sample. These model compounds 
spanned a wide range of functional group types, including: hydrocarbons, phenols, alcohols, ketones, and acids. The sample infused in APPI positive ionization mode favored the formation of the ketone functional group (coprostan-3-one), while phenols and hydrocarbons were only weakly ionized, and straight chain alcohols and acids showed no ionization. Negative ionization mode, on the other hand, preferentially ionized the acids and phenols, while none of the other compounds were detected. The mass spectrum and Kendrick Mass Defect plots of the (-) APPI data for the Elmer's Island mat are presented in Figure 2.11, and show the phenols (in blue) and the acid (in pink) that were ionized and correctly assigned. ESI results from the same spiked sample (results not shown) mostly corroborated the same preferential ionizations (ketones and to a lesser extent phenols in positive mode, and carboxylic acids and phenols in negative mode). These results clearly show that both the APPI and ESI sources ionize only certain functional group types (and out of those some much better than others) depending on the ionization mode, and this has to be accounted for when interpreting heteroatom class assignments plots from high-resolution mass spectrometric analyses. The preferential ionization of singly oxygenated ketones in positive ionization mode with respect to doubly oxygenated carboxylic acids suggests that ketones could be a significant portion of the $\mathrm{O}_{1}$ class that dominates $(+)$ ESI and $(+)$ APPI generated spectra, and this seems to corroborate previous reports that have suggested ketones as oxidation products in crude oil weathering (Ruddy et al., 2014). Phenols have shown to be somewhat ionized and could therefore also contribute to the $\mathrm{O}_{1}$ class, while the lack of ionization of straight chain alcohols makes them an unlikely contributor. The $\mathrm{O}_{2}$ class (and other higher oxygen classes) may be combinations of functional group types, and most likely contain 
well ionizable groups such as ketones. In negative mode, acids are being preferentially ionized by deprotonation, and are thus the most likely contributor to the large relative fraction of the $\mathrm{O}_{2}$ classes, and the acidification of crude oil compounds with weathering and especially biodegradation has been previously reported (Charrie-Duhaut et al., 2000; Ruddy et al., 2014; Watson et al., 2002). Moreover, based on the H/C and DBE values detected, it is clear that the possible acidic fraction consist of both an unsaturated and aromatic hydrocarbon backbone. The model compound study has also shown that phenols, in addition to acids, are a class that is well ionized in negative ionization mode, and the abundant $\mathrm{O}_{1}$ class in the source oil could be largely due to phenolic compounds, which have been proposed as intermediates in photodegradation of PAHs (Chen et al., 2006; Kong and Ferry, 2003; McConkey et al., 2002; Wang et al., 1995a). These compounds have been shown to undergo further photo-oxidation, being converted to ketonic and quinonic compounds (Chen et al., 2006; Kong and Ferry, 2003; McConkey et al., 2002; Wang et al., 1995a). This could explain why the $\mathrm{O}_{1}$ class in negative ionization mode decreases (oppositely to all other oxygenated classes), as singly oxygenated phenols are converted to doubly oxygenated quinones (see Figure 2.8). GC $\times$ GC-TOF data on the same weathering series showed enrichment of straight chain ketones and acids, and a depletion of phenol, strengthening the conclusion on possible functional group types that are being transformed during the weathering process (Ding and Gardinali, 2015). The higher oxygenated fractions $\left(\mathrm{O}_{2}\right.$ and up) are likely combinations of functional group types and contain the well-ionized carboxylic acid and phenolic groups. The ionization study has also illustrated that since straight chain alcohols were not (or very poorly) ionized in any of the ionization techniques, they are not likely to give a 
significant contribution to any observed $\mathrm{O}_{1}$ class. This part of the study, overall, emphasized the need to gain more in-depth knowledge on the ionization of crude oil compounds, and offered valuable insight into the possible functional group types that are making up the $\mathrm{O}_{1}, \mathrm{O}_{2}$, and higher oxygenated hydrocarbon classes that exhibit significant changes with weathering.

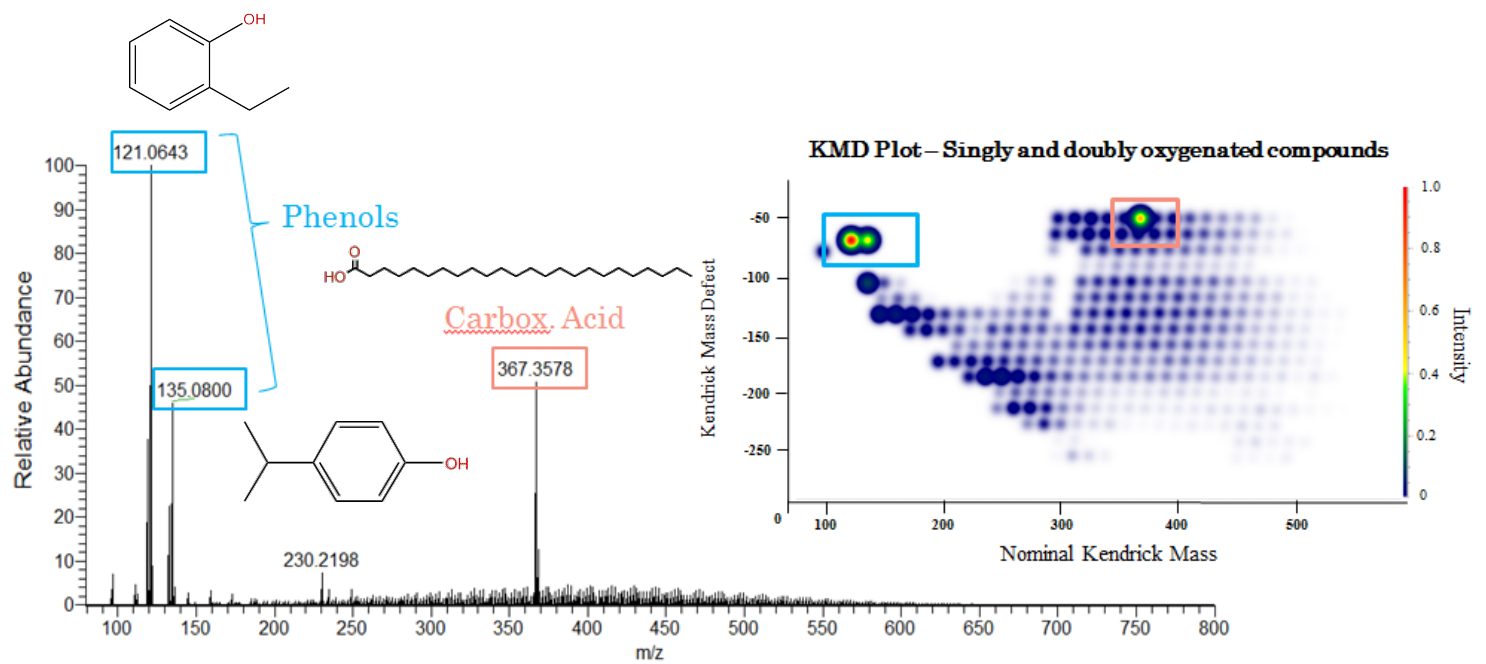

Figure 2.11 (-) APPI spectrum of the Elmer's Island mat fortified with several individual model compounds used to test ionization efficiency, and Kendrick mass defect plot of the $\mathrm{O}_{1}$ and $\mathrm{O}_{2}$ classes of the same sample showing the corresponding detection and correct assignment of the model compounds.

\subsection{Conclusion}

This study presented the first ultrahigh-resolution mass spectrometric characterization of an oil weathering series, including the fresh Macondo oil, two differently weathered surface slick oils, and a beached oil tar. Preliminary GC-MS and GC-FID studies have confirmed the four oils to be a true weathering series, and ratios of 
nC18/phytane and chrysene/benz(a)anthracene have further shown the oils to be likely biodegradation and photodegradation series. Studying a complete weathering sequence provides the opportunity to achieve a better understanding of the type of weathering processes that were most significant in the $D W H$ oil release, and consequently how these mechanisms affected the composition of the oil. Ultrahigh-resolution results from this study have shown an increase in oxygenated compounds as the Macondo oil weathered, additionally suggesting a gain of ketones, quinones, and acidic compounds, with a concurrent decrease in phenolic compounds. The separate ionization study that was conducted by spiking model compounds into an oil sample also helped put the results into a new perspective and further point out serious defects in current interpretations, as results from this study clearly showed how out of the nine spiked compounds some were not ionized while others were fully ionized. This proves that compound class assignment plots might have relative intensities largely skewed by preferential ionizations, while some compounds could be abundant but poorly ionized and thus be underestimated. Future work will include a more extensive study of ionization mechanisms of several crude oil model compounds, spanning a wide size range, and including more functional groups, as well as heteroatom containing compounds. Results of such a study will be necessary in order make more conclusive compound assignments. This will ultimately help to expand the understanding of the type of weathering processes that have played a significant role in the Deepwater Horizon accident, which will be fundamental in evaluating the long-term fate and toxicity of the oil that was released. 


\subsection{Acknowledgements}

This work was supported by BP Exploration \& Production Inc. and the BP Gulf Coast Restoration Organization through FIU project 800001596. This is contribution number 999 from the Southeast Environmental Research Center (SERC) at Florida International University.

\subsection{References}

Aeppli C, Carmichael CA, Nelson RK, Lemkau KL, Graham WM, Redmond, MC, Valentine DL, Reddy CM. Oil Weathering after the Deepwater Horizon Disaster Led to the Formation of Oxygenated Residues. Environmental Science \& Technology 2012; 46: 8799-8807.

Atlas RM, Hazen TC. Oil Biodegradation and Bioremediation: A Tale of the Two Worst Spills in US History. Environmental Science \& Technology 2011; 45: 6709-6715.

Behymer TD, Hites RA. Photolysis of polycyclic aromatic-hydrocarbons adsorbed on flyash. Environmental Science \& Technology 1988; 22: 1311-1319.

BP, Gulf Science Data Reference Oil Characterization Data. In Website: http://gulfsciencedata.bp.com/, directory: Oil; subdirectory: Oil Characteristics additional reference oils; filename: OilChemistry_O-04v01-03.zip. Last modified January 22, 2014.

Burns KA. Evidence for the importance of including hydrocarbon oxidation-products in environmental assessment studies. Marine Pollution Bulletin 1993; 26: 77-85.

Camilli R, Di Iorio D, Bowen A, Reddy CM, Techet AH, Yoerger DR, Whitcomb LL, Seewald JS, Sylva SP, Fenwick J. Acoustic measurement of the Deepwater Horizon Macondo well flow rate. Proceedings of the National Academy of Sciences of the United States of America 2012; 109: 20235-20239.

Carmichael CA, Arey JS, Graham WM, Linn LJ, Lemkau KL, Nelson RK, Reddy CM. Floating oil-covered debris from Deepwater Horizon: identification and application. Environmental Research Letters 2012; 7: 015301.

Charrie-Duhaut A, Lemoine S, Adam P, Connan J, Albrecht P. Abiotic oxidation of petroleum bitumens under natural conditions. Organic Geochemistry 2000; 31: 977-1003. 
Chen J, Ehrenhauser FS, Valsaraj KT, Wornat MJ. Uptake and UV-photooxidation of gas-phase PAHs on the surface of atmospheric water films. 1. Naphthalene. Journal of Physical Chemistry A 2006; 110: 9161-9168.

Ding Y, Gardinali PR. Application of silica gel chromatography coupled with GC $\times$ GCTOF in identification of oxygenated hydrocarbons in complex environmental samples. $39^{\text {th }}$ International Symposium on Capillary Chromatography \& $12^{\text {th }} \mathrm{GC} \times \mathrm{GC}$ Symposium, Fort Worth, TX, USA 2015; http://www.isccgcxgc2015.com/.

Garrett RM, Pickering IJ, Haith CE, Prince RC. Photooxidation of crude oils. Environmental Science \& Technology 1998; 32: 3719-3723.

Gough MA, Rowland SJ. Characterization of unresolved complex-mixtures of hydrocarbons in petroleum. Nature 1990; 344: 648-650.

Hall GJ, Frysinger GS, Aeppli C, Carmichael CA, Gros J, Lemkau KL, Nelson RK, Reddy CM. Oxygenated weathering products of Deepwater Horizon oil come from surprising precursors. Marine Pollution Bulletin 2013; 75: 140-149.

Hsu CS, Hendrickson CL, Rodgers RP, McKenna AM, Marshall AG. Petroleomics: advanced molecular probe for petroleum heavy ends. Journal of Mass Spectrometry 2011; 46: 337-343.

Hughes WB, Holba AG, Dzou LIP. The ratios of dibenzothiophene to phenanthrene and pristine to phytane as indicators of depositional environment and lithology of petroleum source rocks. Geochimica et Cosmochimica Acta 1995; 59: 3581-3598.

Jordan RE, Payne JR. Fate and Weathering of Petroleum Spills in the Marine Environment: A Literature Review and Synopsis. Ann Arbor Science. Publ.: 1980.

Kaiser NK, Savory JJ, McKenna AM, Quinn JP, Hendrickson CL, Marshall AG. Electrically Compensated Fourier Transform Ion Cyclotron Resonance Cell for Complex Mixture Mass Analysis. Analytical Chemistry 2011; 83: 6907-6910.

Kong L, Ferry JL. Effect of salinity on the photolysis of chrysene adsorbed to a smectite clay. Environmental Science \& Technology 2003; 37: 4894-4900.

Kostka JE, Prakash O, Overholt WA, Green SJ, Freyer G, Canion A, Delgardio J, Norton $\mathrm{N}$, Hazen TC, Huettel M. Hydrocarbon-Degrading Bacteria and the Bacterial Community Response in Gulf of Mexico Beach Sands Impacted by the Deepwater Horizon Oil Spill. Applied and Environmental Microbiology 2011; 77: 7962-7974.

Lemkau KL, Peacock EE, Nelson RK, Ventura GT, Kovecses JL, Reddy CM. The M/V Cosco Busan spill: Source identification and short-term fate. Marine Pollution Bulletin 2010; 60: 2123-2129. 
Lima ALC, Farrington JW, Reddy CM. Combustion-derived polycyclic aromatic hydrocarbons in the environment - A review. Environmental Forensics 2005; 6: 109-131.

Liu ZF, Liu JQ, Zhu QZ, Wu W. The weathering of oil after the Deepwater Horizon oil spill: insights from the chemical composition of the oil from the sea surface, salt marshes and sediments. Environmental Research Letters 2012; 7: 035302.

Maki H, Sasaki T, Harayama S. Photo-oxidation of biodegraded crude oil and toxicity of the photo-oxidized products. Chemosphere 2001; 44: 1145-1151.

Mansuy L, Philp RP, Allen J. Source identification of oil spills based on the isotopic composition of individual components in weathered oil samples. Environmental Science \& Technology 1997; 31: 3417-3425.

Mapolelo MM, Stanford LA, Rodgers RP, Yen AT, Debord JD, Asomaning S, Marshall AG. Chemical Speciation of Calcium and Sodium Naphthenate Deposits by Electrospray Ionization FT-ICR Mass Spectrometry. Energy \& Fuels 2009; 23: 349-355.

Mapolelo MM, Rodgers RP, Blakney GT, Yen AT, Asomaning S, Marshall AG. Characterization of naphthenic acids in crude oils and naphthenates by electraspray ionization FT-ICR mass spectrometry. International Journal of Mass Spectrometry 2011; 300: 149-157.

McConkey BJ, Hewitt LM, Dixon DG, Greenberg BM. Natural sunlight induced photooxidation of naphthalene in aqueous solution. Water Air and Soil Pollution 2002; 136: 347-359.

McKenna AM, Nelson RK, Reddy CM, Savory JJ, Kaiser NK, Fitzsimmons JE, Marshall AG, Rodgers RP. Expansion of the Analytical Window for Oil Spill Characterization by Ultrahigh Resolution Mass Spectrometry: Beyond Gas Chromatography. Environmental Science \& Technology 2013; 47: 7530-7539.

McNutt MK, Camilli R, Crone TJ, Guthrie GD, Hsieh PA, Ryerson TB, Savas O, Shaffer F. Review of flow rate estimates of the Deepwater Horizon oil spill. Proceedings of the National Academy of Sciences of the United States of America 2012; 109: 20260-20267.

Plata DL, Sharpless CM, Reddy CM. Photochemical degradation of polycyclic aromatic hydrocarbons in oil films. Environmental Science \& Technology 2008; 42: 2432-2438.

Podgorski DC, Corilo YE, Nyadong L, Lobodin VV, Bythell BJ, Robbins WK, McKenna AM, Marshall AG, Rodgers RP. Heavy Petroleum Composition. 5. Compositional and Structural Continuum of Petroleum Revealed. Energy \& Fuels 2013; 27: 1268-1276.

Prince RC, Garrett RM, Bare RE, Grossman MJ, Townsend T, Suflita JM, Lee K, Owens EH, Sergy GA, Braddock JF, Lindstrom JE, Lessard RR. The roles of photooxidation and 
biodegradation in long-term weathering of crude and heavy fuel oils. Spill Science \& Technology Bulletin 2003; 8: 145-156.

Qian K, Rodgers RP, Hendrickson CL, Emmett MR, Marshall AG. Reading chemical fine print: Resolution and identification of 3000 nitrogen-containing aromatic compounds from a single electrospray ionization Fourier transform ion cyclotron resonance mass spectrum of heavy petroleum crude oil. Energy \& Fuels 2001; 15: 492-498.

Qian KN, Robbins WK, Hughey CA, Cooper HJ, Rodgers RP, Marshall AG. Resolution and identification of elemental compositions for more than 3000 crude acids in heavy petroleum by negative-ion microelectrospray high-field Fourier transform ion cyclotron resonance mass spectrometry. Energy \& Fuels 2001; 15: 1505-1511.

Reddy CM, Arey JS, Seewald JS, Sylva SP, Lemkau KL, Nelson RK, Carmichael CA, McIntyre CP, Fenwick J, Ventura GT, Van Mooy BAS, Camilli R. Composition and fate of gas and oil released to the water column during the Deepwater Horizon oil spill. Proceedings of the National Academy of Sciences of the United States of America 2012; 109: 20229-20234.

Rodgers RP, Schaub TM, Marshall AG. Petroleomics: MS returns to its roots. Analytical Chemistry 2005; 77: 20A-27A.

Roussis SG, Fedora JW. Quantitative determination of polar and ionic compounds in petroleum fractions by atmospheric pressure chemical ionization and electrospray ionization mass spectrometry. Rapid Communications in Mass Spectrometry 2002; 16: 1295-1303.

Ruddy BM, Huettel M, Kostka JE, Lobodin VV, Bythell BJ, McKenna AM, Aeppli C, Reddy CM, Nelson RK, Marshall AG, Rodgers RP. Targeted Petroleomics: Analytical Investigation of Macondo Well Oil Oxidation Products from Pensacola Beach. Energy \& Fuels 2014; 28: 4043-4050.

Savory JJ, Kaiser NK, McKenna AM, Xian F, Blakney GT, Rodgers RP, Hendrickson CL, Marshall AG. Parts-Per-Billion Fourier Transform Ion Cyclotron Resonance Mass Measurement Accuracy with a "Walking" Calibration Equation. Analytical Chemistry 2011; 83: 1732-1736.

Schrader W, Panda SK, Brockmann KJ, Benter T. Characterization of non-polar aromatic hydrocarbons in crude oil using atmospheric pressure laser ionization and Fourier transform ion cyclotron resonance mass spectrometry (APLI FT-ICR MS). Analyst 2008; 133: 867-869.

Speight JG. Petroleum asphaltenes - Part 1 - Asphaltenes, resins and the structure of petroleum. Oil \& Gas Science and Technology-Revue D Ifp Energies Nouvelles 2004; 59: 467-477. 
Wang CY, Chen B, Zhang BY, He SJ, Zhao MM. Fingerprint and weathering characteristics of crude oils after Dalian oil spill, China. Marine Pollution Bulletin 2013; 71: 64-68.

Wang CX, Yediler A, Peng A, Kettrup A. Photodegradation of phenanthrene in the presence of humic substances and hydrogen-peroxide. Chemosphere 1995; 30: 501-510.

Wang ZD, Fingas M, Blenkinsopp S, Sergy G, Landriault M, Sigouin L, Foght J, Semple $\mathrm{K}$, Westlake DWS. Comparison of oil composition changes due to biodegradation and physical weathering in different oils. Journal of Chromatography A 1998; 809: 89-107.

Wang ZD, Fingas M, Sergy G. Chemical characterization of crude-oil residues from an arctic beach by GC/MS and GC/FID. Environmental Science \& Technology 1995; 29: 2622-2631.

Watson JS, Jones DM, Swannell RPJ, van Duin ACT. Formation of carboxylic acids during aerobic biodegradation of crude oil and evidence of microbial oxidation of hopanes. Organic Geochemistry 2002; 33: 1153-1169.

Yim UH, Ha SY, An JG, Won JH, Han GM, Hong SH, Kim M, Jung JH, Shim WJ. Fingerprint and weathering characteristics of stranded oils after the Hebei Spirit oil spill. Journal of Hazardous Materials 2011; 197: 60-69. 


\section{CHAPTER 3}

Understanding the atmospheric pressure ionization of petroleum components: The effects of size, structure, and presence of heteroatoms

This chapter was published in the journal Science of the Total Environment and adapted with permission from all participating authors.

Anna Katarina Huba, Kristina Huba, Piero R. Gardinali, Science of the Total Environment 568 (2016) 1018-1025. 


\subsection{Abstract}

Understanding the composition of crude oil and its changes with weathering is essential when assessing its provenience, fate, and toxicity. High-resolution mass spectrometry (HRMS) has provided the opportunity to address the complexity of crude oil by assigning molecular formulae, and sorting compounds into "classes" based on heteroatom content. However, factors such as suppression effects and discrimination towards certain components severely limit a truly comprehensive mass spectrometric characterization, and, despite the availability of increasingly better mass spectrometers, a complete characterization of oil still represents a major challenge. In order to fully comprehend the significance of class abundances, as well as the nature and identity of compounds detected, a good understanding of the ionization efficiency of the various compound classes is indispensable. The current study, therefore, analyzed model compounds typically found in crude oils by high-resolution mass spectrometry with atmospheric pressure photoionization (APPI), atmospheric pressure chemical ionization (APCI), and electrospray ionization (ESI), in order to provide a better understanding of benefits and drawbacks of each source. The findings indicate that, overall, APPI provides the best results, being able to ionize the broadest range of compounds, providing the best results with respect to ionization efficiencies, and exhibiting the least suppression effects. However, just like in the other two sources, in APPI several factors have shown to affect the ionization efficiency of petroleum model compounds. The main such factor is the presence or absence of functional groups that can be easily protonated/deprotonated, in addition to other factors such as size, methylation level, presence of heteroatoms, and ring structure. Overall, this study evidences the intrinsic limitations and benefits of each 
of the three sources, and should provide the fundamental knowledge required to expand the power of crude oil analysis by high-resolution mass spectrometry.

\subsection{Introduction}

Despite current advances in alternative resources, petroleum is still vital for the production of energy and as precursor for various materials, such as plastics and medicines (Speight et al., 2014). Petroleum discharges during production and transport add to what is already released into the environment through natural seepage; since the fate and potential effect of this released crude oil is highly dependent on its composition (Wang et al., 2013b), both the characterization of crude oil and its evolution with weathering are therefore of uttermost importance. In recent years, unmasking the complexity of crude oil has been mostly addressed thanks to the availability and development of high-resolution mass spectrometry (HRMS). The high-resolution achieved by ion cyclotron resonance (ICR) or Orbitrap mass spectrometers provides the power of separation needed for such a complex matrix, and allows for the assignment of unequivocal molecular formulae (e.g., $\mathrm{C}_{\mathrm{c}} \mathrm{H}_{\mathrm{h}} \mathrm{N}_{\mathrm{n}} \mathrm{O}_{\mathrm{o}} \mathrm{S}_{\mathrm{s}}$ ), which can then be sorted into "classes" based on heteroatom content (e.g., $\mathrm{N}_{\mathrm{n}} \mathrm{O}_{\mathrm{o}} \mathrm{S}_{\mathrm{s}}$ ) (Bae et al., 2010; Koolen et al., 2015; Ray et al., 2014). The most commonly used ionization sources for crude oil studies by HRMS include electrospray ionization (ESI) (Bae et al., 2010; McKenna et al., 2013; Ray et al., 2014; Ruddy et al., 2014), atmospheric pressure photoionization (APPI) (Bae et al., 2010; Koolen et al., 2015; McKenna et al., 2013; Purcell et al., 2006; Ruddy et al., 2014), and atmospheric pressure chemical ionization (APCI) (Hsu et al., 2000; Panda et al., 2009; Qian et al., 2001; Rudzinski and Rai, 2005). Other sources used include 
atmospheric pressure laser ionization (APLI) (Gaspar et al., 2012; Panda et al., 2011) as well as laser desorption ionization (LDI) (Cho et al., 2012; Cho et al., 2013). Each of these ionization sources works through specific mechanisms, has its advantages and disadvantages, and is thus going to be most useful for particular compound species. The ionization mechanism in ESI, for example, is based on a liquid that is passing through a capillary, which is subjected to a strong electric field (Kebarle and Tang, 1993). The droplet at the tip of the capillary breaks once the so-called onset voltage is reached, leading to the formation of a Taylor cone (Kebarle and Verkerk, 2009; Wilm, 2011). The initial droplet then further divides into smaller droplets due to charge accumulation and Coulombic fission, producing a spray (Kebarle and Verkerk, 2009; Wilm, 2011). The ions are then formed by ejection of a solvated ion from the droplet surface (ion evaporation model (Iribarne et al., 1976; Thomson et al., 1979)) or, for very large molecules, by evaporation of the solvent (charged residue model (Dole et al., 1968; Kebarle and Verkerk, 2009)). Overall, since the ionization mechanism in ESI is based on the formation of gas phase ions from ions in solution (Konermann et al., 2013), and therefore requires protonation and deprotonation of the compounds, it targets fairly polar to polar compounds (deHoffman et al., 2007). Moreover, since the ion formation happens in the surface layer of the droplets (Enke, 1997), ions that are most abundant in that layer will be most prevalent in the spectra, and when analyzing mixtures, surface compounds can mask other compounds up to $100 \%$ (deHoffman et al., 2007). Therefore, when using ESI, one of the things that needs to be addressed is that the response is not solely based on analyte concentration, but depends on other factors (such as the ionization efficiency, the presence of certain other ionic species, and the solvation energy) (Cole, 2000; Tang 
and Kebarle, 1991; Tang and Kebarle, 1993). For example, Teräväinen et al. (2007) showed that in their analysis of crude oils using negative mode ESI, the presence of certain easily ionizable impurities, as well as acids originally present in the oils, caused significant suppression that lead to fewer compounds being detected as well as to a general shift to a lower average molecular weight distribution (Teräväinen et al., 2007). APCI ionization, oppositely to ESI, is a gas phase ionization process in which the primary ions that are produced by a corona discharge subsequently ionize the nebulized solvent (Covey et al., 2009; deHoffman et al., 2007). Gas-phase ion-molecule reactions then lead to the final ionization of the analyte through a wide variety of possible ionization reactions, including proton transfer, adduct formation, and charge-transfer (Bruins, 1991; Covey et al., 2009; deHoffman et al., 2007). The most common type of ionized analytes will be the protonated or deprotonated form obtained by abstraction or donation of a proton to an acidic or basic reagent ion, respectively, but adducts and radical species may also be observed. The general reaction mechanisms for the formation of a protonated analyte ion in positive ionization mode is shown in equations 1-4 (deHoffman et al., 2007). The radical ionic species $\left([\mathrm{M}]^{+*}\right.$ ), on the other hand, would form by charge exchange from $\mathrm{N}_{2}^{+\bullet}$ or $\mathrm{O}_{2}^{+\bullet}$ (Anacleto et al., 1995), while the ionization mechanism for deprotonation in negative mode would take place by abstraction of a proton by an $\mathrm{OH}^{-}$ion. The ionization mechanism in APPI, instead, uses photons in order to ionize gas phase molecules. The photons, emitted by a discharge lamp, initiate a series of gas phase reactions that ultimately lead to the ionization of the sample (deHoffman et al., 2007). The ideal photon energy is higher than the ionization energy (IE) of the sample molecules, but lower than the ionization energy of atmospheric gases and solvents; 
therefore, a Krypton lamp (emitting photons at 10.0 and $10.6 \mathrm{eV}$ ) is usually the lamp of choice (Marchi et al., 2009; Robb and Blades, 2006). Direct ionization of the analytes is, however, not always very efficient, and dopant molecules can be used to aid in the ionization (deHoffman et al., 2007; Marchi et al., 2009; Raffaelli and Saba, 2003; Robb and Blades, 2006). A dopant is a substance (present or added) that is photoionizable and that is capable of acting as an intermediate to ionize the analyte (deHoffman et al., 2007; Marchi et al., 2009).

Primary ion formation:

$$
\begin{aligned}
& \mathrm{N}_{2}+e^{-} \rightarrow \mathrm{N}_{2}^{+\bullet}+2 e^{-} \\
& \mathrm{N}_{2}^{+\bullet}+\mathrm{H}_{2} \mathrm{O} \rightarrow \mathrm{N}_{2}+\mathrm{H}_{2} \mathrm{O}^{+\bullet} \\
& \mathrm{H}_{2} \mathrm{O}^{+\bullet}+\mathrm{H}_{2} \mathrm{O} \rightarrow \mathrm{H}_{3} \mathrm{O}^{+}+\mathrm{HO}^{\bullet}
\end{aligned}
$$

Secondary ion formation:

Proton transfer:

$$
\mathrm{H}_{3} \mathrm{O}^{+}+\mathrm{A} \rightarrow\left(\mathrm{M}+\mathrm{H}^{+}+\mathrm{H}_{2} \mathrm{O}\right.
$$

APPI can, therefore, work through multiple different ionization mechanisms, and some of the main ion formation equations are shown in equations 5-11 (D represents the dopant, A the analyte, $\mathrm{S}$ the solvent, and $\mathrm{H}$ a hydrogen atom) (deHoffman et al., 2007; Kamel et al., 2008; Kauppila et al., 2015). In positive ionization mode the abundance of one type of ion (radical or protonated) over the other depends on the relative ionization energies (IE) and proton affinities (PA) of the analytes and solvents (deHoffman et al., 2007). In negative ionization mode, on the other hand, the formation of radical or deprotonated molecules depends on the electron affinities (EA) and gas phase acidity of the analytes (deHoffman et al., 2007; Kauppila et al., 2015). Some reported benefits of APPI have been less ion suppression with respect to other sources, a large dynamic range, and high sensitivity (Short et al., 2007). Overall, both APPI and APCI are conducive to the 
formation of radical cations, allowing for the additional ionization of nonpolar compounds that are not easily ionized in ESI (deHoffman et al., 2007; Kauppila et al., 2015; Short et al., 2007). Overall, it is clear that a comprehensive oil characterization, thus, most likely requires the use of a combination of these complementary sources, or finding operating conditions that will allow at least marginal ionization of most components in the oil.

\section{Positive Mode - Direct APPI}

Radical ion: $A+h v \rightarrow A^{+\bullet}+e^{-} \quad$ If $h v \geq \operatorname{IE}(A)$

Protonated ion: $A^{+\bullet}+S \rightarrow[A+H]^{+}+[S-H]^{\bullet}$

Positive Mode - Dopant assisted APPI
Dopant: $D+h v \rightarrow D^{+\bullet}+e^{-}$
If $h v \geq \operatorname{IE}(D)$
Protonated ion: $D^{+\bullet}+A \rightarrow[D-H]^{\bullet}+[A+H]^{+}$
If PA $(A)>\mathrm{PA}[D-H]^{\circ}$
Radical Ion: $D^{+\bullet}+A \rightarrow A^{+\bullet}+D$
If IE $(D)>\operatorname{IE}(A)$

\section{Negative Mode - Dopant assisted APPI}
Radical Ion: $A+\mathrm{e}^{-} \rightarrow A^{-}$
If $\mathrm{EA}(A)>0$
(10)
Deprotonated ion: $A+[S-H]^{-} \rightarrow[A-H]^{-}+\mathrm{S} \quad$ If $\Delta_{\text {acid }} \mathrm{G}(A)<\Delta_{\text {acid }} \mathrm{G}(S \quad$ (11)

The coupling of liquid and gas chromatography to atmospheric pressure ionization sources and HRMS has been previously reported and has shown some advantages (Barrow et al., 2014; Lababidi et al., 2013; Schwemer et al., 2015). Nonetheless, separating the thousand of compounds in a crude oil is limited by the chromatographic 
resolution and canno be achieved efficiently, and orthogonal separations are limited by boiling point (GC) and/or functionality (LC). Therefore, a comprehensive crude oil characterization frequently relies on infusion analysis, which provides no chromatographic separation, and relies on the power of the ultra-high mass spectrometric resolution to separate and assign the compounds (Aeppli et al., 2012; Hall et al., 2013; McKenna et al., 2013; Ruddy et al., 2014). Even with direct infusion analysis, however, several factors (such as ion suppression effects and discrimination with respect to specific structural features) affect the ionization of petroleum components, and thus severely limit a truly comprehensive mass spectrometric characterization regardless of the operation or resolution of the instrument (Huba and Gardinali, 2016; Panda et al., 2009; Teräväinen et al., 2007). Hence, a comprehensive, detailed, semi-quantitative oil characterization still represents a major challenge. In order to better know how close the spectral representation of the sample is to its true composition, and to fully comprehend the significance of class abundances, a good understanding of the ionization efficiency of the various compound types under the multiple ionization modes available is a critical first step.

When obtaining mass spectra through high-resolution mass spectrometry coupled to one of the previously mentioned sources, thousands of distinct peaks can be detected. For example, Fourier transform ion-cyclotron mass spectrometry (FT-ICR MS) coupled to an ESI source has been shown to produce more than 30,000 distinct peaks (Bae et al., 2010; McKenna et al., 2013), and as many as 50,000 peaks being reported for an Arabian light crude oil (Schaub et al., 2008). The main benefit of high-resolution analysis is the capability to assign a unique elemental composition $\left(\mathrm{C}_{\mathrm{c}} \mathrm{H}_{\mathrm{h}} \mathrm{N}_{\mathrm{n}} \mathrm{O}_{\mathrm{o}} \mathrm{S}_{\mathrm{s}}\right)$ to each one of the 
peaks that are generated. The product of such an analysis is, therefore, an enormous amount of elemental composition data, which needs to be carefully visualized, or grouped by using restrictions and statistical methods, in order to make the data analysis manageable. Plots showing the relative abundance of the different compound "classes" (e.g., the " $\mathrm{O}_{1}$ " class comprising all molecular formulae containing two oxygen atoms, etc.) are often used to obtain a general idea of the type of compounds present in the oil. However, the relative abundance of the classes is inevitably dependent on the overall ionizability of each of the compounds making up that specific class. This means that the ability of ionizing singly oxygenated compounds of multiple functionalities (such as alcohols, phenols, or ketones) will affect their relative contribution within the " $\mathrm{O}_{1}$ " class, but also with respect to, for example, the " $\mathrm{O}_{2}$ " class whose compounds (e.g., carboxylic acids and quinones) may also have different ionization efficiencies. Therefore, a comparison of the abundances of the "classes" is intrinsically biased due to ionization source limitations. Moreover, some compound types might not be ionized at all based on the specific source being used. It becomes very clear that a thorough and comprehensive understanding of the ionization potential and efficiency of the key compound types expected to be present in crude oil will enormously benefit the interpretation of highresolution mass spectrometric data, both by providing a weighing scale for specific functionalities, but also by identifying "silent" areas of the spectra. This will aid in evaluating how close the spectral representation of the sample is to its true composition, and to fully comprehend the significance of class abundance.

The present study, therefore, focused on analyzing a series of model compounds by direct infusion high-resolution mass spectrometry with APPI, APCI and ESI sources. 
Ionization efficiencies were evaluated by comparing molar intensities, and were used to evaluate the role of size, polarity, and heteroatom contribution towards ionization ease. The relative formation of radical and protonated ionic species (where applicable), as well the extent of ion suppression were investigated.

\subsection{Materials and methods}

\subsubsection{Preparation of standards}

Seven separate mixtures, as well as several single-compound standards, were prepared and tested in all ionization modes (APPI, APCI, and ESI). Detailed composition of the standard mixtures is provided in Appendix 4. All initial standard solutions were in dichloromethane (DCM), and were then reconstituted to 50:50 methanol/toluene and spiked with $1 \%$ formic acid or $1 \%$ ammonium hydroxide for positive and negative mode, respectively. The solvents used were all Optima LC/MS grade purchased from Fisher Scientific (Fair Lawn, NJ, USA).

\subsubsection{High-resolution mass spectrometric analysis}

Analysis was carried out on a Q Exactive Orbitrap (Thermo Scientific, NJ, USA) by direct infusion through a $500 \mu \mathrm{L}$ syringe (Thermo Scientific, NJ, USA) at a typical flow rate of $30 \mu \mathrm{L} / \mathrm{min}$. The APPI ionization source (Thermo Scientific, NJ, USA) was equipped with a krypton UV gas discharge lamp (Syagen Technology, Inc, Tustin, CA) that produces 10.0 and $10.6 \mathrm{eV}$ photons $(120 \mathrm{~nm})$. For both positive and negative ionization mode, $\mathrm{N}_{2}$ sheath gas at 40 psi was used to facilitate ionization, while the auxiliary port remained closed. Also, for both modes, the heated vaporizer region was 
held at $350{ }^{\circ} \mathrm{C}$, while the capillary temperature was set to $300{ }^{\circ} \mathrm{C}$. The APCI source (Thermo Scientific, NJ, USA) parameters for positive mode were a sheath gas at $10 \mathrm{psi}$, an auxiliary gas at $7 \mathrm{psi}$, a capillary temperature of $350^{\circ} \mathrm{C}$, and a heated vaporizer region at $400{ }^{\circ} \mathrm{C}$. In negative mode the parameters were a sheath gas at $32 \mathrm{psi}$, an auxiliary gas at $5 \mathrm{psi}$, a capillary temperature of $250{ }^{\circ} \mathrm{C}$, and a heated vaporizer region at $450{ }^{\circ} \mathrm{C}$. For both positive and negative ionization modes the discharge current was set to $4.00 \mu \mathrm{A}$. Finally, for the ESI analysis, a heated electrospray (HESI) source (Thermo Scientific, NJ, USA) was used, and conditions for positive mode were a spray voltage of $5.20 \mathrm{kV}$, a heated vaporizer region at $300{ }^{\circ} \mathrm{C}$, capillary temperature of $300{ }^{\circ} \mathrm{C}$, and sheath and auxiliary gas at 40 and 5 psi, respectively. For negative mode, the typical conditions were a spray voltage of $4.50 \mathrm{kV}$, a heated vaporizer region at $300{ }^{\circ} \mathrm{C}$, capillary temperature of $200{ }^{\circ} \mathrm{C}$, and sheath and auxiliary gas at 35 and $30 \mathrm{psi}$, respectively. Each sample was run in quadruplicate, and average and standard deviation values were calculated.

\subsection{Results and discussion}

The three main atmospheric pressure ionization sources, namely ESI, APPI, and APCI, were used to analyze all standard mixtures and individual compounds (since previous results showed only marginal improvements when exploring the combination of APPI and APCI, this specific ionization method was not further explored in this study). 
Table 3.1 Ionization of the main compound classes in the three ionization sources (APPI, APCI, and ESI), in positive and negative ionization mode. Compounds present at $\geq 1 \%$ relative abundance in a particular source and mode are depicted with a checkmark.

\begin{tabular}{|c|c|c|c|c|c|c|c|c|}
\hline & & & \multicolumn{3}{|c|}{ Positive } & \multicolumn{3}{|c|}{ Negative } \\
\hline & & & APPI & $A P C l$ & $E S I$ & APPI & $A P C I$ & $E S I$ \\
\hline \multirow{9}{*}{ 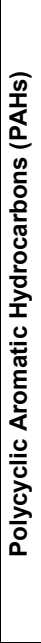 } & 2 Ring $P A H$ & Naphthalene & $\checkmark$ & - & - & - & - & - \\
\hline & 3 Ring PAH & Anthracene & & & - & - & - & - \\
\hline & 4 Ring PAH & Chrysene & & $\checkmark$ & - & - & - & - \\
\hline & 5 Ring PAH & Dibenzo(a,h)anthracene & & & - & - & - & - \\
\hline & 7 Ring PAH & Hexaphenylbenzene & & & - & - & - & - \\
\hline & Sulfur PAH & Dibenzothiophene & & & - & - & - & - \\
\hline & Oxygen PAH & Dibenzofuran & & - & - & - & - & - \\
\hline & \multirow{2}{*}{ Nitrogen PAH } & $\begin{array}{l}\text { Pyridinic Nitrogen: } \\
\text { Dibenzo(a,h)acridine }\end{array}$ & & $\checkmark$ & & - & - & - \\
\hline & & $\begin{array}{l}\text { Pyrrolic Nitrogen: } \\
\text { 7H-Dibenzo }(c, g) \text { carbazole }\end{array}$ & & $\checkmark$ & $\checkmark$ & & $\checkmark$ & \\
\hline \multirow{2}{*}{ 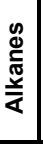 } & \multirow{2}{*}{ Alkanes } & $\begin{array}{l}\text { Straight Chain: } \\
\text { Octadecane }\end{array}$ & - & - & - & - & - & - \\
\hline & & $\begin{array}{l}\text { Cyclic: } \\
\text { Decalin }\end{array}$ & - & - & - & - & - & - \\
\hline \multirow{11}{*}{ 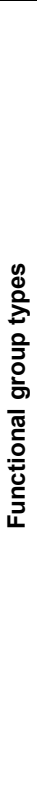 } & \multirow{2}{*}{ Alcohol } & $\begin{array}{l}\text { Aliphatic: } \\
\text { Tetracosanol }\end{array}$ & - & - & - & - & - & - \\
\hline & & $\begin{array}{l}\text { Aromatic: } \\
\text { 1-Pyrenemethanol }\end{array}$ & & & & - & - & - \\
\hline & \multirow{2}{*}{ Aldehyde } & $\begin{array}{l}\text { Aliphatic: } \\
\text { 1-Octadecanal }\end{array}$ & - & - & - & - & - & - \\
\hline & & $\begin{array}{c}\text { Aromatic: } \\
\text { 1-Pyrenecarbaldehyde }\end{array}$ & & & & - & - & - \\
\hline & \multirow{2}{*}{ Ketone } & $\begin{array}{l}\text { Aliphatic: } \\
\text { 2-Nonadecanone }\end{array}$ & & $\checkmark$ & & - & - & - \\
\hline & & $\begin{array}{c}\text { Aromatic: } \\
\text { 1-Acetylpyrene }\end{array}$ & & $\checkmark$ & $\checkmark$ & & - & - \\
\hline & \multirow{2}{*}{ Carboxylic Acid } & $\begin{array}{l}\text { Aliphatic: } \\
\text { Stearic acid }\end{array}$ & - & - & - & & $\checkmark$ & \\
\hline & & $\begin{array}{c}\text { Aromatic: } \\
\text { 1-Pyrenecarboxylic acid }\end{array}$ & & & - & & & \\
\hline & Phenol & 4-Isopropylphenol & - & - & - & $\checkmark$ & - & \\
\hline & Lactone & $\gamma$-Octalactone & $\checkmark$ & $\checkmark$ & $\checkmark$ & - & - & - \\
\hline & Anhydride & Phthalic anhydride & $\checkmark$ & - & $\checkmark$ & - & - & - \\
\hline \multirow{3}{*}{ 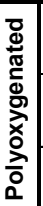 } & Carboxylic Acid & $\begin{array}{c}\text { 2,6-Naphthalenedicarboxylic } \\
\text { acid }\end{array}$ & - & - & - & $\checkmark$ & $\checkmark$ & $\gamma$ \\
\hline & Ketone & Anthraquinone & $\checkmark$ & $\checkmark$ & $\checkmark$ & $\checkmark$ & $\checkmark$ & - \\
\hline & Alcohol & 1,5-Dihydroxynaphthalene & $\checkmark$ & $\checkmark$ & - & $\checkmark$ & $\checkmark$ & $\gamma$ \\
\hline
\end{tabular}


Table 3.1 shows the primary different compound classes and whether or not they were ionized in the three sources; since concentrations were kept consistent across the range of compounds, the differences observed are mostly due to ionization efficiency. It is very noticeable that APPI and APCI are able to ionize a much larger range of compound classes when compared to ESI. Moreover, when comparing APPI to APCI it is clear that even though most of the results overlap, APPI provides some advantages over APCI as it enables the efficient ionization and detection of two-ring PAHs, oxygen containing PAHs (such as dibenzofuran), and anhydrides. Overall, thus, APCI or ESI do not seem to provide any significant advantages over the APPI ionization source as there is no compound class that can only be ionized in those sources, and one could claim that APPI is the most versatile atmospheric pressure ionization source for crude oil analysis. The ability of APPI (and to a lesser extent of APCI) to significantly expand the range of compounds that can be ionized (especially with respect to ESI) by being able to ionize compounds that are nonpolar and cannot be easily protonated/deprotonated, can be attributed to their ionization mechanisms and has been widely reported and explained (deHoffman and Stroobant, 2007; Kauppila et al., 2015; Short et al., 2007). On the other hand, ESI, as expected, is limited to ionizing acidic and basic compounds that easily lose or gain a hydrogen atom, respectively. Another noticeable feature illustrated in Table 3.1 is the complete inability of any of the sources (even APPI) to ionize pure alkanes; this can be attributed to their absence of either an aromatic ring structure (which allows for the detection of PAHs), or of heteroatom containing functional groups (i.e. lactones, anhydrides). The only instance in which alkanes are ionized is when they present easily ionizable groups, such as a carboxylic acid (APPI, APCI, and ESI) or a ketone (APPI 
only). Even though the ionization of pure hydrocarbons was previously achieved under very specific conditions (Tose et al., 2015), the lack of ionization of non-functionalized alkanes under common crude oil analysis conditions (such as the ones employed in this study), evidences a significant limitation of crude oil characterization by atmospheric pressure ionization HRMS. This is especially noteworthy since alkanes usually represent one of the most abundant compound classes of a typical oil (Fingas, 2015). While Table 3.1 provides useful information regarding the potential ionization, or lack thereof, of the main compound classes that one may expect to find in crude oil samples, it does not give any information on the relative ionization efficiencies between the different compounds and ionization techniques. In order to investigate the influence of structure on ionization efficiencies, the molar intensities of the ions were calculated (by dividing the intensity by the molarity) and compared. Moreover, to provide a better way of comparison, the relative molar intensities were then calculated by normalizing all values to the largest peak in a specific data set. Figure 3.1 illustrates the total ionization efficiencies (the sum of the radical and protonated species) of the major compound classes that were shown to be ionized in at least one of the three sources. The results from each ionization type and mode are shown normalized to the highest abundance compound class in that particular source and mode. Overall, from Figure 3.1 it is clear that compounds prone to protonation or deprotonation (such as pyrrolic and pyridinic nitrogens, ketones, and carboxylic acids) have the highest ionization efficiencies irrespectively to the source type. Besides that, it is obvious that the ionization efficiencies in the three ionization sources vary greatly based on compound type. While APPI and APCI show similar results with respect to their most abundant classes (aromatic ketones and pyrrolic nitrogens in positive 
and negative mode, respectively), the abundances of the other classes are highly variable, especially in negative mode. In APPI, for example, phenols represent the second most abundant class in negative mode, while this class is completely absent in APCI. In ESI on the other hand, the two classes that are preferentially ionized in positive and negative mode, respectively, are pyridinic nitrogens and aromatic carboxylic acids. As previously seen in Table 3.1, Figure 3.1 also illustrates the ability of APPI to enable the ionization of species that are not easily protonated/deprotonated, such as PAHs and heteroatom containing PAHs. It also shows that APPI and APCI positive mode enable the efficient detection of both the nitrogen containing compound classes (pyridinic and pyrrolic), while ESI only marginally detects the pyrrolic species in positive mode and would likely require a combination of the positive and negative mode analysis. This advantage is in accordance with previously reported results obtained with the APPI ionization source (Purcell et al., 2006; Purcell et al., 2007). As mentioned before, Figure 3.1 depicts the total ionization efficiencies, i.e., for compounds producing both radical and protonated ions the sum is calculated and plotted. In ESI the formation of the radical ion is very unlikely, and in APPI and APCI the respective ease to form radical or protonated ions depends on several factors, namely the composition of the solvent and mobile phase, and the ionization energies and proton/electron affinities of the solvents, mobile phase, and analytes (deHoffman and Stroobant, 2007). For example, in the presence of a dopant such as toluene, solvents like methanol or acetonitrile have shown to initiate the formation of protonated ions (Kauppila et al., 2002; Raffaelli and Saba, 2003). On the other hand, solvents which have low proton affinity (e.g., chloroform, hexane, and water) preferentially form radical ions by charge exchange reactions (Kauppila et al., 2002). 


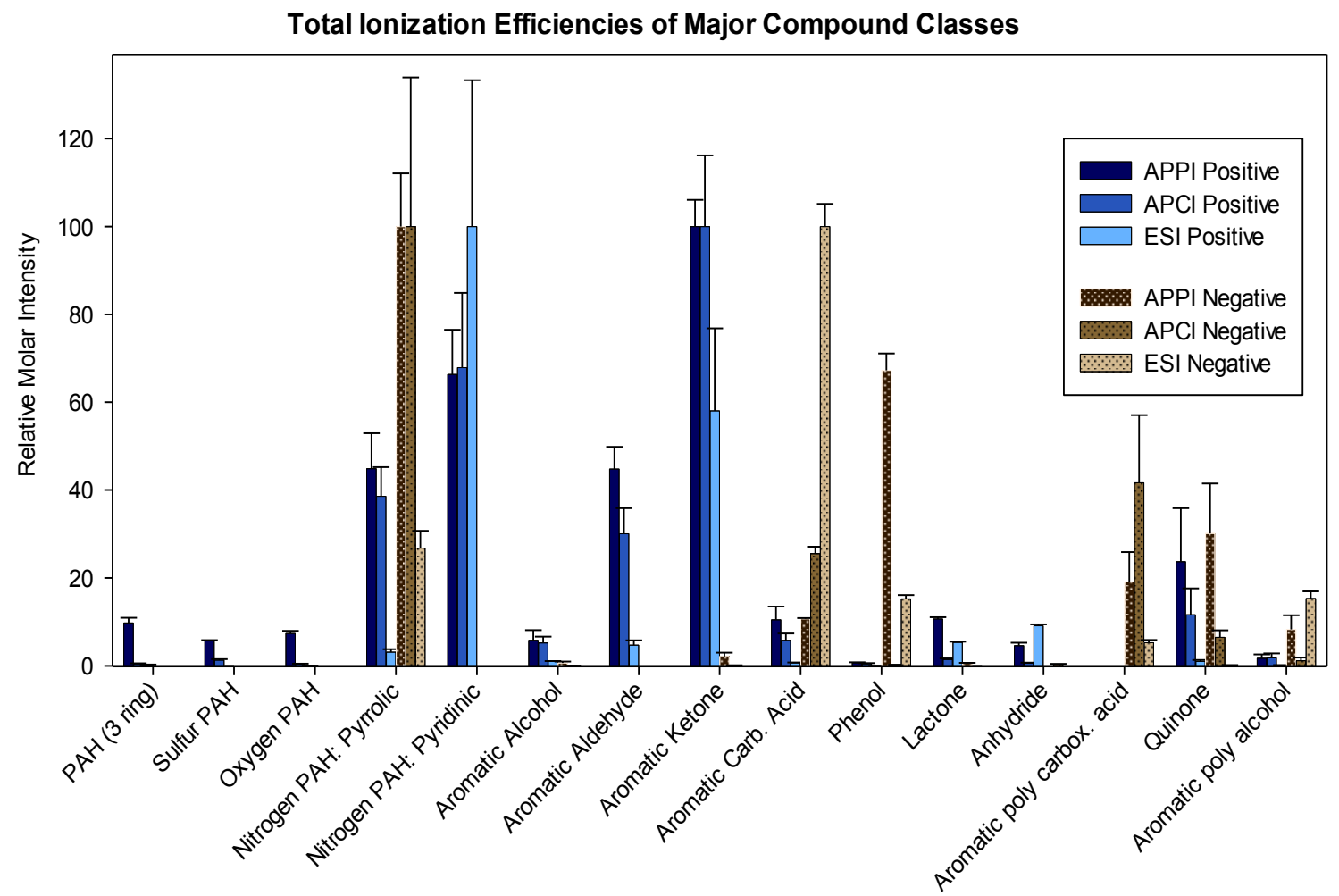

Figure 3.1 Graph illustrating the total relative ionization efficiencies of the major compound classes that were ionized in at least one ionization source. Each compound was run in quadruplicate, all values portrayed represent averages, with the error bars representing the relative percent error.

Figures $3.2 \mathrm{a}$ and $3.2 \mathrm{~b}$ were created in order to obtain a more detailed interpretation of the relative ratio of the radical versus protonated ion formation, and show compound classes that are relevant in APPI and APCI positive mode. The ratios of radical versus protonated ions in APPI and APCI are very similar, and it is very obvious that some compound classes preferentially form radical ions, while others get protonated more easily. More specifically, heteroatom containing functional groups such as pyrrolic and pyridinic nitrogens, aldehydes, ketones, and lactones preferentially form protonated ions, while PAH species form mainly radical ions. However, for PAHs, it can be noticed 
that as the size of the PAH increases (by increasing the number of rings) the formation of the protonated ionic species increases as well (e.g., protonated ions are not formed for a 2- or 3-ring $\mathrm{PAH}$, while for a 5-ring $\mathrm{PAH}$ there is a radical to protonated ion ratio of about 1). This result is in accordance with previous findings reporting that the protonated ion is often dominant for larger PAHs (Anacleto et al., 1995; Mansoori, 1998; Marvin et al., 1999). In addition, one can also notice that larger PAHs show a higher relative molar intensity, and are thus ionized more efficiently. This trend is more clearly illustrated in Figure 3.3a, which shows an increase in total ionization efficiency with PAH size in both APPI and APCI. The statistical significance of the results was evaluated by a student's ttest and showed significant increases $(\mathrm{p}<0.01)$ in ionization as the ring size increases for all transitions (2-3, 3-4, 4-5 rings). The difference in ionization energy can explain the higher relative molar intensity of 3-ring PAHs over 2-ring PAHs $(8.1444 \pm 0.001 \mathrm{eV}$ for naphthalene (Lias, 2016), $7.439 \pm 0.06 \mathrm{eV}$ for anthracene (Lias, 2016), and 7.891 \pm $0.001 \mathrm{eV}$ phenanthrene (Lias, 2016)), while the increased formation of protonated cations can explain the remainder of the trend (3-4, and 4-5 rings). One can also notice that, when normalized to the highest molar intensity peak (the 5-ring $\mathrm{PAH}$ ), the relative ionization efficiency of smaller PAHs is better in APPI compared to APCI. The ability of APPI to better ionize small PAHs is in accordance with results obtained by Robb et al. (2000), showing a much better sensitivity for naphthalene in APPI with respect to APCI (Robb et al., 2000). A separate trend was found when looking at how methylation affects the ionization efficiencies, and is illustrated in Figure 3.3b. 

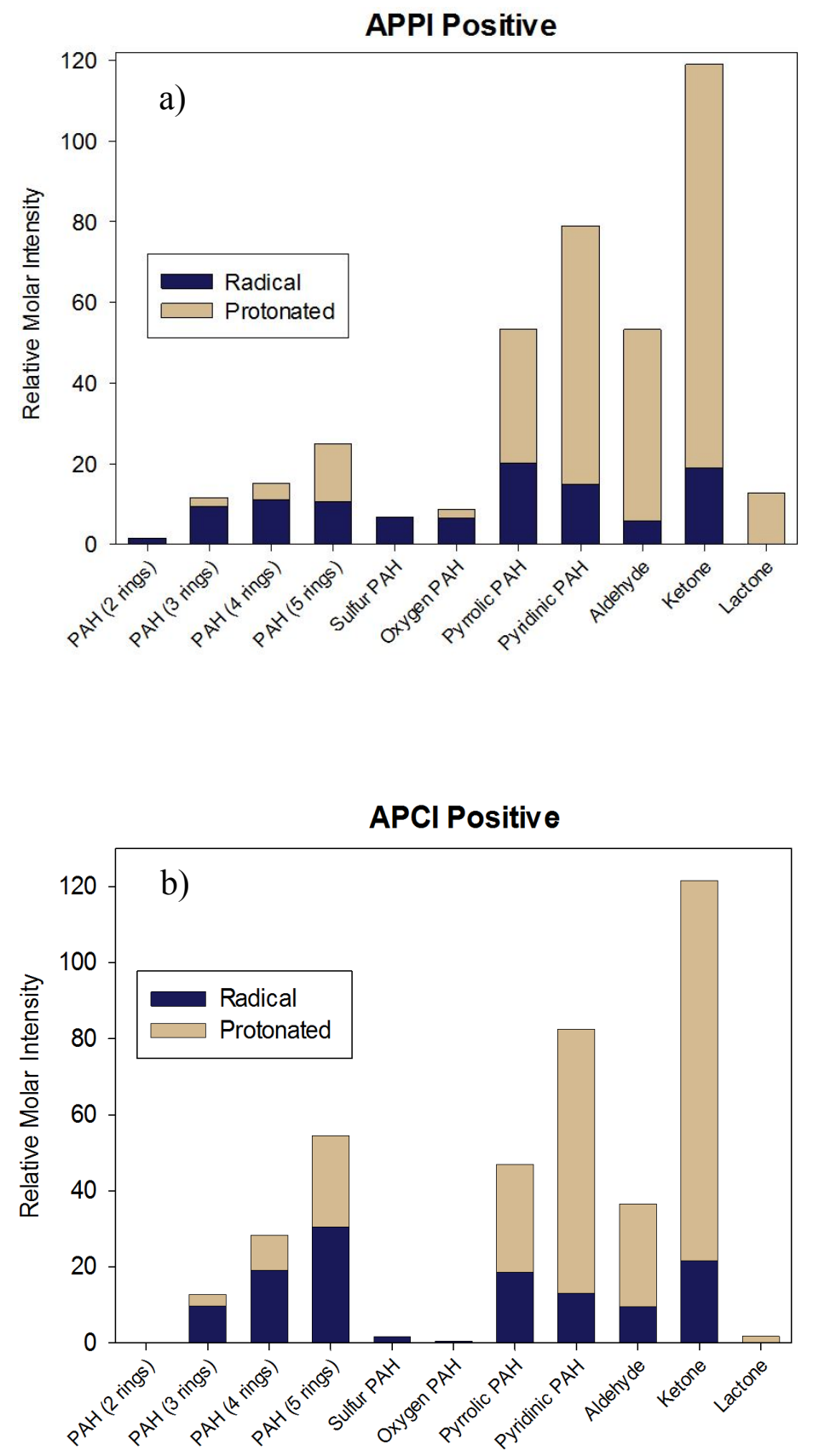

Figure 3.2 Comparison of the average relative molar intensities of the radical versus the protonated ion in (a) APPI and (b) APCI positive mode. 
As can be seen, the relative molar intensity significantly $(\mathrm{p}<0.01)$ increases as the level of methylation increases for all transitions, with the exception of naphthalene to methyl-naphthalene in the APCI source (both only marginally ionized). This correlates well and can be explained with the decreasing ionization energies of methylated naphthalenes $(8.1444 \pm 0.001 \mathrm{eV}$ for naphthalene (Lias, 2016), $7.96 \pm 0.03 \mathrm{eV}$ for 1 methyl naphthalene (Lias, 2016), and $7.78 \pm 0.03 \mathrm{eV}$ for 1,4-dimethyl naphthalene (Nounou, 1966)). Further results regarding the methylation trend with larger PAHs, however, suggest that this trend weakens with the increase of PAH size, and eventually disappears for large (4-ring) PAHs. These same trends also hold true for heteroatom containing PAHs, such as the sulfur containing benzothiophene, and can be observed in Figure 4.4a and Figure 4.4b.
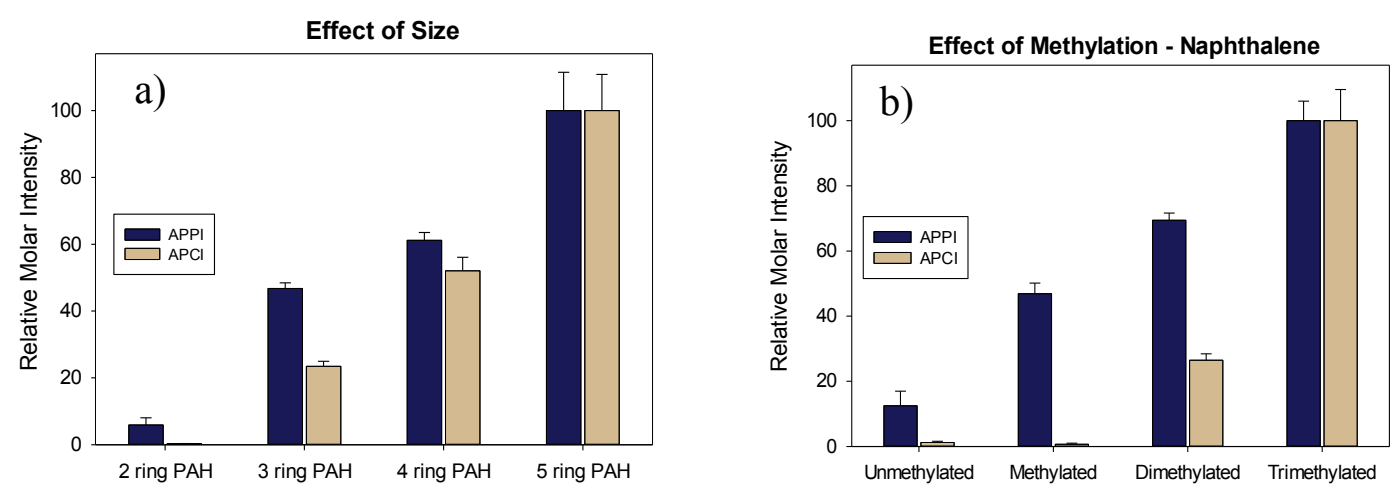

Figure 3.3 Relative total molar intensities in APPI and APCI positive mode, showing (a) the effect of size $(2$ ring $\mathrm{PAH}=$ naphthalene, 3 ring $\mathrm{PAH}=$ mixture of anthracene/phenanthrene, 4 ring $\mathrm{PAH}=$ mixture of chrysene/benz(a)anthracene, and 5 ring $\mathrm{PAH}=$ dibenzo(a,h)anthracene), and (b) the effect of methylation on the ionization efficiencies of PAHs. Average molar intensities are depicted, with error bars showing the relative percent error. 

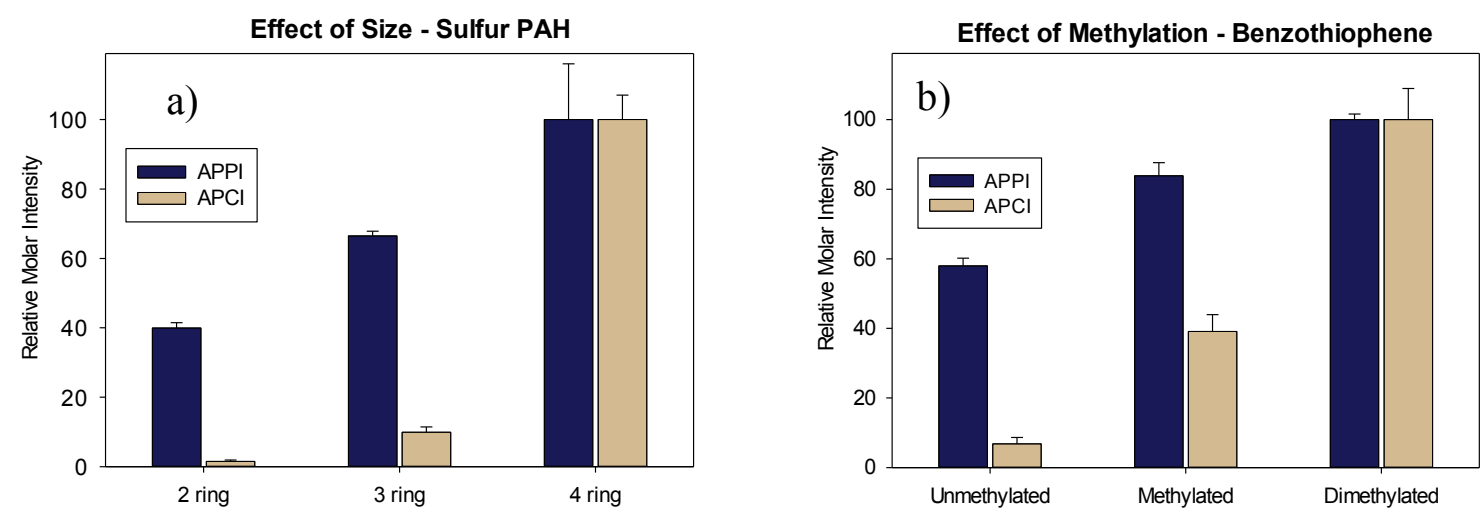

Figure 3.4 Relative total molar intensities in APPI and APCI positive mode, showing (a) the effect of size ( 2 ring $\mathrm{PAH}=$ benzothiophene, 3 ring $\mathrm{PAH}=$ dibenzothiophene, and 4 ring $\mathrm{PAH}=$ naphthodibenzothiophene) and (b) the effect of methylation on the ionization efficiencies of a sulfur containing PAH. Average molar intensities are depicted, with error bars showing the relative percent error.

Another interesting finding that was obtained from the size distribution study, was the varying nature in ionization efficiencies of specific compounds with the same number of rings but different ring structure (i.e., isomeric compounds such as chrysene and benzo(a)anthracene). This result is shown in Figure 3.5 and clearly points out how the ionization efficiency of benzo(a)anthracene is significantly higher than the one of chrysene $(\mathrm{p}<0.05)$ in both ionization sources, but most prevalently in APPI. This trend can be explained, similarly to the methylation trend, by looking at the ionization energies of the two compounds (7.60 $\pm 0.03 \mathrm{eV}$ for chrysene (Shahbaz et al., 1981), and $7.46 \pm$ $0.03 \mathrm{eV}$ for benzo(a)anthracene (Akiyama et al., 1981)). An additional interesting aspect of ionization differences for isomeric compounds illustrated in Figure 3.5, is the clear dissimilarity in the extent of protonation of the two compounds. While for benzo(a)anthracene the amount of the protonated ionic species is almost $50 \%$ of the total ions formed, for chrysene protonation is almost completely absent $(<1 \%$ in APPI, and $<$ 
$4 \%$ in APCI). Since isomeric compounds often times have considerably different physical, chemical, and toxicological properties (Dabestani and Ivanov, 1999), it is extremely important to use all available information (such as differences in ionization behavior) in order to interpret a mixture of unknown compounds. Figure 3.5 shows that, in this particular case, the relative amount of protonated ion formation could suggest the presence of one of the two isomers over the other.

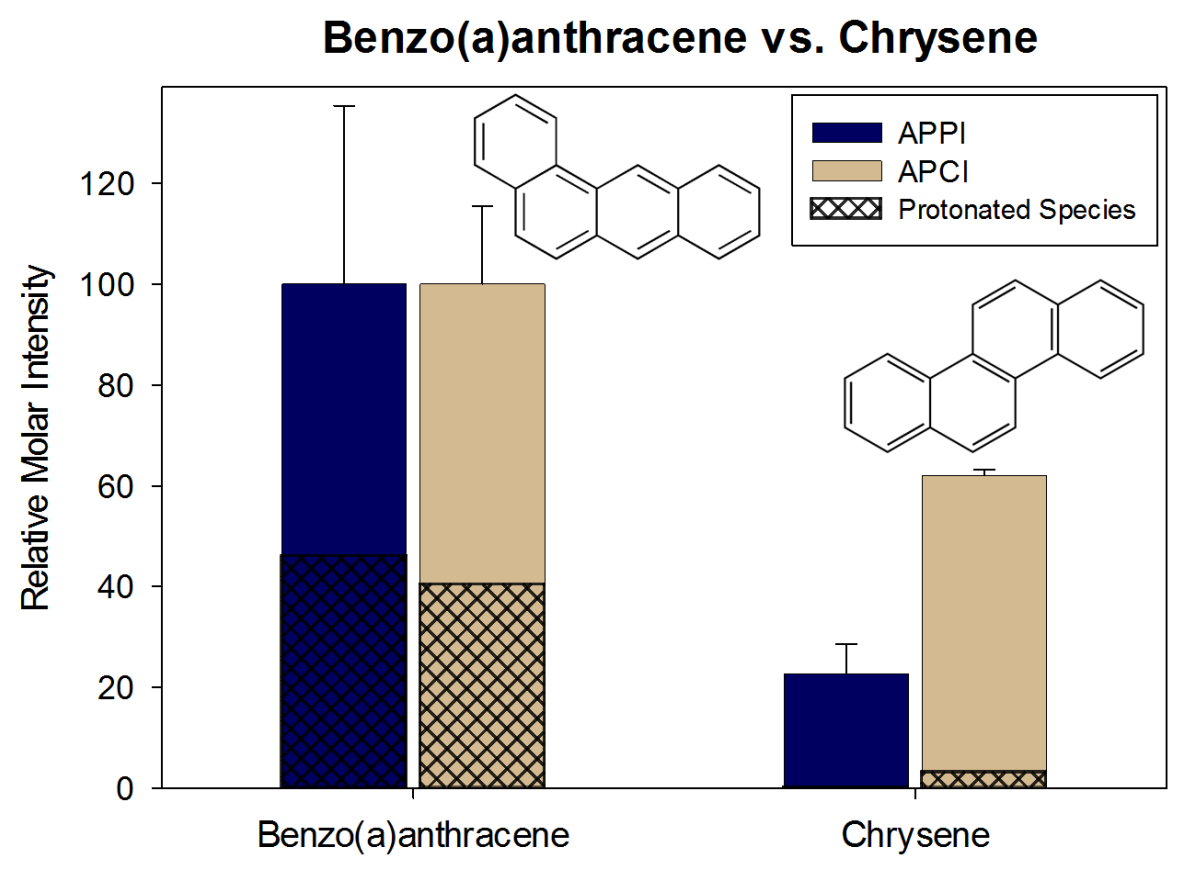

Figure 3.5 Comparison of two 4-ring isomeric PAHs (benzo(a)anthracene and chrysene), showing significant differences in ionization efficiency and formation of the protonated ionic species (depicted by the shaded area). The compounds were both run in quadruplicate with the relative molar intensity representing the average value and the error bars the relative percent error. 
So far, these results have shown that factors such as size, methylation, and ring structure affect the ionization efficiencies of PAHs in APPI as well as in APCI. An additional factor is shown in Figure 3.6, which takes a closer look at the effect that heteroatoms have on the ionization efficiency of PAHs. In order to exclude the contribution of any of the previously described factors, four PAHs of equal size, methylation level, and ring type ( 3 rings, 2 six membered rings and 1 five membered ring) were chosen and compared (i.e., fluorene, carbazole, dibenzofuran, and dibenzothiophene). As expected, carbazole is the compound that is most efficiently ionized, and this can be attributed mainly to its ease to be protonated. This is also the only compound that is detected in ESI since this technique relies on protonation and deprotonation. All the other PAHs (containing no heteroatoms, sulfur, and oxygen) do not have easily protonable groups and thus only significantly ionize by the radical ionization mechanism which is less efficient and only possible in APPI or APCI. When comparing APPI to APCI it can be seen that APCI provides a better ionization of carbazole ( $\mathrm{p}<0.01)$, but for all other compounds the ionization efficiency is significantly $(\mathrm{p}<0.01)$ better for APPI. It can therefore be concluded from Figure 3.6 that, overall, APPI provides the best ionization efficiencies over the range of heteroatom containing compounds depicted in this study.

Lastly, this study aimed at illustrating how and to what extent ion suppression effects (in the three atmospheric pressure ionization sources here used) affect molar relative intensities. In order to do so, a proof of concept study with the same four PAHs (which covered a range of possible heteroatoms) shown in Figure 3.6 were analyzed in individual solutions, additionally to the mixture containing about 50 other PAHs. Figure 3.7 
illustrates the results that were obtained, and clearly shows that significant suppression ( $p$ $<0.05$ ) is present in APCI (for fluorene, dibenzofuran, and dibenzothiophene). APPI also shows some suppression for fluorene $(\mathrm{p}<0.01)$, while the ionization of carbazole $(\mathrm{p}<$ 0.01 ) is enhanced in the mixture with respect to the individual solution. The other two compounds in APPI do not show statistically different ionization efficiencies whether present in a complex mixture or not. Surprisingly, ESI does not show ion suppression with the exception of dibenzothiophene. One has to take into account, however, that the overall ionization efficiencies of all compounds except carbazole, was negligible $(<1 \%)$ in ESI when compared to the other two ionization sources (see Figure 3.6). Moreover, the mixture is solely comprised of PAHs, which are compounds not ionized in ESI.The here obtained ESI results were included to give a comprehensive picture of all the sources, and to show that, as expected, even though a complex matrix was present the lack of ionization of the majority of compounds in such matrix led to almost no suppression. In order to better demonstrate suppression effects in ESI, a future study including a mixture containing compounds well ionized in ESI (such as pyridinic nitrogen compounds) should be performed. When comparing solely APCI and APPI, the latter provides the more consistent ionization efficiencies and thus less suppression from the matrix. These, results are in agreement with previous reports showing that APPI exhibits reduced suppression effects when compared to both ESI and APCI (Hanold et al., 2004; Short et al., 2007). Overall, it is evident that suppression does influence the ionization efficiencies, even for the least affected ionization method (APPI). This is clearly shown by the relative molar intensities of fluorene and carbazole: while for the mixture the ionization efficiency for carbazole was significantly higher than the one for fluorene, for 
the individual solutions the two values were not statistically different. Thus, when referring and comparing relative ionization efficiencies in comprehensive petroleum studies by HRMS, which heavily rely on infusion data (with no prior chromatographic separation and thus particularly affected by suppression effects), it is imperial to take the matrix into consideration.

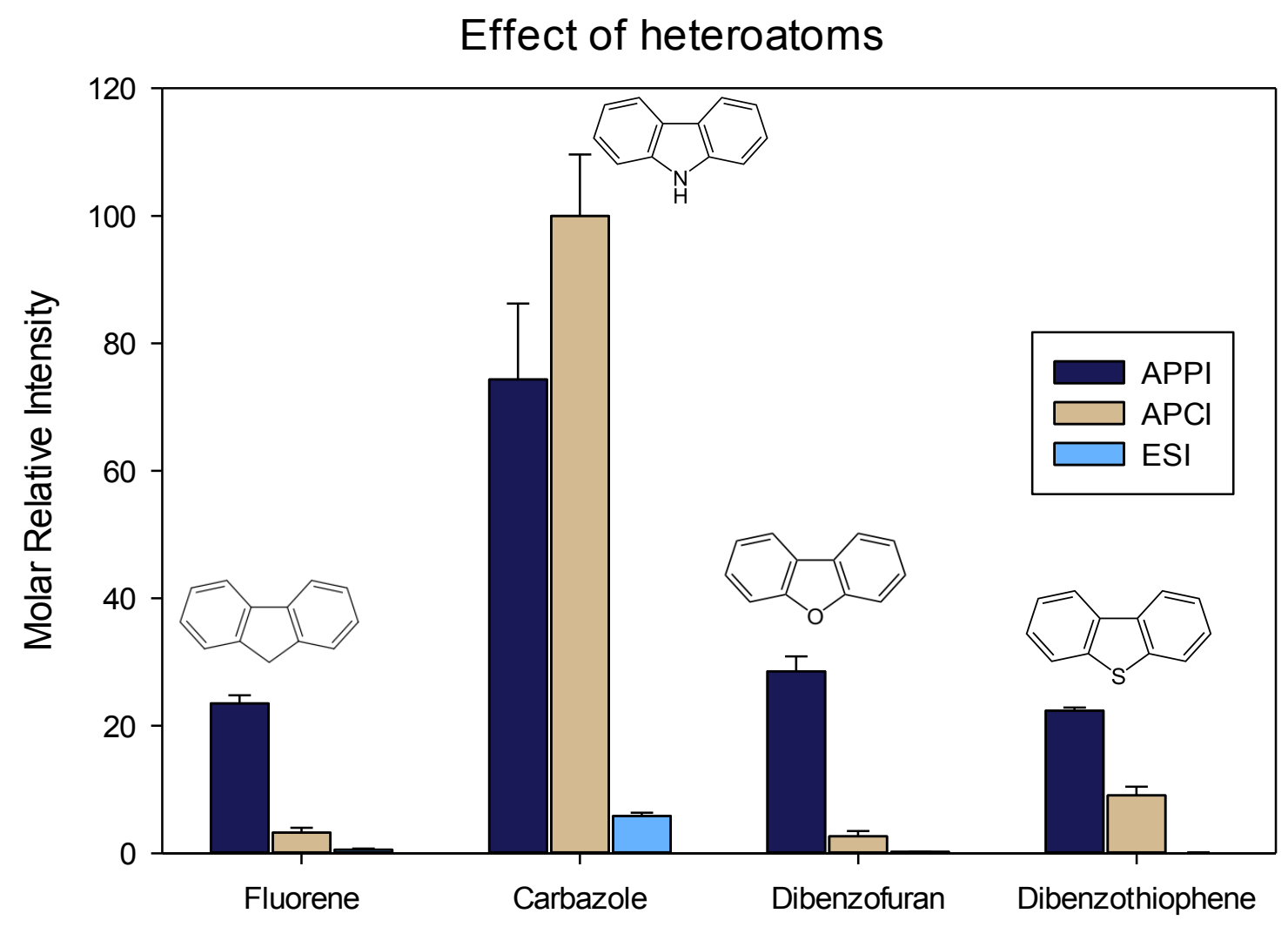

Figure 3.6 Total relative molar intensities depicting the ionization efficiencies of heteroatom containing PAHs in the positive ionization mode. Relative molar intensities are an average of quadruplicate runs, and error bars represent the relative percent error. 
Overall, the results here presented provide a fairly comprehensive picture of the ionization behavior of major compound classes present in crude oil under the specific conditions used in this analysis. Even though the APPI source seems to provide the best results (with the data being concentration independent on a range from $0.2-2 \mathrm{ppm}$ ), significant limitations with respect to the analysis of complex environmental mixtures were shown. As previously mentioned, elemental composition data and the comparison of so-called compound "classes" are fundamental tools used to interpret and compare oil composition. However, since this data is intrinsically biased due to limitations in the ionization of the numerous different compound types present in the crude oil, an understanding of such biases is fundamental in order to evaluate the significance of the results obtained. Several research areas, such as understanding the compositional changes of crude oil due to weathering, rely on the accuracy of HRMS data to portray the "true" composition of the crude oil (Huba and Gardinali, 2016; Ray et al., 2014; Ruddy et al., 2014). This is a very crucial step in understanding the ultimate fate and toxicity of oil released into the environment. It is thus evident that this study provides knowledge that is critical when interpreting crude oil characterization results by HRMS, and that the results here presented will benefit future research in this field.

\subsection{Conclusion}

The present study provides a comprehensive overview of the benefits and drawbacks of the three main atmospheric pressure ionization sources (ESI, APPI, and APCI) with respect to the ionization of the principal compound classes expected to be found in crude oil.Moreover, computation of molar intensities allowed for semi- 
quantitative comparisons of the relative ionization efficiencies. The overall complete lack of ionization of non-functionalized alkanes was a clear and significant limitation pertinent to all three sources. Out of the three sources, the results showed that, if a comprehensive oil characterization is targeted, the APPI source seems to provide the best results, by being able to ionize the broadest range of compounds, as well as providing the best overall ionization efficiencies, and less ionization suppression with respect to APCI. ESI, on the other hand, showed severe limitations, as the amount of different compound classes that are ionized is significantly lower compared to both APPI and APCI. This study, moreover, showed that the ionization efficiency is influenced by several factors: the presence of easily protonated or deprotonated functional groups (primary factor), the size, the methylation level, the presence/absence/type of heteroatoms, the isomeric structure, and the presence/absence of a complex matrix.

These results are critical information needed in order to interpret HRMS oil characterization results, and additionally provide the knowledge needed to aid in the selection of a specific ionization source with respect to a compound type of interest. Therefore, these findings, which can be further applied to other high-resolution mass analyzers beyond the Orbitrap, in addition to future studies expanding the range of compound classes and dopants used, will provide the fundamental understanding required to greatly expand the power of HRMS analysis of crude oils.

\subsection{Acknowledgements}

The Environmental Analysis Research Laboratory acknowledges the support from the Thermo Scientific Corporation in the development of this work. AKH would like to 
thank Kathia Sandoval for helpful discussions. This is contribution number 795 from the Southeast Environmental Research Center at Florida International University.
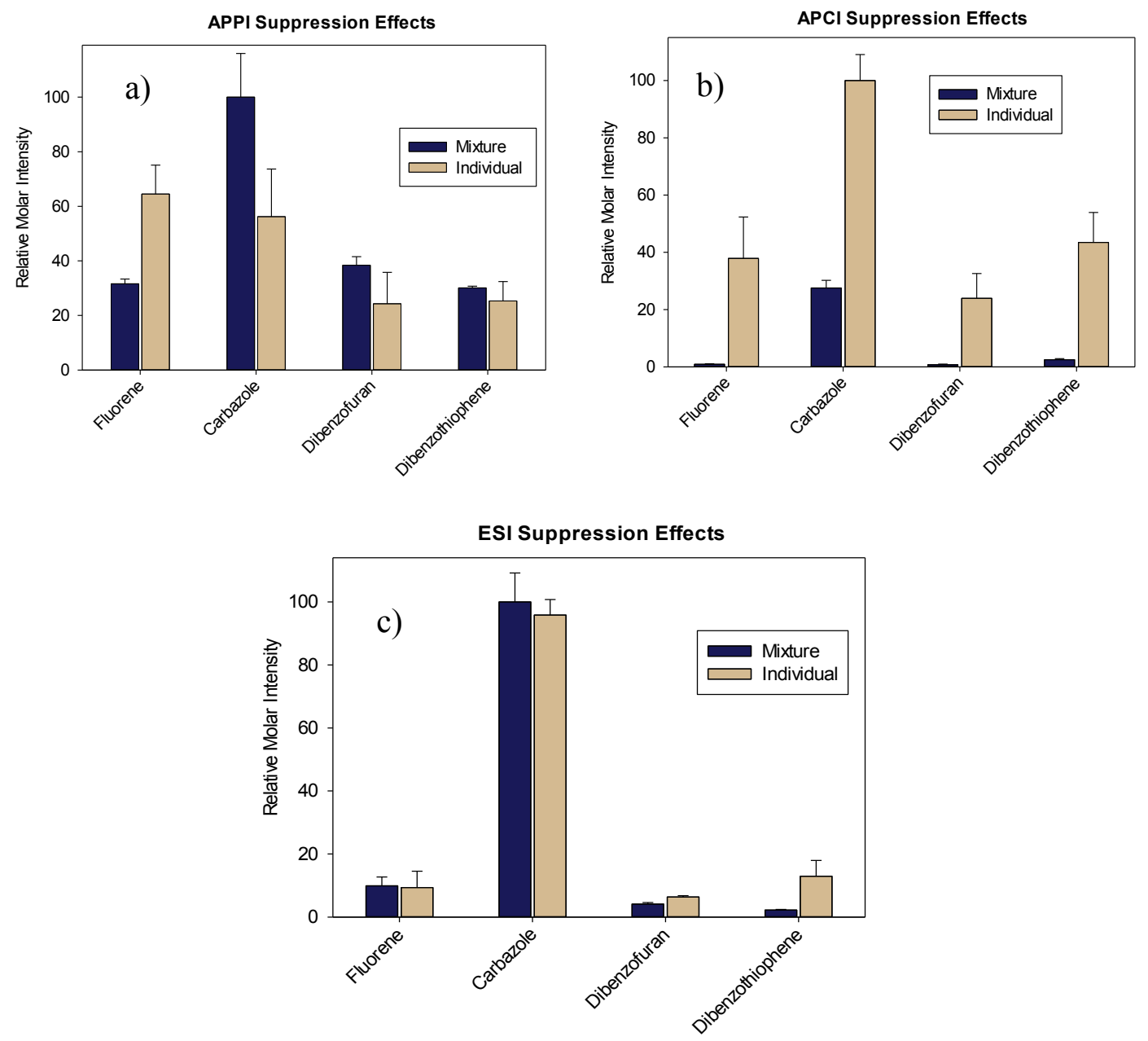

Figure 3.7 Comparison of ionization efficiencies of four PAHs analyzed in quadruplicate in individual solutions and in a PAH mixture, illustrating the extent of ionization suppression in (a) APPI, (b) APCI, and (c) ESI. Relative molar intensities and error bars represent the average value and the relative percent error, respectively. 


\subsection{References}

Aeppli C, Carmichael CA, Nelson RK, Lemkau KL, Graham WM, Redmond MC, et al. Oil Weathering after the Deepwater Horizon Disaster Led to the Formation of Oxygenated Residues. Environmental Science \& Technology 2012; 46: 8799-8807.

Akiyama I, Harvey RG, LeBreton PR. Ultraviolet photoelectron studies of methylsubstituted benz(a)anthracenes. J. Am. Chem. Soc. 1981; 103: 6330.

Anacleto JF, Ramaley L, Benoit FM, Boyd RK, Quilliam MA. Comparison of liquid chromatography/mass spectrometry interfaces for the analysis of polycyclic aromatic compounds. Analytical Chemistry 1995; 67: 4145-4154.

Bae E, Na J-G, Chung SH, Kim HS, Kim S. Identification of about 30000 Chemical Components in Shale Oils by Electrospray Ionization (ESI) and Atmospheric Pressure Photoionization (APPI) Coupled with 15 T Fourier Transform Ion Cyclotron Resonance Mass Spectrometry (FT-ICR MS) and a Comparison to Conventional Oil. Energy \& Fuels 2010; 24: 2563-2569.

Barrow MP, Peru KM, Headley JV. An Added Dimension: GC Atmospheric Pressure Chemical Ionization FTICR MS and the Athabasca Oil Sands. Analytical Chemistry 2014; 86: 8281-8288.

Bruins AP. Mass spectrometry with ion sources operating at atmospheric pressure. Mass Spectrometry Reviews 1991; 10: 53-77.

Cho Y, Jin JM, Witt M, Birdwell JE, Na J-G, Roh N-S, et al. Comparing Laser Desorption Ionization and Atmospheric Pressure Photoionization Coupled to Fourier Transform Ion Cyclotron Resonance Mass Spectrometry To Characterize Shale Oils at the Molecular Level. Energy \& Fuels 2013; 27: 1830-1837.

Cho Y, Witt M, Kim YH, Kim S. Characterization of Crude Oils at the Molecular Level by Use of Laser Desorption Ionization Fourier-Transform Ion Cyclotron Resonance Mass Spectrometry. Analytical Chemistry 2012; 84: 8587-8594.

Covey TR, Thomson BA, Schneider BB. Atmospheric pressure ion sources. Mass Spectrometry Reviews 2009; 28: 870-897.

Dabestani R, Ivanov IN. A Compilation of Physical, Spectroscopic and Photophysical Properties of Polycyclic Aromatic Hydrocarbons. Photochemistry and Photobiology 1999; 70: 10-34.

de Hoffman E, Stroobant V. Mass Spectrometry: Principles and Applications. John Wiley \& Sons Ltd, The Atrium, Southern Gate, Chichester, West Sussex PO19 8SQ, England: Wiley, 2007. 
Fingas, M. Handbook of Oil Spill Science and Technology. Hoboken, New Jersey: John Wiley \& Sons, 2015.

Gaspar A, Zellermann E, Lababidi S, Reece J, Schrader W. Impact of Different Ionization Methods on the Molecular Assignments of Asphaltenes by FT-ICR Mass Spectrometry. Analytical Chemistry 2012; 84: 5257-5267.

Hall GJ, Frysinger GS, Aeppli C, Carmichael CA, Gros J, Lemkau KL, et al. Oxygenated weathering products of Deepwater Horizon oil come from surprising precursors. Marine Pollution Bulletin 2013; 75: 140-149.

Hanold KA, Fischer SM, Cormia PH, Miller CE, Syage JA. Atmospheric Pressure Photoionization. 1. General Properties for LC/MS. Analytical Chemistry 2004; 76: 28422851.

Hsu CS, Dechert GJ, Robbins WK, Fukuda EK. Naphthenic Acids in Crude Oils Characterized by Mass Spectrometry. Energy \& Fuels 2000; 14: 217-223.

Huba AK, Gardinali PR. Characterization of a Crude Oil Weathering Series by Ultrahighresolution Mass Spectrometry Using Multiple Ionization Modes. Science of the Total Environment 2016; 563-564: 600-610.

Kauppila TJ, Kuuranne T, Meurer EC, Eberlin MN, Kotiaho T, Kostiainen R. Atmospheric Pressure Photoionization Mass Spectrometry. Ionization Mechanism and the Effect of Solvent on the Ionization of Naphthalenes. Analytical Chemistry 2002; 74: 5470-5479.

Kauppila TJ, Syage JA, Benter T. Recent developments in atmospheric pressure photoionization-mass spectrometry. Mass Spectrometry Reviews 2015: n/a-n/a.

Kebarle P, Tang L. From ions in solution to ions in the gas phase - the mechanism of electrospray mass spectrometry. Analytical Chemistry 1993; 65: 972A-986A.

Kebarle P, Verkerk UH. Electrospray: From ions in solution to ions in the gas phase, what we know now. Mass Spectrometry Reviews 2009; 28: 898-917.

Konermann L, Ahadi E, Rodriguez AD, Vahidi S. Unraveling the mechanism of electrospray ionization. Analytical Chemistry 2013; 85: 2-9.

Koolen HHF, Swarthout RF, Nelson RK, Chen H, Krajewski LC, Aeppli C, et al. Unprecedented Insights into the Chemical Complexity of Coal Tar from Comprehensive Two-Dimensional Gas Chromatography Mass Spectrometry and Direct Infusion Fourier Transform Ion Cyclotron Resonance Mass Spectrometry. Energy \& Fuels 2015; 29: 641648. 
Lababidi S, Panda SK, Andersson JT, Schrader W. Direct Coupling of Normal-Phase High-Performance Liquid Chromatography to Atmospheric Pressure Laser Ionization Fourier Transform Ion Cyclotron Resonance Mass Spectrometry for the Characterization of Crude Oil. Analytical Chemistry 2013; 85: 9478-9485.

Lias SG. Ion Energetics Data. In: Linstrom PJ, Mallard WG, editors. NIST Chemistry WebBook, NIST Standard Reference Database, National Institute of Standards and Technology, Gaithersburg MD, 20899. Retrieved 2016.

Mansoori BA. Isomeric identification and quantification of polycyclic aromatic hydrocarbons in environmental samples by liquid chromatography tandem mass spectrometry using a high pressure quadrupole collision cell. Rapid Communications in Mass Spectrometry 1998; 12: 712-728.

Marvin CH, Smith RW, Bryant DW, McCarry BE. Analysis of high-molecular-mass polycyclic aromatic hydrocarbons in environmental samples using liquid chromatography-atmospheric pressure chemical ionization mass spectrometry. Journal of Chromatography A 1999; 863: 13-24.

McKenna AM, Nelson RK, Reddy CM, Savory JJ, Kaiser NK, Fitzsimmons JE, et al. Expansion of the Analytical Window for Oil Spill Characterization by Ultrahigh Resolution Mass Spectrometry: Beyond Gas Chromatography. Environmental Science \& Technology 2013; 47: 7530-7539.

Nounou P. Etude des composes aromatiques par spectrometrie de masse. I. Mesure des potentials d'ionisation et d'apparition par la methode du potential retardateur et interpretation des courbes d'ionisation differentielle. J. Chim. Phys. 1966; 63: 994.

Panda SK, Andersson JT, Schrader W. Characterization of Supercomplex Crude Oil Mixtures: What Is Really in There? Angewandte Chemie 2009; 121: 1820-1823.

Panda SK, Brockmann K-J, Benter T, Schrader W. Atmospheric pressure laser ionization (APLI) coupled with Fourier transform ion cyclotron resonance mass spectrometry applied to petroleum samples analysis comparison with electrospray ionization and atmospheric pressure photoionization methods, Rapid Communications in Mass Spectrometry Volume 25, Issue 16. Rapid Communications in Mass Spectrometry. 25, 2011, pp. 2317-2326.

Purcell JM, Hendrickson CL, Rodgers RP, Marshall AG. Atmospheric Pressure Photoionization Fourier Transform Ion Cyclotron Resonance Mass Spectrometry for Complex Mixture Analysis. Analytical Chemistry 2006; 78: 5906-5912.

Purcell JM, Rodgers RP, Hendrickson CL, Marshall AG. Speciation of Nitrogen Containing Aromatics by Atmospheric Pressure Photoionization or Electrospray 
Ionization Fourier Transform Ion Cyclotron Resonance Mass Spectrometry. Journal of the American Society for Mass Spectrometry 2007; 18: 1265-1273.

Qian K, Rodgers RP, Hendrickson CL, Emmett MR, Marshall AG. Reading Chemical Fine Print: Resolution and Identification of 3000 Nitrogen-Containing Aromatic Compounds from a Single Electrospray Ionization Fourier Transform Ion Cyclotron Resonance Mass Spectrum of Heavy Petroleum Crude Oil. Energy \& Fuels 2001; 15: 492-498.

Raffaelli A, Saba A. Atmospheric pressure photoionization mass spectrometry. Mass Spectrometry Reviews 2003; 22: 318-331.

Ray PZ, Chen H, Podgorski DC, McKenna AM, Tarr MA. Sunlight creates oxygenated species in water-soluble fractions of Deepwater horizon oil. Journal of Hazardous Materials 2014; 280: 636-643.

Robb DB, Covey TR, Bruins AP. Atmospheric Pressure Photoionization: An Ionization Method for Liquid Chromatography-Mass Spectrometry. Analytical Chemistry 2000; 72: 3653-3659.

Ruddy BM, Huettel M, Kostka JE, Lobodin VV, Bythell BJ, McKenna AM, et al. Targeted Petroleomics: Analytical Investigation of Macondo Well Oil Oxidation Products from Pensacola Beach. Energy \& Fuels 2014; 28: 4043-4050.

Rudzinski WE, Rai V. Detection of Polyaromatic Sulfur Heterocycles in Crude Oil Using Postcolumn Addition of Tropylium and Tandem Mass Spectrometry. Energy \& Fuels 2005; 19: 1611-1618.

Schaub TM, Hendrickson CL, Horning S, Quinn JP, Senko MW, Marshall AG. HighPerformance Mass Spectrometry: Fourier Transform Ion Cyclotron Resonance at 14.5 Tesla. Analytical Chemistry 2008; 80: 3985-3990.

Schwemer T, Rüger CP, Sklorz M, Zimmermann R. Gas Chromatography Coupled to Atmospheric Pressure Chemical Ionization FT-ICR Mass Spectrometry for Improvement of Data Reliability. Analytical Chemistry 2015; 87: 11957-11961.

Shahbaz M, Akiyama I, LeBreton P. Ultraviolet photoelectron studies of methyl substituted chrysenes. Biochem. Biophys. Res. Commun. 1981; 103: 25.

Short LC, Cai SS, Syage JA. APPI-MS: Effects of Mobile Phases and VUV Lamps on the Detection of PAH Compounds. Journal of the American Society for Mass Spectrometry 2007; 18: 589-599.

Speight, G., James. The Chemistry and Technology of Petroleum: CRC Press, 2014. 
Teräväinen MJ, Pakarinen JMH, Wickström K, Vainiotalo P. Comparison of the Composition of Russian and North Sea Crude Oils and Their Eight Distillation Fractions Studied by Negative-Ion Electrospray Ionization Fourier Transform Ion Cyclotron Resonance Mass Spectrometry: The Effect of Suppression. Energy \& Fuels 2007; 21: 266-273.

Tose LV, Cardoso FMR, Fleming FP, Vicente MA, Silva SRC, Aquije GMFV, et al. Analyzes of hydrocarbons by atmosphere pressure chemical ionization FT-ICR mass spectrometry using isooctane as ionizing reagent. Fuel 2015; 153: 346-354.

Wang CY, Chen B, Zhang BY, He SJ, Zhao MM. Fingerprint and weathering characteristics of crude oils after Dalian oil spill, China. Marine Pollution Bulletin 2013; 71: 64-68.

Wilm M. Principles of Electrospray Ionization. Molecular \& Cellular Proteomics : MCP 2011; 10: M111.009407. 


\section{CHAPTER 4}

Occurrence of suspect and non-target contaminants in a typical system impacted by treated domestic wastewater 


\subsection{Abstract}

As a consequence of the finite nature of the world's fresh water sources, the recycling of treated wastewater has been a significant area of development in recent years. Water recycling, however, leads to considerable apprehension with respect to the presence and persistence of unregulated contaminants that are introduced through treated wastewater releases. Water treatment plants, although designed to remove a variety of contaminants, are not always efficient and may, additionally, introduce new products, which are formed during the treatment. Owing to the recent development of increasingly sensitive and selective analytical tools, non-target screening methods have gained significant interest. These approaches allow for a rather comprehensive screening since the a priori selection of compounds is no longer needed, opening the possibility for retrospective analysis. In this work, the potential of suspect and non-target screening workflows was demonstrated for the analysis of contaminants in surface and drinking water in a typical system impacted by a treated domestic effluent. High performance liquid chromatography-high resolution mass spectrometric (HPLC-HRMS) analysis was carried out on an Orbitrap Q Exactive, and subsequent data processing was performed with the use of the Compound Discoverer 2.0 software. Mostly automated suspect and non-target screening workflows were used in order to tentatively identify over 70 compounds, including pharmaceuticals, plasticizers and other domestic use contaminant classes, many of which were shown to be persistent along the entire system. Analysis of a drinking water treatment plant influent and effluent water showed the presence of 242 components not efficiently removed (including the tentatively identified DEET, 4nonylphenol, and hexamethoxymelamine) as well as 269 newly formed components, 
likely by-products of the treatment process. Further analysis also yielded the identification of transformation products, including cotinine, O-desmethyltramadolol, and O-desmethylvenlafaxine. Different types of mass defect plots (Kendrick, ehtoxylates, $\mathrm{H} / \mathrm{Cl}$, and $\mathrm{H} / \mathrm{Br}$ ) were used to identify potential regions of interest, such as heteroatom containing byproducts as well as surfactants, which represent an area for further development of advanced treatment technologies. Moreover, passive and grab sampling were compared, where the former seemed to capture a broader amount of contaminants as over double the number of components and tentatively identified compounds were identified in these samples.

\subsection{Introduction}

The incessantly growing human population constantly introduces a vast amount of natural and anthropological substances into the environment, directly through practices such as agriculture and farming, or indirectly through treated wastewater outfalls. Although wastewater treatment plants (WWTPs) are designed to clean up the incoming raw sewage, the treatment is often not enough to efficiently remove persistent compounds (Kümmerer, 2009; Verlicchi et al., 2012). The introduced contaminants can include: human and veterinary-use drugs, personal care products, pesticides, surfactants, hormones, plasticizers, and fire retardants among others (Odendaal et al., 2015). Reports of contaminants in surface (Kunacheva et al., 2011), ground (Jurado et al., 2012; Lapworth et al., 2012), and drinking (Cooney, 2009; Guo and Krasner, 2009) water have been published. The recalcitrant and ubiquitous nature of some of these compounds is especially concerning in an era where water scarcity has become a growing issue, and 
water recycling has become a significant alternative method for obtaining sufficient and safe fresh and drinking water (Bixio et al., 2006; Miller, 2006). Moreover, when reclaimed water is reintroduced into the environment through irrigation, artificial lakes, agriculture etc., these contaminants are further spread and potentially accumulated (Ong, 2016). While the persistence, accumulation, and biomagnification of these compounds pose significant concern (Fono et al., 2006; Guo and Krasner, 2009), degradation mechanisms such as photodegradation, biodegradation, or adsorption onto sediments, can lead to the gradual disappearance of some compounds, but their transformation products are potentially just as hazardous as their parent molecules and thus also need to be closely monitored (Gosetti et al., 2016). While numerous water quality guidelines are being enforced by agencies that are concerned with the wellbeing of our environment, because of the changing nature of human practices and the subsequent variability of substances introduced into aquatic systems, the monitoring of previously well-known contaminants may not be sufficient. The development of methods to monitor the environment for new and emerging contaminants (contaminants of emerging concern (CEC)), which are not (yet) commonly monitored for, is thus imperative.

The recent evolution of high-resolution mass spectrometry (HRMS), which provides high resolving power, excellent mass accuracy, and good sensitivity in full scan, has allowed for the separation of the thousands of peaks present in complex matrices. Moreover, HRMS offers the possibility to assign unique molecular formulae, without a prior selection of compounds of interest, which opens up the possibility of retrospective analysis (Bijlsma et al., 2011; Krauss et al., 2010). Thus, while target analysis still remains the method of choice for a quick and quantitative screening of a small set of 
known contaminants, the need of pre-selecting a limited number of specific compounds (which have reference standards available) represents a clear drawback, and target analysis is now often complemented by suspect and non-target screening. Suspect screening requires some prior information of the compounds, which leads to the creation of comprehensive "suspect" lists that are then searched for. Non-target analysis, on the other hand, assumes no prior knowledge of the compounds, and is by far the most comprehensive mode of analysis, and the method of choice for identifying new contaminants. However, the amount of data produced and the lengthy (and often manual) data processing, represent significant shortcomings. The data analysis usually includes steps such as peak-picking, blank subtraction, componentization, molecular formula generation, isotopic pattern comparison, evaluation of adducts, and the assessment and comparison of fragmentation patterns (Schymanski et al., 2015). The benefits of suspect and non-target analysis to screen for known and emerging contaminants and their transformation products have been extensively documented in the literature (Avagyan et al., 2016; Bletsou et al., 2015; Gago-Ferrero et al., 2015; Heuett, 2015; Ruff et al., 2015; Schymanski et al., 2015).

Even though HRMS based suspect and non-target screening provide a far more comprehensive picture of the aquatic pollutant composition, the fluctuating and low concentrations of contaminants still represent a significant limitation of conventional grab sampling, as this only provides a snapshot of the actual situation in a specific water source. One way to overcome this limitation is to employ passive samplers, which accumulate and retain contaminants over long periods of time (up to several weeks), enabling the detection of trace and ultra-trace contaminants, providing time weighted 
averaged (TWA) concentrations, and allowing for a more accurate ecological risk assessment (Alvarez et al., 2004; Vrana et al., 2005). A polar organic chemical integrative sampler (POCIS) is a type of passive sampler, which is employed to sample polar and semi-polar $(\operatorname{logKow} \leq 4)$ compounds such as pharmaceuticals, pesticides, etc. (Alvarez et al., 2004). The combination of passive sampling, HRMS, and non-target analysis thus seems a very promising tool to create contamination profiles and patterns, which could be used to compare different sampling sites, and be used to ultimately detect new and emerging contaminants. At last, these results would provide a great contribution to public policy guidelines by pointing out relevant and novel contaminants.

The following study employed grab and passive sampling to characterize different sampling points along a wastewater impacted river whose water ultimately serves as a drinking water source. The samples were analyzed by high-performance liquidchromatography HPLC-HRMS, and processed through a suspect and non-target screening workflow. The results were used in order to detect contamination patterns, to tentatively identify likely contaminants and evaluate their persistence and distribution, along with potential transformation products.

\subsection{Materials and methods}

\subsubsection{Sample collection}

Grab and passive sampling were used to obtain surface water samples along a wastewater-impacted water system on August 4, 2015 (shown in Figure 4.1). Grab sampling points included: upstream water (UP) (unaffected by the wastewater effluent), treated effluent water (EFF) (water directly released by the wastewater treatment plant 
pipe), intake water of a drinking water treatment plant (DWI), and the final treated drinking water (TDW). Polar organic chemical integrative samplers containing the Oasis HLB SPE sorbent (for detailed composition see Alvarez et al. (2004)) were deployed and retrieved after 27 days. The sampling points were consistent with the grab samples (upstream, drinking water intake, and treated drinking water), with exception of the wastewater treatment plant effluent, which was not sampled. A POCIS was, however, deployed at the effluent mixing zone (EMZ), and a sample collected at the latter was analyzed in addition to the three previously mentioned sites. The total distance between the upstream and the drinking water intake sampling points was about $14.5 \mathrm{~km}$. All samples were stored in the dark at $-20^{\circ} \mathrm{C}$ until analyzed.

\subsubsection{Sample preparation}

All grab samples were first filtered through a $0.5 \mu \mathrm{m}$ PreSep Prefilter glass fiber filters (Fisher Scientific, Fair Lawn, NJ, USA). Subsequently, after basifying the $500 \mathrm{~mL}$ of sample with ammonium hydroxide, a first liquid-liquid extraction with $250 \mathrm{~mL}$ of methylene chloride was performed. After collecting the organic phase the sample was acidified to $\mathrm{pH} 4$ using formic acid, and was again extracted with $250 \mathrm{~mL}$ methylene chloride. The two organic phase subsamples were collected and combined, dried over anhydrous sodium sulfate, concentrated in a water bath, evaporated to dryness under a stream of purified nitrogen, and reconstituted into $2 \mathrm{~mL}$ of methanol. For the passive samplers, the methanol extracts were injected into the mass spectrometer with no further dilution. All samples were spiked with an internal standard mixture of 21 compounds. All 
solvents used were Optima LC/MS grade purchased from Fisher Scientific (Fair Lawn, NJ, USA).

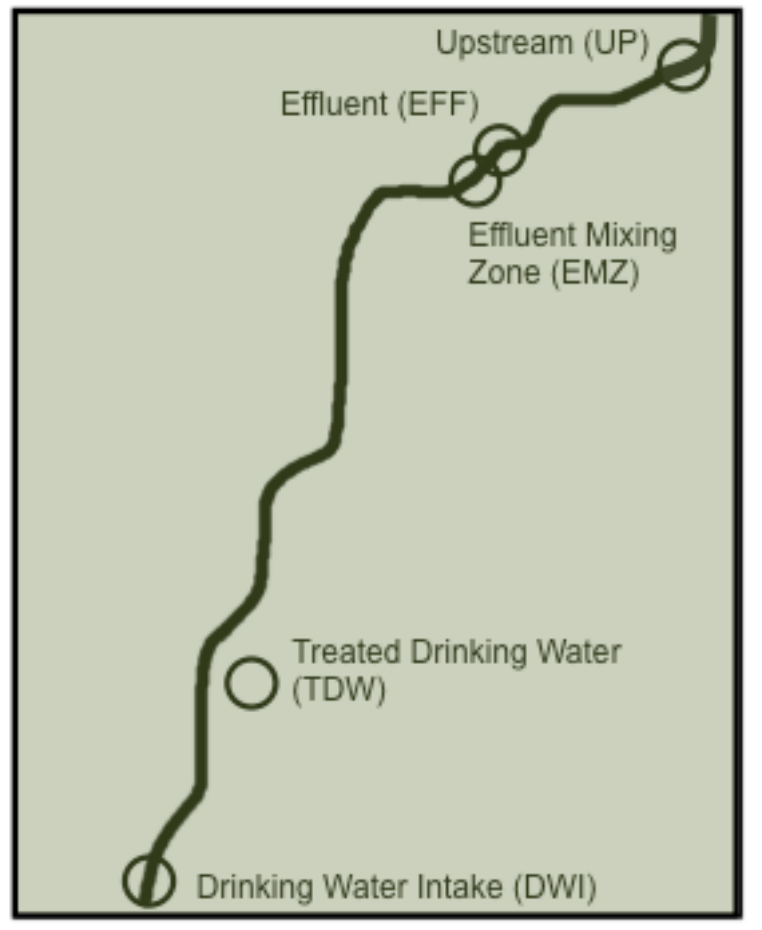

Figure 4.1 Scheme depicting the linked water system with the grab (UP, EFF, EMZ, DWI, and TDW) and POCIS (UP, EMZ, DWI, and TDW) sampling points.

\subsubsection{High-resolution mass spectrometric analysis}

The HPLC-HRMS analysis was carried out on a Q Exactive Orbitrap (Thermo Scientific, NJ, USA) mass spectrometer equipped with a heated electrospray (HESI) source (Thermo Scientific, NJ, USA). Chromatographic separation was performed on a Hypersil Gold aQ analytical column $(50 \times 2.1 \mathrm{~mm}, 1.9 \mu \mathrm{m})$, protected by a Hypersil Gold aQ guard column $(10 \times 2.1 \mathrm{~mm}, 1.9 \mu \mathrm{m})$. The analytical method was adapted from (Heuett, 2015), to include data-dependent MS/MS analysis. Source conditions included a 
spray voltage of $4.00 \mathrm{kV}$, and a heated vaporizer region at $250{ }^{\circ} \mathrm{C}$, in both positive and negative ionization mode. In positive mode, moreover, the capillary temperature was held at $350{ }^{\circ} \mathrm{C}$, while the sheath, auxiliary, and sweep gases were kept at 30,20 and $5 \mathrm{psi}$, respectively. For negative mode, a capillary temperature of $300{ }^{\circ} \mathrm{C}$ was used, and the sheath, auxiliary, and sweep gas pressured were held at 35,30 , and 5 psi, respectively. The full scan spectra were obtained on a range from $100-1000 \mathrm{~m} / \mathrm{z}$, at a resolution of 140,000, while data dependent MS/MS spectra were obtained on the top 10 peaks, at a resolution of 35,000 using a higher-energy collisional dissociation (HCD) energy of 35.

\subsubsection{Suspect and non-target workflows}

Data processing, and suspect and non-target workflows were performed with the Compounds Discoverer 2.0 software (Thermo Scientific, NJ, USA). The suspect screening workflow is presented in Figure 4.2 and included selection of the spectra, retention time alignment, detection and grouping of unknown compounds (peak-picking and componentization), background subtraction, and suspect list search (match based solely on accurate mass). The non-target workflow (illustrated in Figure 4.3), included the same six initial steps, but since no prior knowledge of the compounds is assumed no suspect list match was performed. On the other hand, all components obtained were assigned possible molecular formulae (including element restriction and isotopic pattern fit), searched for in ChemSpider, and finally searched for in the mzCloud MS/MS spectral library. 
File Inputting

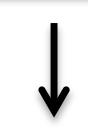

Selection of Spectra

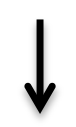

Retention Time Alignment

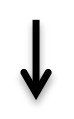

Detection of Unknown Compounds

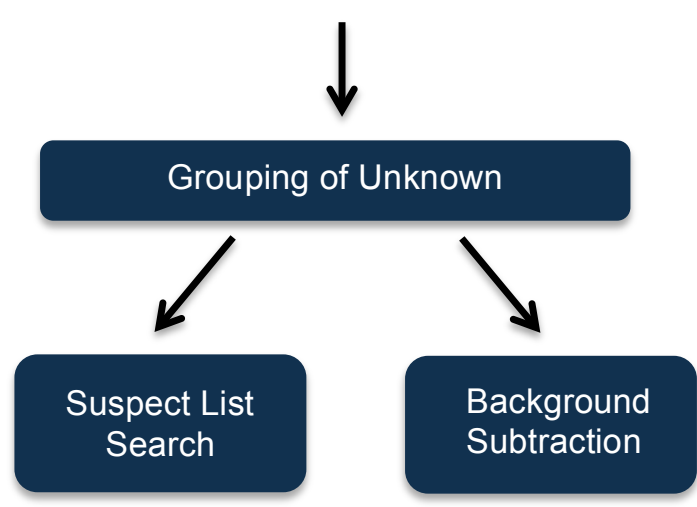

Figure 4.2 Suspect screening workflow created in Compound Discoverer 2.0, including peak-picking, retention time alignment, background subtraction, and matching of the detected $\mathrm{m} / \mathrm{z}$ values to a previously uploaded "suspects" list. 
File Inputting

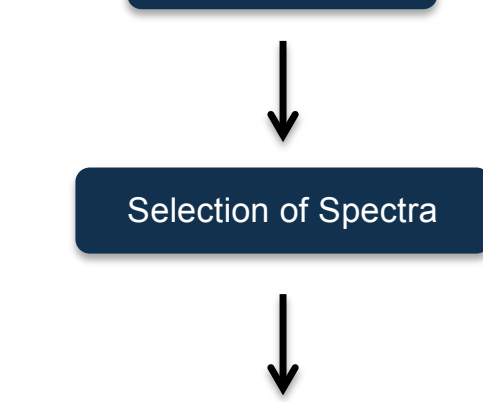

Retention Time Alignment

Detection of Unknown Compounds

$\downarrow$

Grouping of Unknown Compounds
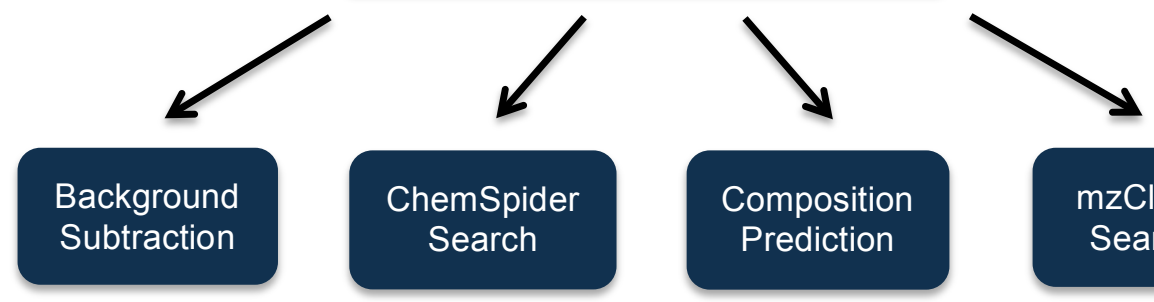

Background

Subtraction

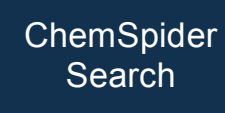

\section{mzCloud \\ Search}

Figure 4.3 Non-target screening workflow created in Compound Discoverer 2.0, including peak-picking, retention time alignment, background subtraction, elemental composition prediction (which includes an isotopic pattern match), ChemSpider search, and mzCloud fragmentation pattern search. 


\subsection{Results and discussion}

\subsubsection{Suspect screening of grab samples}

Grab samples of the upstream, effluent, drinking water intake, and treated drinking water were first subjected to suspect screening in order to obtain a general overview of the types and quantity of "suspected" contaminants present in each of the sampling sites. The workflow presented in Figure 4.2 was used in order to screen for over 7000 compounds (e.g., pharmaceuticals, pesticides, plasticizers, metabolites), and the summary of the results is shown in Table 4.1. Overall, in the four sampling sites, in positive ionization mode a total of 654 "hits" with a mass accuracy of 5 ppm or less were found on the suspect list. In order to solidify the tentative identifications, "hits" corresponding to components with available MS/MS data, were compared to library fragmentation spectra (an example of a positive match is provided in Appendix 5). Out of the 654 initial "hits", 58 compounds were found to have an MS/MS spectrum matching its library spectrum to a score of $50 \%$ or higher. This initial low threshold of $50 \%$ was used to avoid any false negatives, but a further critical and manual investigation of the 58 matches (which included manual MS/MS spectral review and an evaluation of plausibility) was needed, and resulted in the elimination of 20 initial assignments, leading to a final number of 36 tentatively identified compounds. In negative mode, on the other hand, 165 features initially matched a compound on the suspect list; this number was then reduced to 24 and 13 , using the MS/MS spectral data comparison and the manual investigation of the results. When comparing the individual sampling sites, the number of "hits" present in the effluent was clearly the most, with 516 and 132 matches in positive and negative mode, respectively. Moreover, out of the total number of assignments in 
positive and negative mode (654 and 165, respectively) 411 and 93 were found exclusively in the effluent sampling site (values in the parentheses shown in Table 4.1). The number of "hits" in the upstream, drinking water intake, and treated drinking water sampling sites were 128, 157, and 140 and 46, 49, 41, in positive and negative mode, respectively. It is somewhat surprising that the number of initial "hits" is fairly high in the treated drinking water, but the formation of new byproducts of the drinking water treatment could partially explain this result. When looking at the more refined set of tentatively identified compounds, the biggest number was found in the effluent (35 tentative identifications), followed by the upstream and drinking water intake sites (18 and 17 tentative identifications, respectively), and the treated drinking water (8 tentatively identified compounds only).

Table 4.1 Summary of suspect screening results, illustrating the initial number of "hits" on the suspect list as well as the final number of tentatively identified compounds. "Numbers in parentheses represent "hits" exclusively present in the effluent sampling site.

\begin{tabular}{cccc} 
Mode & $\begin{array}{c}\text { Number of "hits" in } \\
\text { suspect list }\end{array}$ & $\begin{array}{c}\text { Number of MS/MS } \\
\text { "hits" }\end{array}$ & $\begin{array}{c}\text { Number of tentatively } \\
\text { identified compounds }\end{array}$ \\
\hline$(+)$ & $654(411)^{\mathrm{a}}$ & $58(22)^{\mathrm{a}}$ & $38(19)^{\mathrm{a}}$ \\
$(-)$ & $165(93)^{\mathrm{a}}$ & $24(6)^{\mathrm{a}}$ & $13(7)^{\mathrm{a}}$
\end{tabular}

Overall, the 51 tentatively identified compounds were part of a variety of different contaminant classes (see Figure 4.4), including different types of pharmaceuticals (e.g., antidepressants, anesthetics, and antibiotics, such as venlafaxine, lidocaine, and 
sulfamethoxazole), plasticizers (e.g., citroflex 2 and tributyl phosphate), transformation products (e.g., cotinine, o-desmethyltramadol, and o-desmethylvenlafaxine), etc. (a list of the 51 tentatively identified suspect compounds is provided in Appendix 6). Many of the detected compounds represent frequently reported emerging contaminants (e.g., caffeine, DEET, metropolol, sulfamethoxazole, trimethoprim, and valsartan) (Batt et al., 2016; Padhye et al., 2014; Sun et al., 2014), which are often detected at very low concentrations, but whose effects of chronic exposure are still largely unknown. Overall, the suspect screening workflow provided a quick and useful general overview of the types and quantities of contaminants present in different water sites along a wastewater impacted river. However, results suggest that, as expected, when screening solely based on molecular weight matches a large presence of false positives is encountered, and thus MS/MS fragmentation information and a manual evaluation of the preliminary results are essential to refining the initial data set.

\section{Classes of Contaminants}
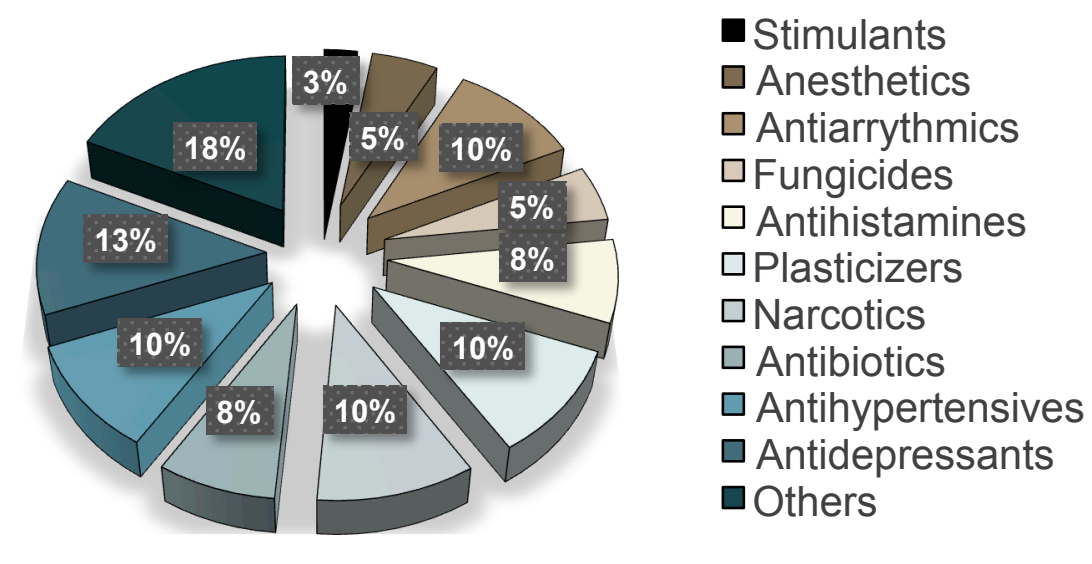

Figure 4.4 Distribution of the contaminant classes for all grab sampling locations analyzed using the suspect screening workflow. 


\subsubsection{Non-target screening of grab samples}

The same samples analyzed with the suspect screening workflow, were then analyzed with the non-target workflow shown in Figure 4.3. After the initial peak-picking and componentization performed in Compound Discoverer 2.0, a total of 4565 components were found, 938 of which were found using the negative ionization mode. The 3627 components found in positive ionization mode are shown in the Kendrick mass defect plot in Figure 4.5. Kendrick mass defect plots, which plot the Kendrick Mass Defect (difference between the nominal and exact Kendrick masses) over the nominal Kendrick mass $($ Kendrick mass $=$ IUPAC mass $\times(14.00000 / 14.01565))$, can be useful to visualize and find areas of interest in complex data sets (Sleno, 2012). In this study this type of plot is used to compare the distribution of the components between the four sampling sites. An immediately noticeable feature of Figure 4.5 is that while most of the components of the upstream, drinking water intake, and treated drinking water samples fall within common areas, the effluent clearly presents the greatest amount of components especially in two regions of the Kendrick mass plot that are unique to this site (highlighted by the black ovals in Figure 4.5). These components represent compounds with high molecular weight $(\mathrm{m} / \mathrm{z}>500)$ and negative mass defect $(-)(0.2-$ 0.4). These obvious regions of interest were previously found in an independent analysis on samples from the same wastewater impacted water system (Heuett, 2015), and the sole presence and subsequent disappearance of these components in the effluent, suggests a likely transformation/degradation. Moreover, a negative mass defect indicates the possible presence of elements such as halogens. Therefore, potentially harmful disinfection byproducts (which have been a topic of concern and interest with respect to 
advanced water treatment technologies (Neale et al., 2012; Postigo and Richardson, 2014)) could be present in this specific region of the Kendrick mass defect plot. When comparing the other three sampling sites (upstream, drinking water intake, and treated drinking water), the Kendrick mass defect plots (shown in Appendix 7) appear very similar, however the drinking water intake site appears to have the greatest number of components, most likely residual compounds introduced by the wastewater effluent, which are sufficiently removed in the subsequent drinking water treatment. The actual number of components of the four sites confirms these results (606 for the upstream, 2823 for the effluent, 706 for the drinking water intake, and 622 for the treated drinking water sampling sites).

When evaluating the Kendrick mass defect plots for the negative mode data (shown in Figure 4.6), similarly to the positive mode plots, the effluent clearly presents the greatest number of components. However, in negative mode data a significant difference can be seen within the remaining three sampling sites, as the treated drinking water contains clearly visible homologous series (which are also seen in the effluent sample), showing as equally spaced horizontal points. These homologous $\left(\mathrm{CH}_{2}\right)$ series, are likely non-ionic surfactants, a class of organic pollutants that has been previously reported in treated wastewater, as well as drinking water (Cantero et al.,; Ikehata et al., 2008; Skutlarek et al., 2006). In order to further investigate the nature of these possible non-ionic surfactants, mass defect plots were created for ethoxylated species (mass $=$ IUPAC mass $\times(44.00000 / 44.026215)$. Such plots evidence any polyethoxylated homologous series by depicting them as lines of horizontal points separated by 44 mass units (corresponding to a $\mathrm{C}_{2} \mathrm{H}_{4} \mathrm{O}$ group). While the upstream, drinking water intake, and 
treated drinking water samples did not show any significant presence of ethoxylated species, the effluent sample appears to be largely dominated by this type of surfactant. This result is clearly illustrated in Figure 4.7, which shows several examples of ethoxylated series (marked by the red diamonds), and also points out the numerous homologous series separated by 44 mass units, all representing polyethoxylated species. Since polyethoxylated compounds have been linked to endocrine disrupting activity, the presence (and consequent lack of removal during wastewater treatment processes) of such compounds is of great environmental concern, and has been extensively reported in the literature (Ciofi et al., 2014; Vega-Morales et al., 2010).

Another type of graph that was investigated, was the use of chlorine and bromine mass defect plots in order to highlight any polychlorinated or polybrominated series. These particular mass scales are defined by the substitution of a hydrogen by a chlorine and bromine atom, respectively, and similarly to the Kendrick mass scale the IUPAC mass is multiplied by $34 / 33.96102$ for the $\mathrm{H} / \mathrm{Cl}$ scale, and $78 / 77.9105$ for the $\mathrm{H} / \mathrm{Br}$ scale. The application and development of these mass defect plots to the identification of novel halogenated species has been shown and used for GC data (Jobst et al., 2013; Taguchi et al., 2010). In the present work, these plots $(\mathrm{H} / \mathrm{Cl}$ graphs are shown in Figure 4.8) have not revealed any apparent series of chlorinated or brominated compounds, which could be due to the nature of the analytical method used; nonetheless, the thousands of components detected in the four sampling sites were nicely visualized, and seem to be concentrated in distinct regions of the plot. Figure 4.8 highlights an area mainly prevalent in the surface water samples (shown in the black oval), as well as several regions that are exclusive to the effluent site (depicted by red ovals). Overall, the usefulness of mass 
defect plots (including Kendrick, chlorine, bromine, and ethoxylates), to identify patterns, contamination signatures, and areas for further investigation has been clearly shown in Figures 4.5-4.8.

Following the pattern analysis via mass defect plots, molecular formula assignments, number of database hits, and especially MS/MS fragmentation data were used to make tentative compound identifications. In positive ionization mode, out of the 3627 components that were detected throughout all the sampling sites, 82 were found to have an MS/MS spectral library match (in mzCloud) with a match score above 50\%. Critical review of these initial matches, which included isotopic pattern comparison and manual MS/MS spectral match evaluation, further reduced this number to 47 tentatively identified compounds. In negative ionization mode, 938 initial components were identified, which were reduced to 25 and 16 compounds, respectively. These tentatively identified compounds are depicted by red crosses in Figure 4.5, and are all present in a general area with positive Kendrick mass defect and m/z of 100-500, evidencing one of the main current limitations of non-target analysis; although spectral libraries have enormously developed throughout recent years, they still include only a very limited amount of common compounds. When one is interested in compounds that fall outside of this previously mentioned region in the Kendrick mass defect plot, then tentative identification become labor intensive, and a more traditional non-target analysis needs to be performed, by using theoretical prediction tools rather than mass spectral databases. The distribution of the tentatively identified compounds between the four sampling sites is shown in Figure 4.9. It is, again, clearly evident that the effluent presents the largest amount of compounds, as well as the highest overall concentrations (even for 
ubiquitously present compounds such as 5-methylbenzotriazole, DEET, lamotrigine, and TBE). It is also important to notice the presence of several transformation products (e.g., cotinine, O-desmethyltramadol, and O-desmethylvenlafaxine), some of which are present at areas higher than their parent compound (e.g., venlafaxine and its transformation product O-desmethylvenlafaxine). The need to consider transformation products in addition to the parent compounds thus becomes evident. When comparing the results obtained from the suspect and the non-target workflow, $100 \%$ of the compounds that were tentatively identified based on the suspect list were also found in the non-target workflow. Moreover, the non-target screening found 12 additional tentatively identified compounds, including persistent and emerging contaminants (benzotriazole, 5methylbenzotriazole, and 4-nitrophenol), pharmaceuticals (losartan and bicalutamide), and a transformation product (N4-acetylsulfamethoxazole). The fact that all suspect screening "hits" were also picked up by the non-target workflow (which considered no "a priori" information) is promising; however, a clear drawback of the non-target workflow is the dependence on the mzCloud spectral library. The latter prevents a true and thorough non-target search, since the number and type of compounds present in the library is limited and mostly overlaps with "suspected" targets. Therefore, while this workflow represents a valuable quick and mostly automated method to screen for contaminants without assuming any prior knowledge, in order to investigate compounds not present in the mzCloud spectral library, a further investigation using prediction tools is required. 


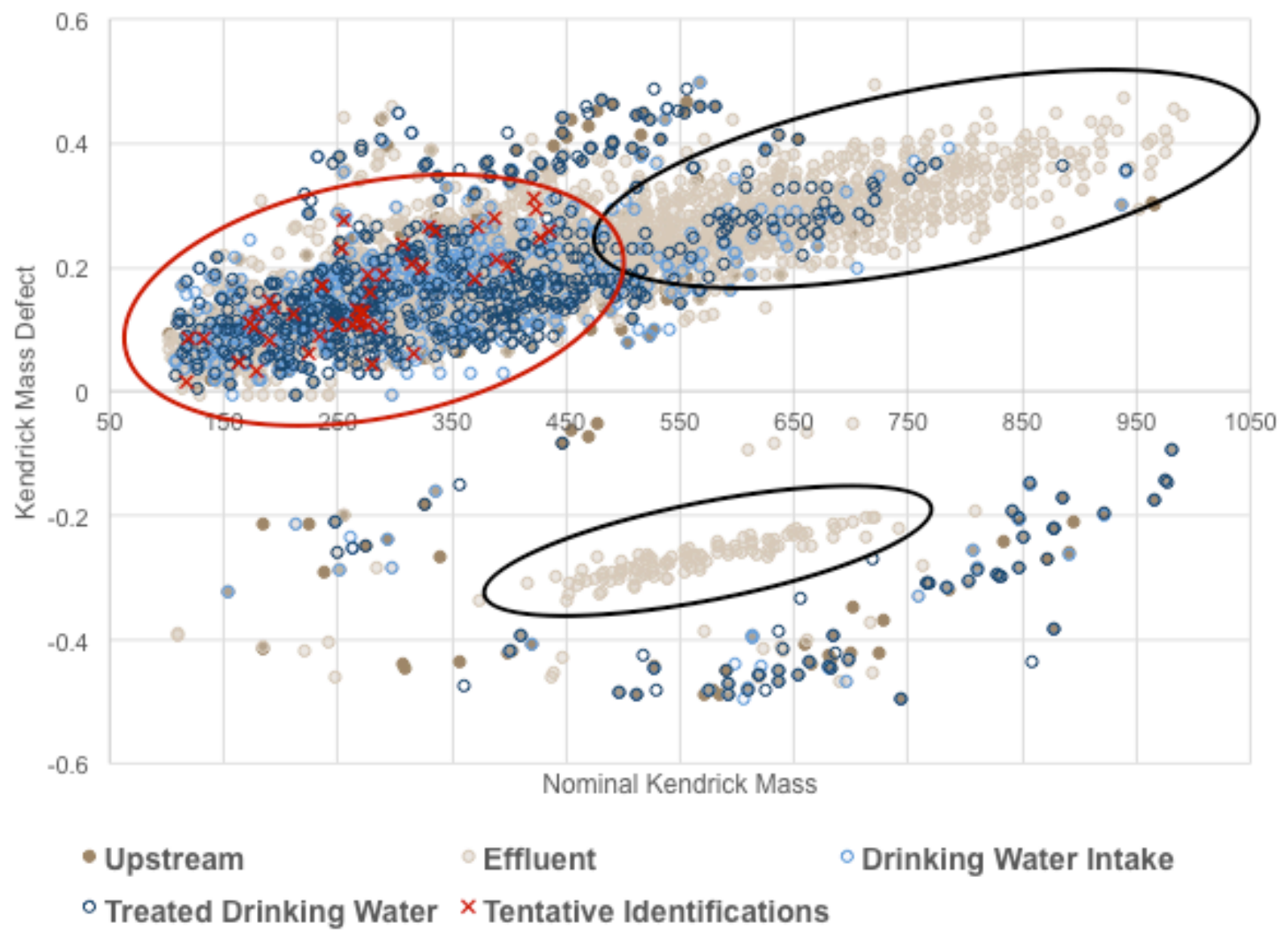

Figure 4.5 Kendrick mass defect plot showing the distribution of components within the four sampling sites. The two areas unique to the effluent are highlighted by black ovals, while the red encircled area highlights the components that were tentatively identified by the non-target screening workflow. 

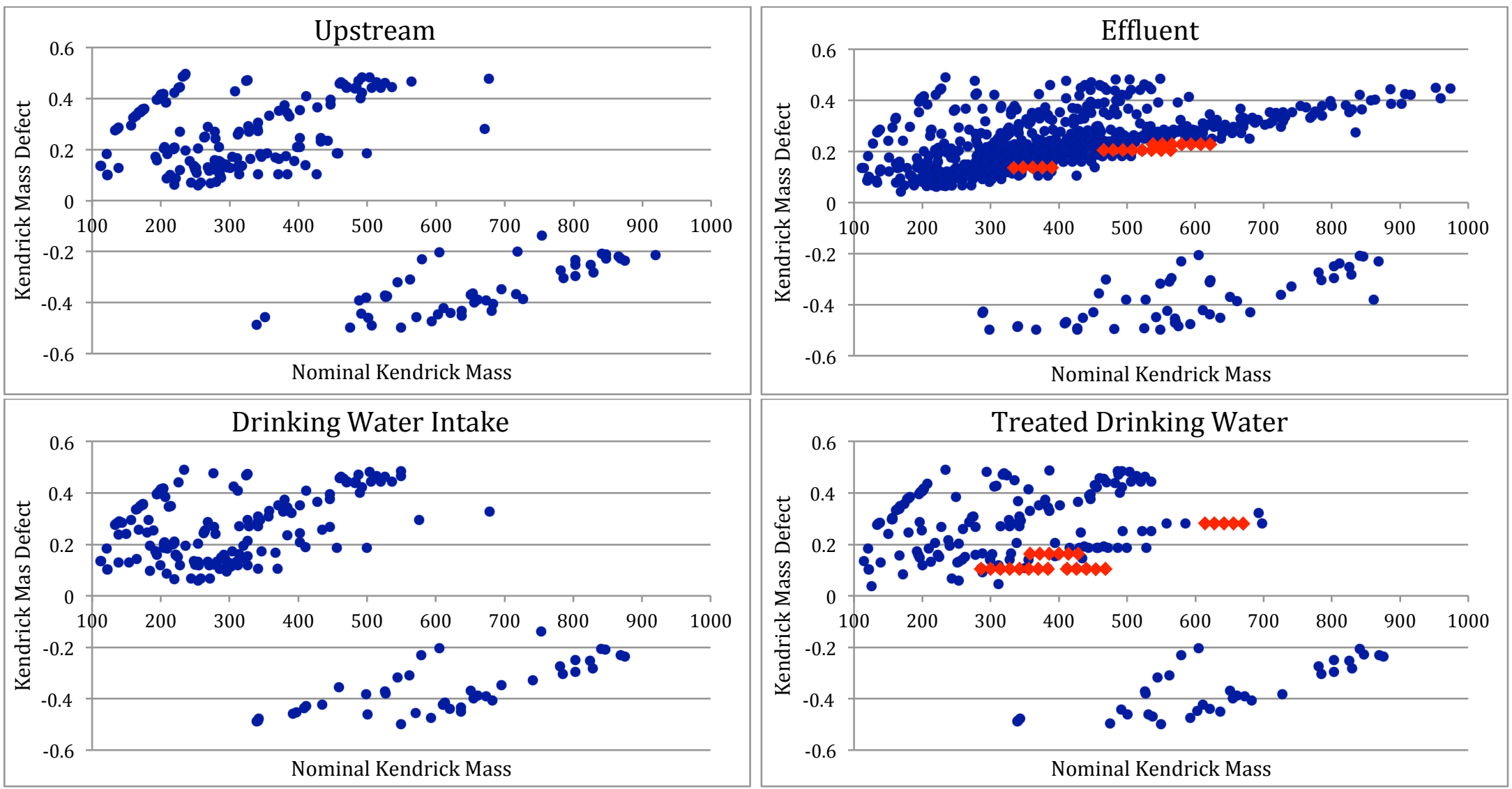

Figure 4.6 Kendrick mass defect plots of the negative mode data for the four sampling sites. Homologous series (examples depicted by red diamonds) are highlighted and are clearly present in both the effluent and the treated drinking water samples. 


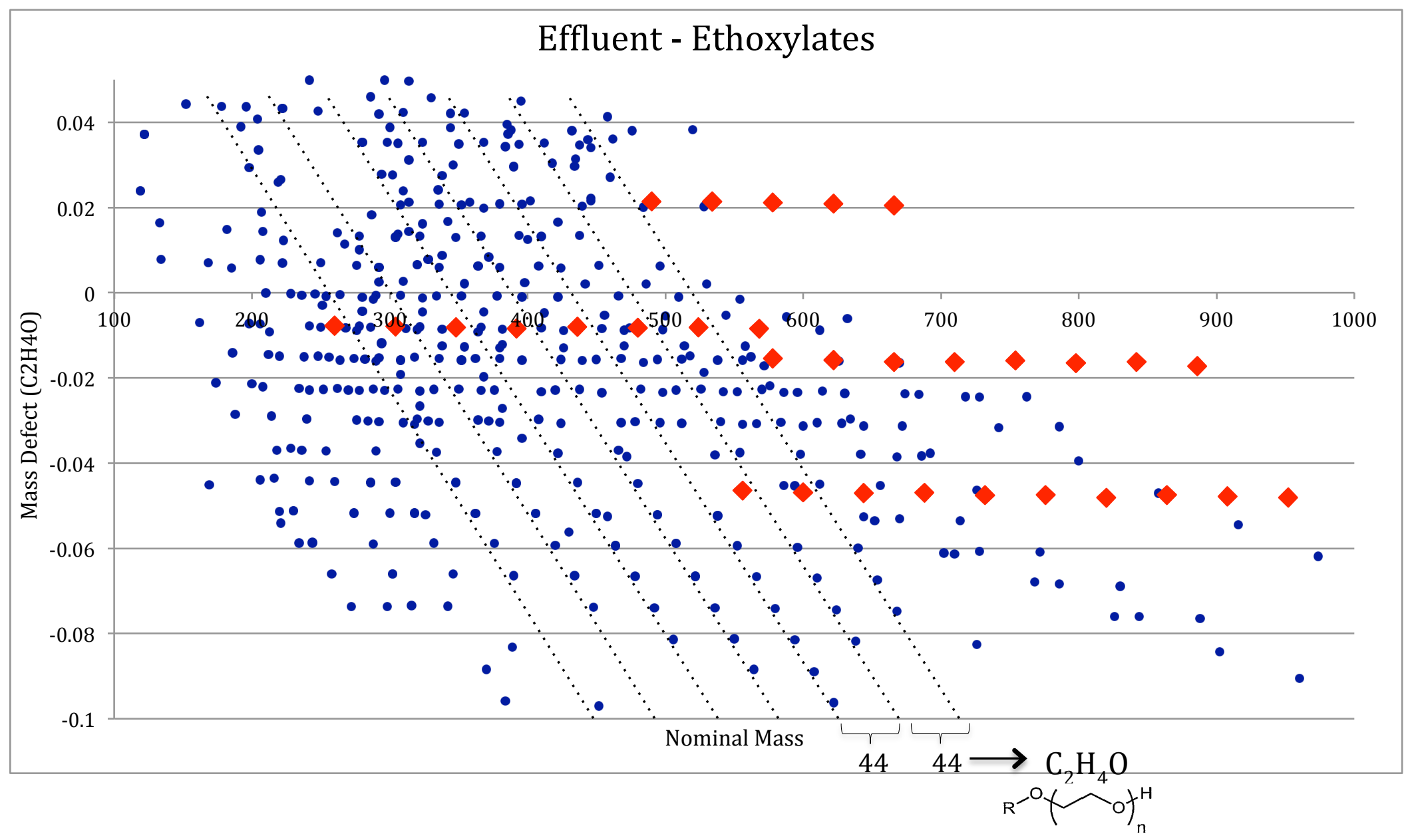

Figure 4.7 Mass defect plot defined by the ethoxylate repeat $\left(\mathrm{C}_{2} \mathrm{H}_{4} \mathrm{O}\right)$, clearly illustrating the numerous polyethoxylated series that dominate the negative mode data of the effluent sampling site (red diamonds are examples of specific series, while the "grid" depicts numerous other homologous series differing by 44 mass units and thus an ethoxylate unit). 


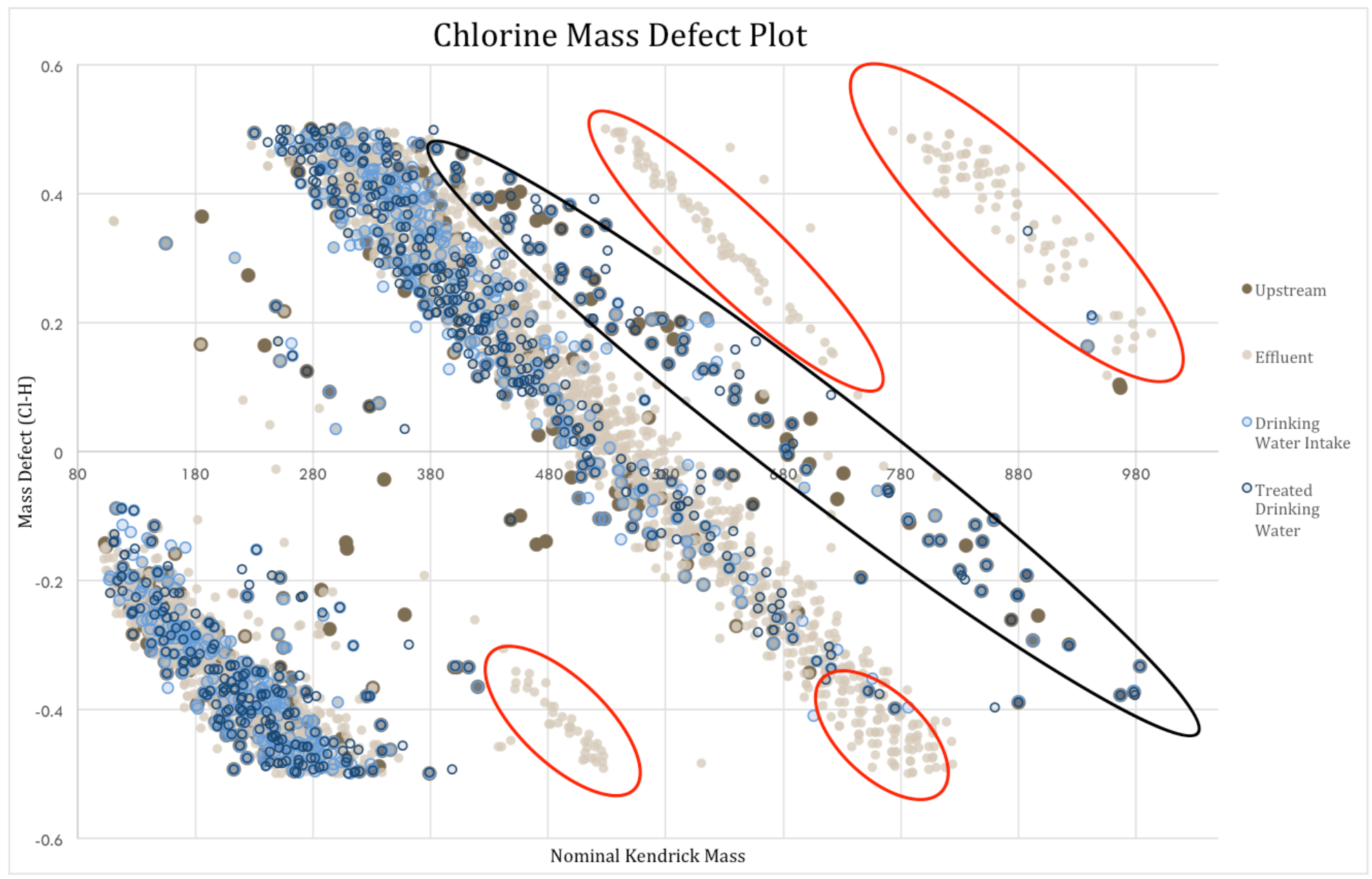

Figure 4.8 Mass defect plot defined by the substitution of a hydrogen with a chlorine $(\mathrm{H} / \mathrm{Cl})$, showing the distribution of components within the four sampling sites. Areas unique to the effluent sampling site are highlighted by red ovals, while the area marked by the black oval represents components mainly present in the other (surface) water samples. 


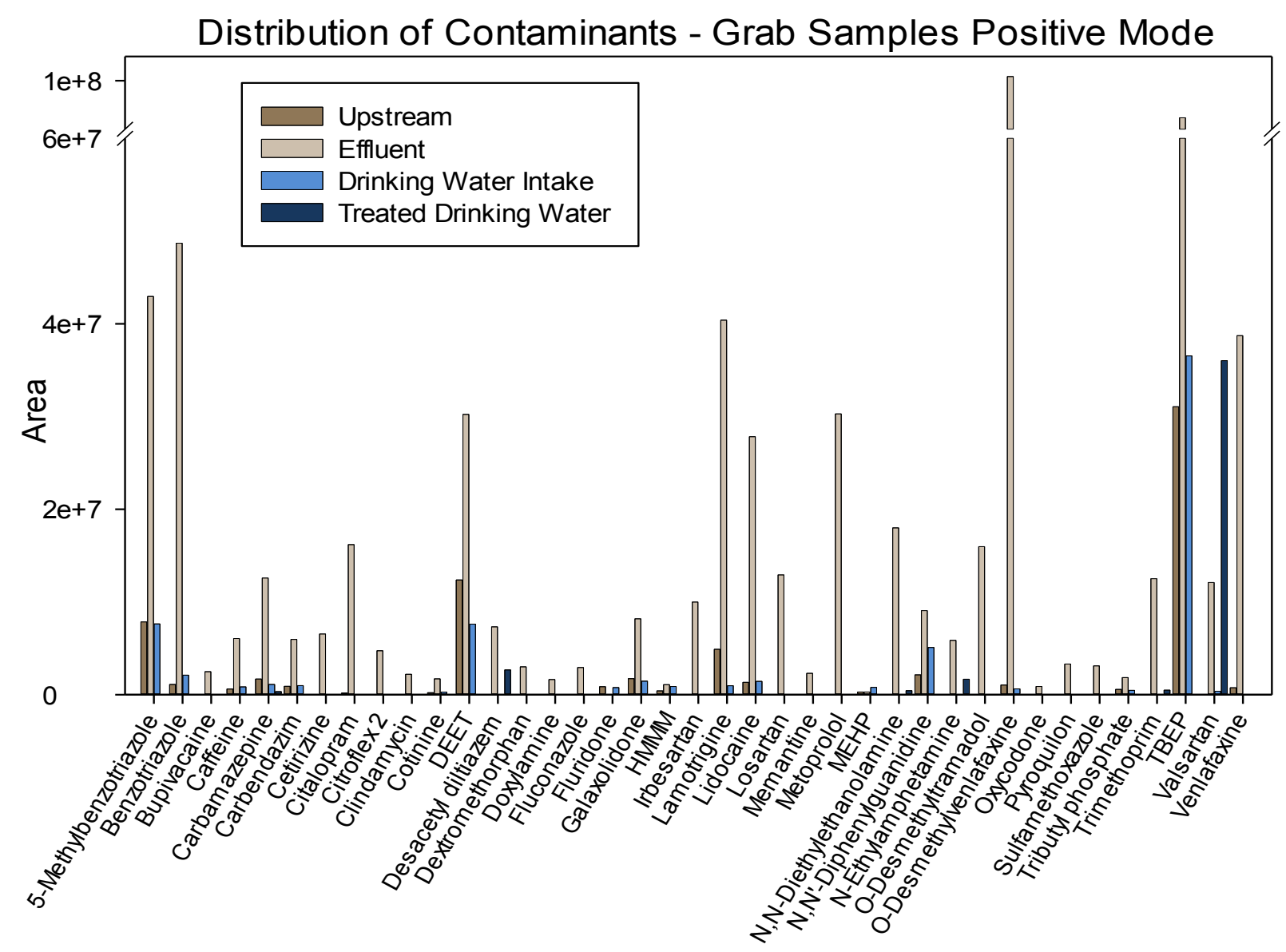

Figure 4.9 Graph illustrating the major compounds tentatively identified by the non-target screening workflow in the grab samples, and their distribution within the four sampling sites. 


\subsubsection{Comparison of passive and grab sampling: suspected and non-targeted analysis}

One of the major drawbacks of grab sampling is the fact that it only provides "snapshots" of the actual situation in the water system. One way to overcome this issue is to use passive samplers, which are deployed into a water stream and left in place accumulating compounds over a long period of time, providing the opportunity to compare time weighted average (TWA) concentrations, rather than data related to a specific point in time. In the current study, POCIS samples were analyzed under the same analytical conditions as the grab samples, and processed with the same suspect and nontarget screening workflows in order to evaluate the advantages and disadvantages of this sampling method. Results of the three sampling sites common to both techniques (upstream, drinking water intake, and treated drinking water) were compared. Overall, the number of components detected in the POCIS samples exceeded the ones in the grab samples by a factor of about two. In positive mode 2451 and 1232 components were detected in the POCIS and the grab samples, respectively. In negative mode, on the other hand, 686 components were detected in the passive samplers, while only 372 components were detected in the original grab samples. This result is clearly illustrated in the Kendrick mass defect plot in Figure 4.10, which compares the results from the grab and the POCIS sampling technique in the drinking water intake sampling site. The higher number of components detected in the passive samples is confirmed by the results obtained through the suspect screening workflow (a summary of which is provided in Table 4.2). When comparing the total number of "hits" on the suspect list within the three common sampling sites (upstream, drinking water intake, and treated drinking water), the 
number of matches in the POCIS samples is about twice the ones found in the grab samples (580 to 243 in positive, and 124 to 72 in negative ionization mode, respectively). In positive ionization mode the number of tentatively identified suspect compounds is also significantly higher in the POCIS samples (32) with respect to the grab samples (17), while in negative mode no compounds were found in the grab samples, while one compound was tentatively identified in the POCIS samples. When comparing the tentatively identified compounds in positive mode, 9 compounds were commonly found in the two sampling techniques (i.e., carbamazepine, carbendazim, fluridone, hexamethoxymethyl melamine, lamotrigine, lidocaine, N,N'-diphenylguanidine, venlafaxine, and o-desmethylvenlafaxine), while 16 were exclusive to the POCIS (e.g., desacetyl diltiazem, diphenhydramine, metoprolol, tramadol, and tran-3hydroxycotinine), and 8 were exclusive to the grab samples (e.g., caffeine, citalopram, cotinine, and oleamide) (the detailed results are shown in Figure 4.11).

Processing through the non-target workflow was also performed, and yielded similar results; in addition to tentatively identifying all the compounds found through the "suspect" workflow, 8 compounds were additionally identified in positive mode and 5 in negative mode (e.g., 10,11-dihydro-10,11-dihydroxycarbamazepine, benzotriazole, and perfluoro-1-hexanesulfonic acid). Generally, the benefits of passive sampling were clearly evident, as a larger amount of compounds appears to be detected, which can most likely be attributed to the benefits of considering time weighted average concentrations. However, the selective nature of the passive samplers needs to be considered since it might lead to the loss of specific types of compounds that are not retained by the POCIS. For example, while the acidification and basification of the samples in the liquid-liquid 
extraction help in neutralizing compounds that are charged at usual river $\mathrm{pH}$, these charged compounds could cause issues in the POCIS (Bäuerlein et al., 2012). Moreover, the intrinsic properties of the sorbent used for this specific POCIS set up (Oasis HLB), limits the type of compounds sampled to slightly polar and polar ones having a $\operatorname{logKow} \leq$ 4 (Alvarez et al., 2004; Alvarez et al., 2007). It is thus evident, that although passive sampling seems to provide clear advantages with respect to active sampling, nonetheless, the two methods represent complimentary techniques.

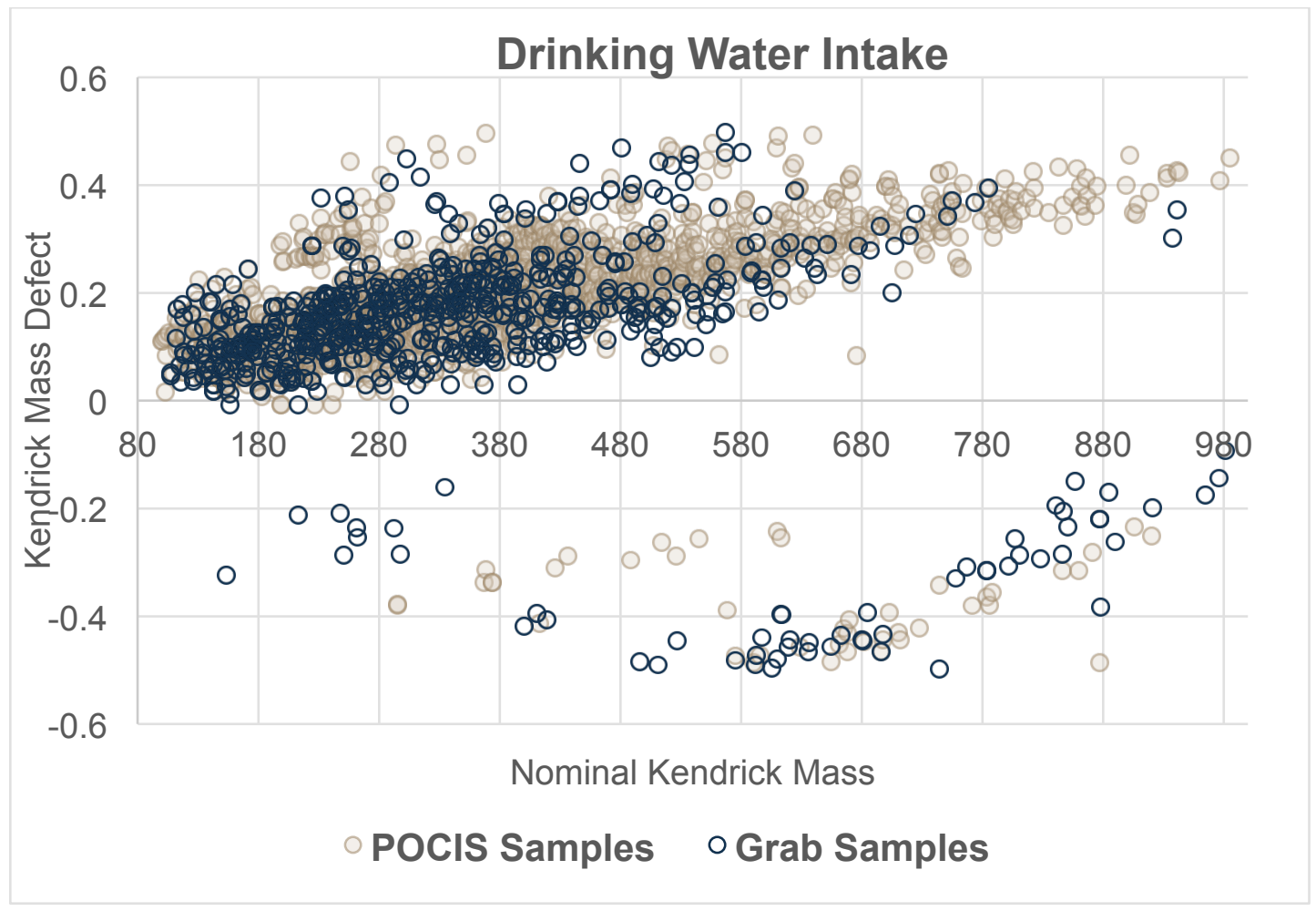

Figure 4.10 Comparison of number and distribution of components in the drinking water intake sampling site for the grab versus passive sampling methods. 
Table 4.2 Comparison of suspect screening results for the grab and POCIS sampling methods.

\begin{tabular}{cccc}
\hline $\begin{array}{c}\text { Sampling } \\
\text { and Analysis } \\
\text { Method }\end{array}$ & $\begin{array}{c}\text { Number of "hits" } \\
\text { in suspect list }\end{array}$ & $\begin{array}{c}\text { Number of } \\
\text { MS/MS "hits" }\end{array}$ & $\begin{array}{c}\text { Number of tentatively } \\
\text { identified compounds }\end{array}$ \\
\hline Grab (+) & 243 & 26 & 17 \\
POCIS (+) & 580 & 56 & 32 \\
Grab (-) & 72 & 8 & 0 \\
POCIS (-) & 124 & 3 & 1 \\
\hline
\end{tabular}

Grab
Samples
Only:
Carvone,
Citalopram,
MEHP,
Oleamide,
Valsartan,
Caffeine,
Cotinine,
PEG n6

\section{Common compounds:}

Carbamazepine, Carbendazim, Fluridone, HMMM, Lamotrigine, Lidocaine, N,N'-Diphenylguanidine, O-Desmethylvenlafaxine, Venlafaxine
POCIS Samples Only:

$5,6-$

Dimethylbenzimidazole Abscisic acid Adenosine Anabasine Cetirizine Desacetyl diltiazem Diphenhydramine Doxylamine Escitalopram Flecainide Meperidine Metoprolol N,N'Dicyclohexylurea Tramadol Trans-3Hydroxycotinine Triethyl phosphate

Figure 4.11 Comparison of number and distribution of components in the drinking water intake sampling site for the grab versus passive sampling methods. 


\subsubsection{Persistence, fate, and transformation of contaminants through the water stream and the treatment processes}

As a result of the greater number of contaminants detected in the POCIS samples, the passive sampling dataset was used in order to assess the persistence, fate, and transformation of contaminants. Firstly, a Venn diagram (Figure 4.12) was used to gain a general overview of the number of components present at each site affected by the effluent (i.e., effluent mixing zone, drinking water intake, and treated drinking water), and of the number of components common to two or more of the sites. The upstream sampling site was considered a "background" for this part of the study, and was subtracted (along with the regular blanks) to all the other sites. As expected, the treated drinking water presented the least overall number of components detected (637 compared to 1402 and 1847 for the effluent mixing zone and the drinking water intake, respectively). The area common between the effluent mixing zone and the drinking water intake, and the area common to all three sites were indicators of persistence. 825 components were found to be persistent throughout the river (EMZ to DWI) but efficiently removed in the drinking water treatment, while 242 were persistent throughout the whole process. The detailed nature of these persistent chemicals is shown in the insert in Figure 4.12, and includes compounds such as (4-nonylphenol, caffeine, DEET, perfluoro-1-hexanesulfonic acid, and tris(2-butoxytheyl)phosphate), some of which have been previously reported as compounds resisting treatment processes (Benotti et al., 2009; Stackelberg et al., 2004; Stackelberg et al., 2007). An additional area of interest shown in the Venn diagram are the 269 components exclusively present in the treated drinking water; these represent components that were not present in the original water 
system, nor were introduced through the wastewater effluent, and thus are compounds either introduced during the drinking water treatment process, or treatment by-products. The formation of by-products during water treatment and disinfection processes has been well reported, and is cause for concern since it can introduce potentially toxic compounds (Jeong et al., 2015).

\subsection{Conclusion}

This study successfully developed both suspect and non-target screening workflows using the Compound Discoverer 2.0 software, and applied these in order to assess the impact of a WWTP effluent on surface and drinking water samples. The presence and persistence of contaminants of emerging concern in surface water (e.g., carbamazepine, diphenhydramine, tramadol, and venlafaxine) and drinking water (e.g., 4nonylphenol, DEET, and triethyl phosphate) affected by an upstream wastewater effluent was shown. While these workflows provide a quick and fairly automated method of screening for a large amount of compounds with no need of pre-selection, drawbacks such as the limited amount of compounds currently present in MS/MS databases were also evidenced. This work, moreover, demonstrated the benefits of passive sampling with respect to grab sampling, as the analysis of POCIS samples detected over double the amount of components and tentatively identified compounds. Passive sampling, however, cannot completely replace active sampling as these two techniques are still considered complimentary, due to some intrinsic limitations of the POCIS (e.g., selective uptake of specific types of analytes and difficult quantitation of analytes). 
Mass defect plots (Kendrick, $\mathrm{C}_{2} \mathrm{H}_{4} \mathrm{O}, \mathrm{H} / \mathrm{Cl}$, and $\mathrm{H} / \mathrm{Br}$ ) were used in order to highlight regions of components of interest, as well as to evidence different types of homologous series $\left(\mathrm{CH}_{2}\right.$ and $\left.\mathrm{C}_{2} \mathrm{H}_{4} \mathrm{O}\right)$. Results identified several regions exclusively present in the treated wastewater effluent (including a region at negative Kendrick mass defect which suggests a presence of halogenated species, which are possible treatment byproducts), as well as the presence of surfactants in the effluent and the treated drinking water, and specifically the dominance of polyethoxylated species in the wastewater effluent. Limitations of the available MS/MS database prevented an identification of specific components in these areas with the here used workflows, and the need for a manual search using different prediction tools becomes clear in order to elucidate the nature of this large amount of components of interest.

Overall, this work clearly showed the potential of suspect and non-target techniques to provide a comprehensive preliminary screening of contaminants, but also revealed the limitations of current spectral databases, which cause the need for more extensive and manual data processing steps in order to elucidate the nature of compounds not (yet) present in open source databases.

\subsection{Acknowledgements}

The authors would like to acknowledge the support from the Florida International University (FIU) Graduate School through a Dissertation Evidence Acquisition Fellowship to AKH, Dr. Susan Glassmeyer and Dr. Marc Mills (EPA), and Dr. Dave Alvarez (USGS) for providing all of the samples for this work, and Thermo Scientific for providing partial analytical and software support. 


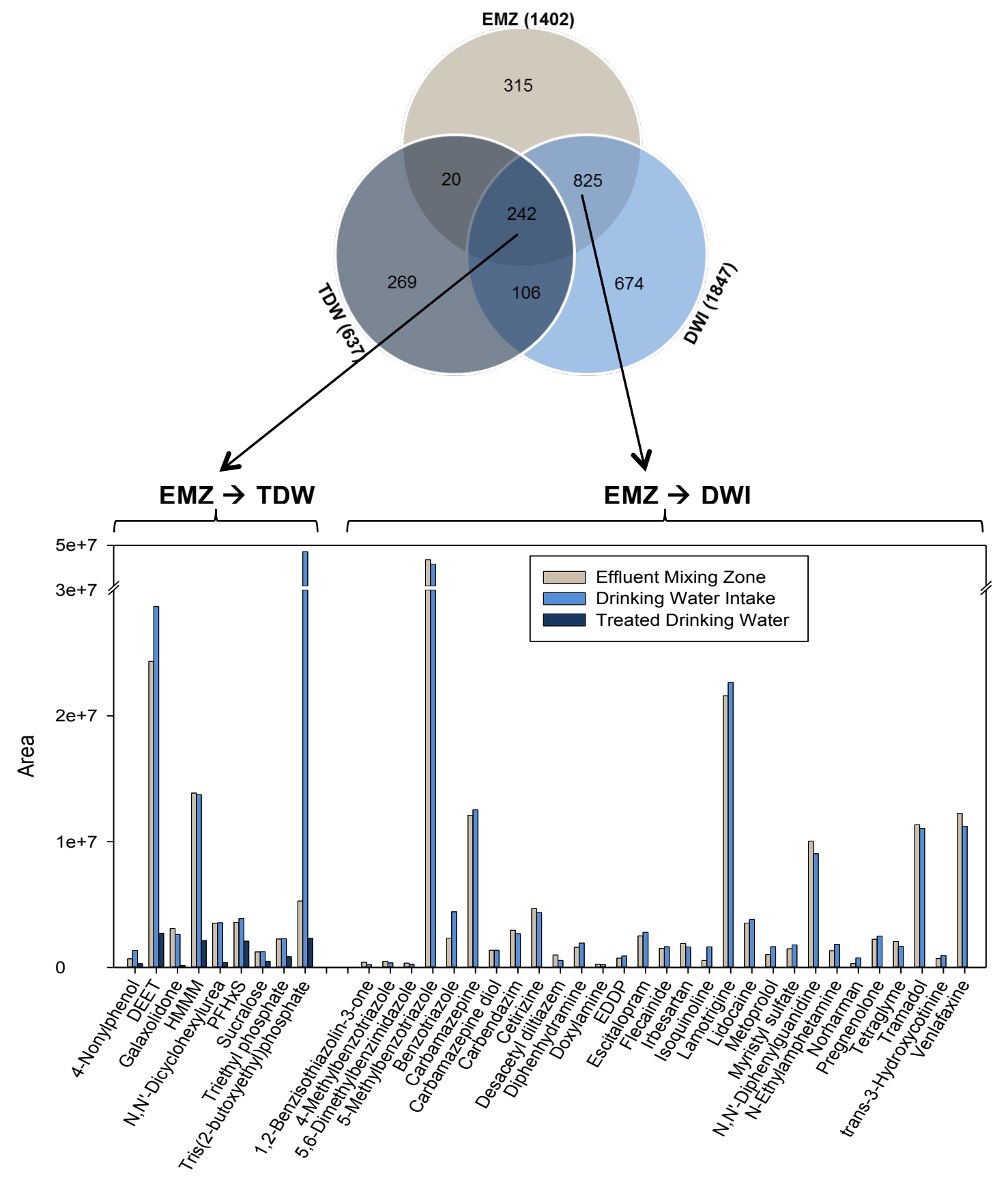

Figure 4.12 Evaluation of recalcitrance of the tentatively identified compounds: compounds persistent through the river stream $(E M Z \rightarrow D W I)$, and all the way through the drinking water $(\mathrm{EMZ} \rightarrow \mathrm{TDW})$ are shown. 


\subsection{References}

Alvarez DA, Petty JD, Huckins JN, Jones-Lepp TL, Getting DT, Goddard JP, et al. Development of a passive, in situ, integrative sampler for hydrophilic organic contaminants in aquatic environments. Environmental Toxicology and Chemistry 2004; 23: $1640-1648$.

Alvarez DA, Huckins JN, Petty JD, Jones-Lepp T, Stuer-Lauridsen F, Getting DT, Goddard JP, Gravell A. Tool for monitoring hydrophilic contaminants in water: polar organic chemical integrative sampler (POCIS). Comprehensive Analytical Chemistry 2007; 48: 171-197.

Batt AL, Kincaid TM, Kostich MS, Lazorchak JM, Olsen AR. Evaluating the extent of pharmaceuticals in surface waters of the United States using a National-scale Rivers and Streams Assessment survey. Environmental Toxicology and Chemistry 2016; 35: 874881.

Bäuerlein PS, Mansell JE, ter Laak TL, de Voogt P. Sorption Behavior of Charged and Neutral Polar Organic Compounds on Solid Phase Extraction Materials: Which Functional Group Governs Sorption? Environmental Science and Technology 2012; 46: 954-961.

Benotti MJ, Trenholm RA, Vanderford BJ, Holady JC, Stanford BD, Snyder SA. Pharmaceuticals and Endocrine Disrupting Compounds in U.S. Drinking Water. Environmental Science \& Technology 2009; 43: 597-603.

Bijlsma L, Sancho JV, Hernández F, Niessen WMA. Fragmentation pathways of drugs of abuse and their metabolites based on QTOF MS/MS and MSE accurate-mass spectra. Journal of Mass Spectrometry 2011; 46: 865-875.

Bixio D, Thoeye C, De Koning J, Joksimovic D, Savic D, Wintgens T, et al. Integrated Concepts in Water RecyclingWastewater reuse in Europe. Desalination 2006; 187: 89101.

Bletsou AA, Jeon J, Hollender J, Archontaki E, Thomaidis NS. Targeted and nontargeted liquid chromatography-mass spectrometric workflows for identification of transformation products of emerging pollutants in the aquatic environment. TrAC Trends in Analytical Chemistry 2015; 66: 32-44.

Cantero M, Rubio S, Perez-Bendito D. Determination of non-ionic polyethoxylated surfactants in wastewater and river water by mixed hemimicelle extraction and liquid chromatography-ion trap mass spectrometry. Journal of Chromatography A 2005; 1067: 161-170. 
Ciofi L, Ancillotti C, Chiuminatto U, Fibbi D, Checchini L, Orlandini S, Del Bubba M. Liquid chromatographic-tandem mass spectrometric method for the simultaneous determination of alkylphenols polyethoxylates, alkylphenoxy carboxylates and alkylphenols in wastewater and surface-water. Journal of Chromatography A 2014; 1362: 75-88.

Cooney CM. Study detects trace levels of pharmaceuticals in U.S. drinking water. Environmental Science \& Technology 2009; 43: 551-551.

Diamond JM, Latimer HA, Munkittrick KR, Thornton KW, Bartell SM, Kidd KA. Prioritizing contaminants of emerging concern for ecological screening assessments. Environmental Toxicology and Chemistry 2011; 30: 2385-2394.

Fono LJ, Kolodziej EP, Sedlak DL. Attenuation of Wastewater-Derived Contaminants in an Effluent-Dominated River. Environmental Science \& Technology 2006; 40: 72577262.

Gago-Ferrero P, Schymanski EL, Bletsou AA, Aalizadeh R, Hollender J, Thomaidis NS. Extended Suspect and Non-Target Strategies to Characterize Emerging Polar Organic Contaminants in Raw Wastewater with LC-HRMS/MS. Environmental Science \& Technology 2015; 49: 12333-12341.

Gosetti F, Mazzucco E, Gennaro MC, Marengo E. Contaminants in water: non-target UHPLC/MS analysis. Environmental Chemistry Letters 2016; 14: 51-65.

Guo YC, Krasner SW. Occurrence of Primidone, Carbamazepine, Caffeine, and Precursors for N-Nitrosodimethylamine in Drinking Water Sources Impacted by Wastewater1. JAWRA Journal of the American Water Resources Association 2009; 45: 58-67.

Heuett N. Target and Non-target Techniques for the Quantitation of Drugs of Abuse, Identification of Transformation Products, and Characterization of Contaminants of Emergent Concern by High Resolution Mass Spectrometry. Chemistry and Biochemistry. $\mathrm{PhD}$. Florida International University, 2015.

Ikehata K, El-Din MG, Snyder SA. Ozonation and Advanced Oxidation Treatment of Emerging Organic Pollutants in Water and Wastewater. Ozone: Science and Engineering 2008; 30: 21-26.

Jobst KJ, Shen L, Reiner EJ, Helm PA, McCrindle R, Backus S. The use of mass defect plots for the identification of (novel) halogenated contaminants in the environment. Analytical and Bioanalytical Chemistry 2013; 405: 3289-3297.

Jurado A, Vàzquez-Suñé E, Carrera J, López de Alda M, Pujades E, Barceló D. Emerging organic contaminants in groundwater in Spain: A review of sources, recent occurrence and fate in a European context. Science of The Total Environment 2012; 440: 82-94. 
Krauss M, Singer H, Hollender J. LC-high resolution MS in environmental analysis: from target screening to the identification of unknowns. Analytical and Bioanalytical Chemistry 2010; 397: 943-951.

Kunacheva C, Tanaka S, Fujii S, Boontanon SK, Musirat C, Wongwattana T. Determination of perfluorinated compounds (PFCs) in solid and liquid phase river water samples in Chao Phraya River, Thailand. Water Science and Technology 2011; 64: 684.

Kümmerer K. The presence of pharmaceuticals in the environment due to human use present knowledge and future challenges. Journal of Environmental Management 2009; 90: 2354-2366.

Lapworth DJ, Baran N, Stuart ME, Ward RS. Emerging organic contaminants in groundwater: A review of sources, fate and occurrence. Environmental Pollution 2012; 163: 287-303.

Maruya KA, Dodder NG, Sengupta A, Smith DJ, Lyons JM, Heil AT, et al. Multimedia screening of contaminants of emerging concern (CECS) in coastal urban watersheds in southern California (USA). Environmental Toxicology and Chemistry 2016; 35: 19861994.

Neale PA, Antony A, Bartkow ME, Farré MJ, Heitz A, Kristiana I, et al. Bioanalytical Assessment of the Formation of Disinfection Byproducts in a Drinking Water Treatment Plant. Environmental Science \& Technology 2012; 46: 10317-10325.

Odendaal C, Seaman MT, Kemp G, Patterton HE, Patterton H-G. An LC-MS/MS based survey of contaminants of emerging concern in drinking water in South Africa. South African Journal of Science 2015; 111: 01-06.

Ong CN. Water reuse, emerging contaminants and public health: state-of-the-art analysis. International Journal of Water Resources Development 2016; 32: 514-525.

Padhye LP, Yao H, Kung'u FT, Huang C-H. Year-long evaluation on the occurrence and fate of pharmaceuticals, personal care products, and endocrine disrupting chemicals in an urban drinking water treatment plant. Water Research 2014; 51: 266-276.

Postigo C, Richardson SD. Transformation of pharmaceuticals during oxidation/disinfection processes in drinking water treatment. Journal of Hazardous Materials 2014; 279: 461-475.

Ruff M, Mueller MS, Loos M, Singer HP. Quantitative target and systematic non-target analysis of polar organic micro-pollutants along the river Rhine using high-resolution mass-spectrometry - Identification of unknown sources and compounds. Water Research 2015; 87: 145-154. 
Schymanski EL, Singer HP, Slobodnik J, Ipolyi IM, Oswald P, Krauss M, et al. Nontarget screening with high-resolution mass spectrometry: critical review using a collaborative trial on water analysis. Analytical and Bioanalytical Chemistry 2015; 407: 6237-6255.

Skutlarek D, Exner M, Färber H. Perfluorinated surfactants in Surface and Drinking Waters. Environmental Science and Pollution Research 2006; 13: 299-307.

Sleno L. The use of mass defect in modern mass spectrometry. Journal of Mass Spectrometry 2012; 47: 226-236.

Stackelberg PE, Furlong ET, Meyer MT, Zaugg SD, Henderson AK, Reissman DB. Persistence of pharmaceutical compounds and other organic wastewater contaminants in a conventional drinking-water-treatment plant. Science of The Total Environment 2004; 329: 99-113.

Sun Q, Lv M, Hu A, Yang X, Yu C-P. Seasonal variation in the occurrence and removal of pharmaceuticals and personal care products in a wastewater treatment plant in Xiamen, China. Journal of Hazardous Materials 2014; 277: 69-75.

Taguchi VY, Nieckarz RJ, Clement RE, Krolik S, Williams R. Dioxin analysis by gas chromatography-Fourier transform ion cyclotron resonance mass spectrometry (GCFTICRMS). Journal of the American Society for Mass Spectrometry 2010; 21: 19181921.

Vega-Morales T, Sosa-Ferrera Z, Santana-Rodriguez JJ. Determination of alkylphenol polyethoxylates, bisphenol-A, $17 \alpha$-ethynylestradiol and $17 \beta$-estradiol and its metabolites in sewage samples by SPE and LC/MS/MS. Journal of Hazardous Materials 2010; 183: 701-711.

Verlicchi P, Al Aukidy M, Zambello E. Occurrence of pharmaceutical compounds in urban wastewater: Removal, mass load and environmental risk after a secondary treatment-A review. Science of The Total Environment 2012; 429: 123-155.

Vrana B, Allan IJ, Greenwood R, Mills GA, Dominiak E, Svensson K, et al. Passive sampling techniques for monitoring pollutants in water. TrAC Trends in Analytical Chemistry 2005; 24: 845-868.

Wade Miller G. Integrated Concepts in Water RecyclingIntegrated concepts in water reuse: managing global water needs. Desalination 2006; 187: 65-75. 
CHAPTER 5

\section{Conclusion}


The detection of contaminants in environmental matrices has been a longtime field of analysis. Limitations in analytical techniques, however, dictated the amount, concentration, and type of contaminants that could be detected. With recent advances in analytical chemistry (especially the mass spectrometry field), the trace detection of contaminants has become part of routine quality monitoring programs. Moreover, the development of high-resolution mass spectrometry has allowed for non-targeted screening, i.e., full scan analysis that requires no previous knowledge or selection of compounds. Overall, these advancements have allowed for a more comprehensive screening of known trace contaminants, as well as contaminants that are unknown and thus not (yet) regulated. This dissertation successfully used high-resolution mass spectrometry in combination with matrix specific software, in order to look at characterized and uncharacterized compounds in crude oil and wastewater impacted water samples.

More specifically, the first part of this study focused on the characterization of a crude oil weathering series, collected during the Deepwater Horizon oil spill. A preliminary characterization with "traditional" techniques such as GC-MS and GC-FID was performed in order to evaluate the weathering trends and analyze for well known, targeted crude oil components, such as PAHs and aliphatics. This was followed by a more complex, ultrahigh-resolution mass spectrometric analysis of the oils, in order to comprehensively characterize them and evaluate any unknown weathering products. The traditional analysis was able to confirm the authenticity of the weathering series, which was comprised of an unweathered oil (Massachusetts), two surface slick oils with different weathering degrees (CTC and Juniper), and a beached oil sample (Elmer's 
Island mat). In addition to processes such as evaporation of the volatile compounds, biodegradation and photodegradation were also shown to significantly contribute to the weathering of the oil. The high-resolution mass spectrometric analysis was combined with several visualization plots (Kendrick Mass Defect, Van Krevelen, and Double Bond Equivalents) in order to demonstrate the overall changes occurring in the oil composition. A clear increase in oxygenated species (with a concurrent decrease in pure hydrocarbons) was found with weathering, and further suggested a likely formation of ketonic, quinonic, and acidic species (all of which have been linked to potential toxicity).

While the previously mentioned analysis was successful in furthering our knowledge on the compositional changes that occurred with the weathering of the Macondo oil released during the $D W H$ spill, it also highlighted one of the principal current issues with non-targeted crude oil characterization studies. While no pre-selection of compounds would suggest a truly comprehensive analysis, intrinsic limitations of the ionization sources most commonly employed in such studies (e.g., ESI, APCI, and APPI), severely bias the final results and impede a proper comprehensive analysis. In order to investigate the limitations of each of the three most commonly used atmospheric pressure ionization sources, an ionization study was performed by analyzing a wide range of petroleum model compounds. As expected, ionization efficiencies were greatly dependent on the ionization source used, and the structural features (e.g., size, heteroatom content, methylation level) of the compounds. Such results are critical information needed when analyzing crude oil characterization results (e.g., relative abundance plots of different compound classes), which are highly affected by the ionization efficiencies of 
specific compounds. Ignoring these limitations would severely bias the final results, and false conclusions would likely be drawn.

Lastly, this study applied non-target and suspect screening workflows to a different type of complex environmental matrix (i.e., treated wastewater), in order to evaluate the levels of aquatic pollution in interrelated surface and drinking water samples impacted by a wastewater effluent. Two different types of sampling techniques (grab and POCIS) were compared, and although passive sampling detected about twice the number of compounds, the two techniques were nonetheless shown to be complimentary. Overall, numerous compounds were tentatively identified, some of which proving to be persistent along the whole water system (e.g., 4-nonylphenol and DEET). The simpler nature of the wastewater matrix, and the routine coupling to HPLC separation and MS/MS fragmentation, allowed for a much more robust and reliable search for "unknowns" with respect to crude oil. However, even for wastewater, a truly comprehensive screening was shown to be restricted by the limited number of compounds available in open-source spectral libraries. Thus, an investigation into more "exotic" regions and types of compounds still requires a manual evaluation of the data, by using alternative identification tools such as the mass defect plots employed in this work. These graphs enabled the identification of several clusters of components that were seen exclusively in the wastewater treatment plant effluent, as well as the identification and visualization of several surfactant homologous series (especially polyethoxylates).

Overall, this dissertation performed state-of-the-art target, suspect, and non-target analysis in two complex mixtures, namely petroleum and wastewater, and highlighted the current benefits and drawbacks associated with this novel type of contaminant screening. 
While crude oil, being one of the most complex mixtures in existence, exhibits several areas of limitations (e.g., suppression effects, lack of chromatographic and fragmentation data), the somewhat simpler nature of wastewater-impacted samples allows for a more confident identification of emerging contaminants and "unknowns". Nonetheless, the promising nature and great potential of this growing field of non-targeted analysis was clearly shown for both types of matrices, as it allows to significantly expand the range of compounds investigated to include emerging and uncharacterized portions of the contaminant pool. Addressing some of the current restrictions (e.g., the intrinsic limitations of analytical methods and the relatively small amount of compounds available in open-source databases), harmonizing and evaluating current methods by conducting inter-laboratory studies, and further developing and using standardized "confidence scales" to report identifications, will further advance this exciting field of mass spectrometry and establish it at the forefront of environmental-analytical chemistry. 
APPENDICES 
Appendix 1. UHRMS spectra obtained in the (a) ESI $(+)$ and (b) APPI (+) sources of the Massachusetts, CTC, Juniper, and Elmer's Island mat samples. Characteristic variations and patterns with weathering are highlighted.

(a)
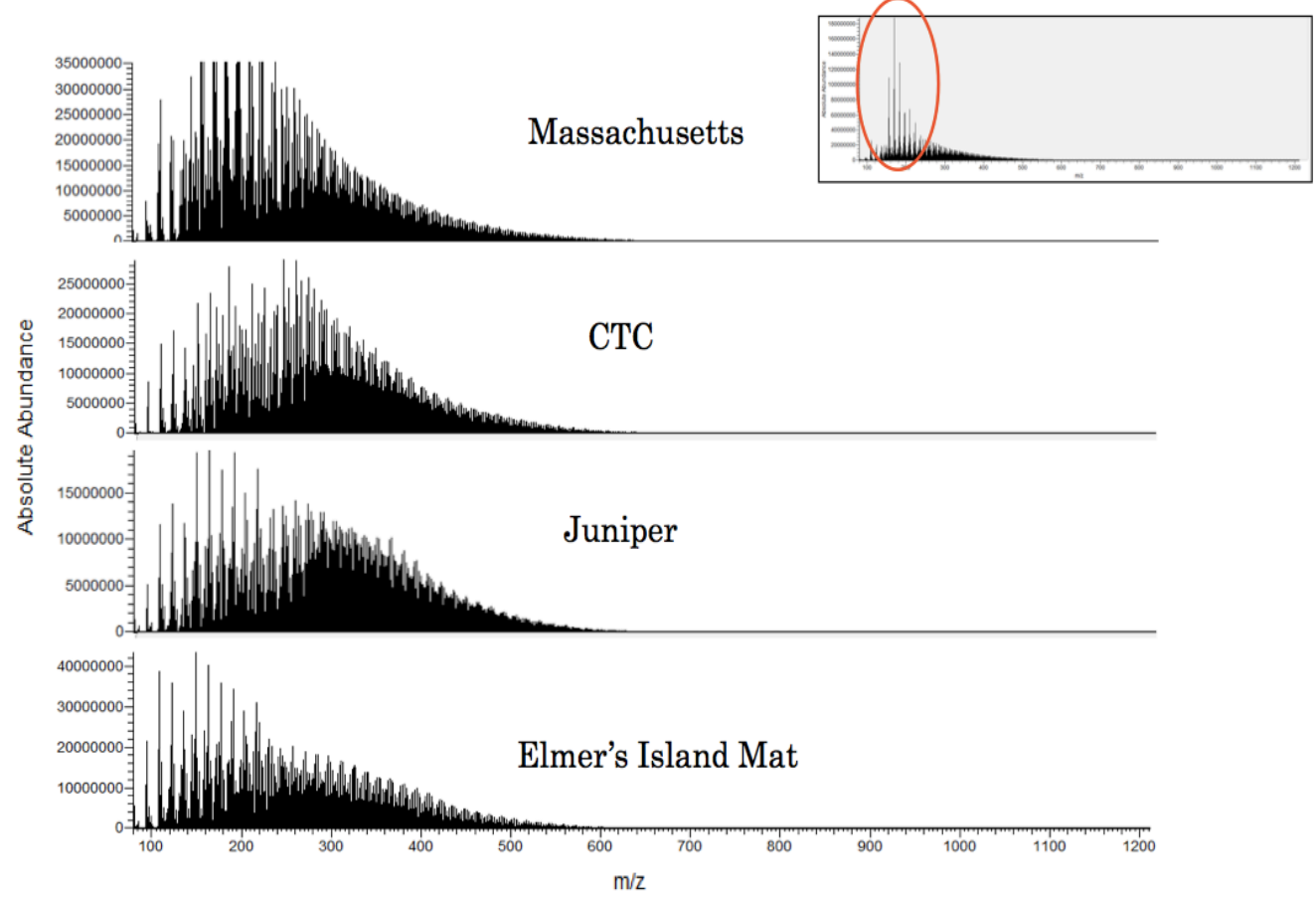

(b)

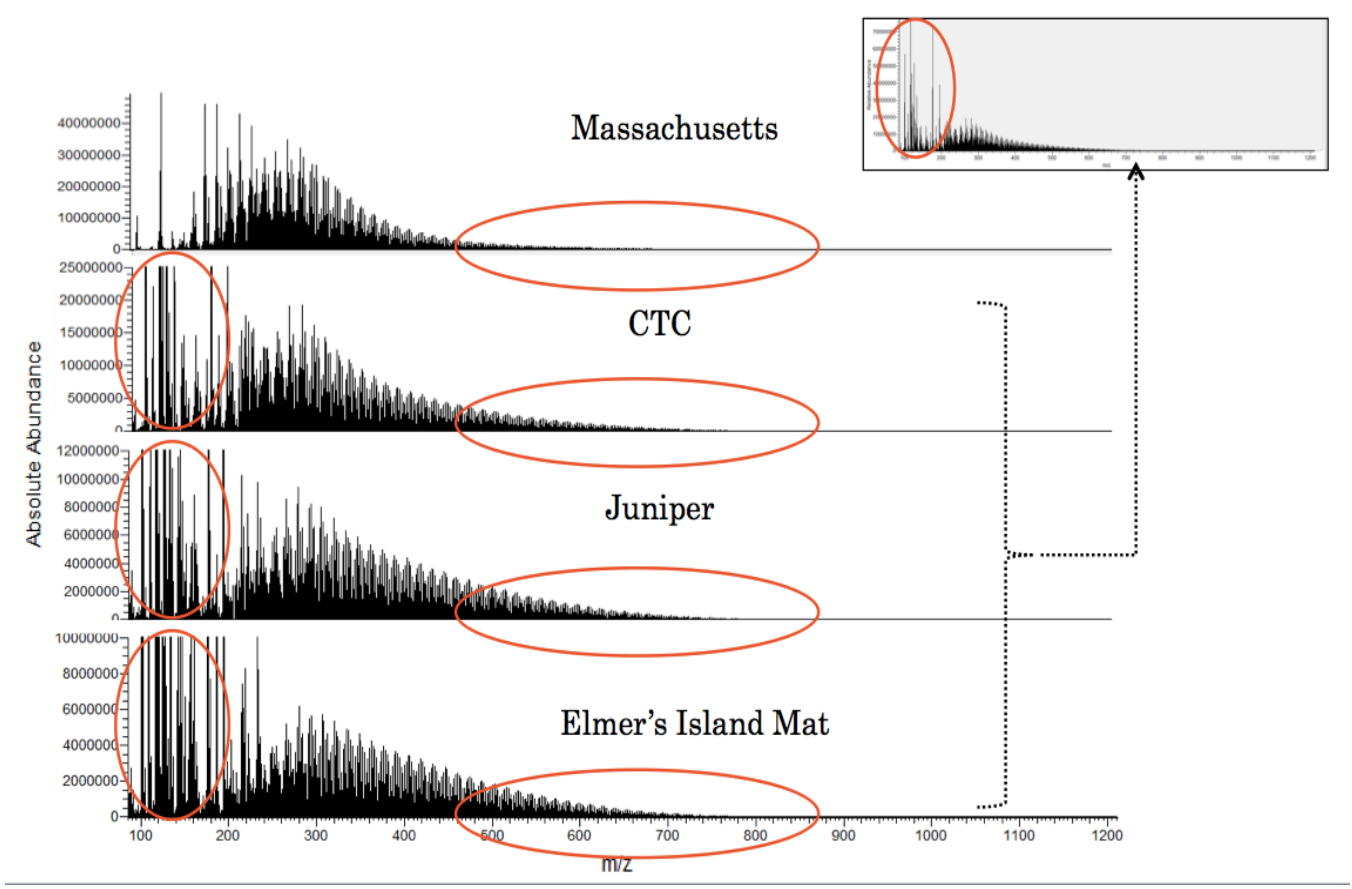


Appendix 2. DBE vs. Carbon number plots for the $\mathrm{O}(\mathrm{H})$ class of the four oils in the weathering series. A comparison of the $\operatorname{ESI}(+)$ and $\mathrm{APPI}(+)$ data shows a similar overall trend, but differences in the amount and size of the areas of concentration.
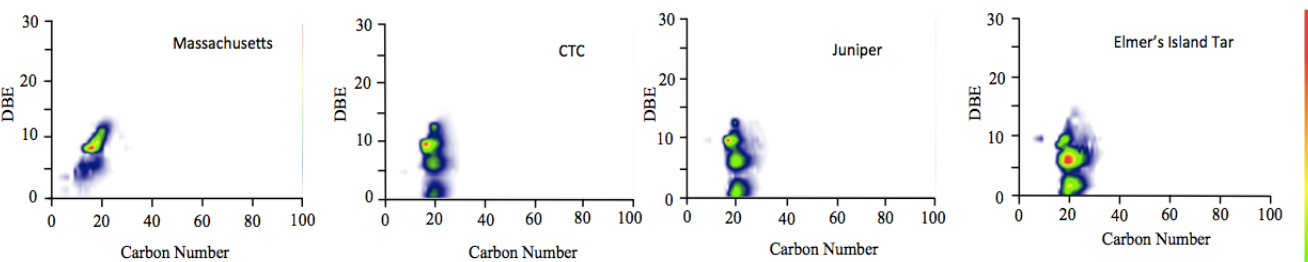

ESI (+)
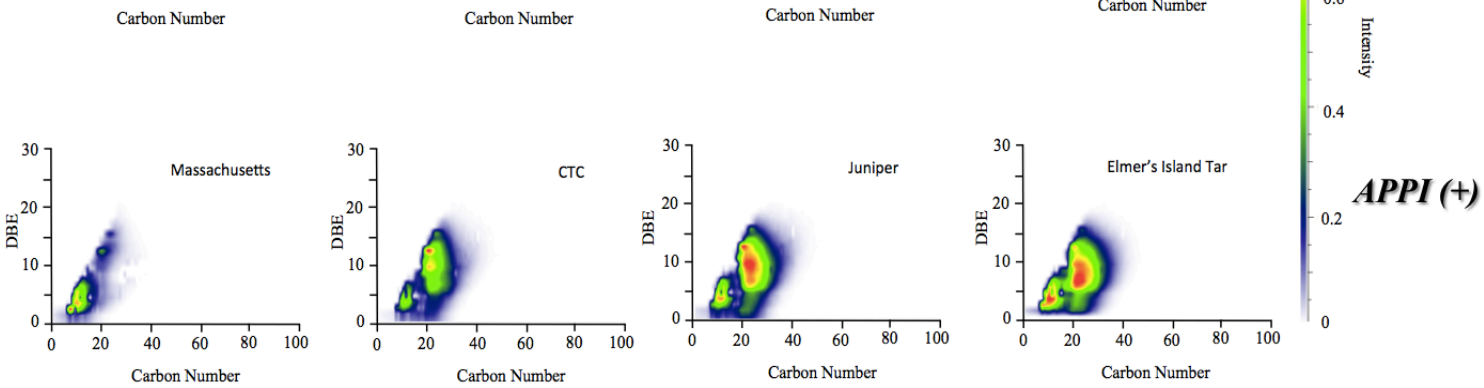

Appendix 3. (-) ESI DBE vs. Carbon number plots for the oxygen classes of the four oils in the weathering series. Results show similar trends to the positive mode data, with a increase in carbon number and unsaturation with weathering
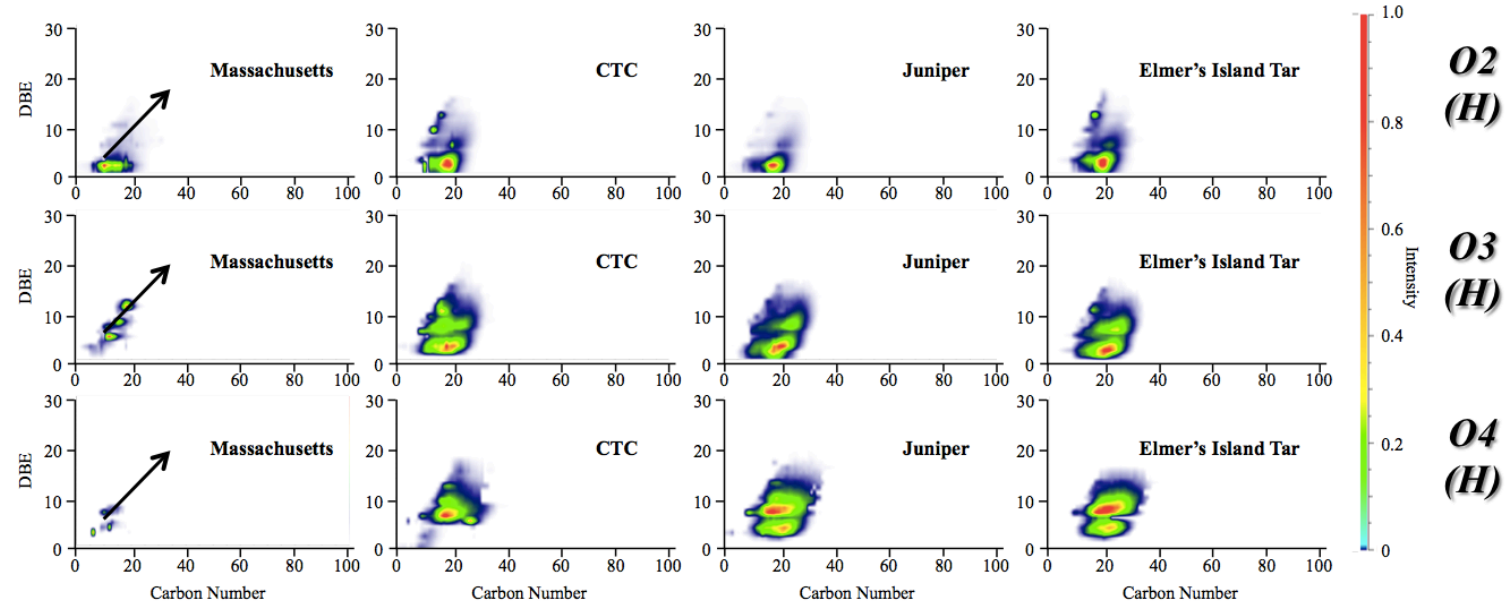

Weathering 
Appendix 4. Detailed composition of the standard mixtures and individual standards used in the atmospheric pressure ionization study

\begin{tabular}{|c|c|c|c|c|c|}
\hline \multicolumn{6}{|c|}{ Mixture \#1 - PAHs } \\
\hline Analyte & $\begin{array}{c}\text { Concentration } \\
(\mathrm{mg} / \mathrm{L})\end{array}$ & $\begin{array}{c}\text { Mass } \\
(\mathrm{g} / \mathrm{mol})\end{array}$ & $\begin{array}{c}\text { Molecular } \\
\text { Formula }\end{array}$ & Purity & Manufacturer \\
\hline Naphthalene & 0.9980 & 128.0626 & $\mathrm{C} 10 \mathrm{H} 8$ & $99.8 \%$ & AccuStandard \\
\hline Benzothiophene & 0.9988 & 134.019 & $\mathrm{C} 8 \mathrm{H} 6 \mathrm{~S}$ & $99.0 \%$ & AccuStandard \\
\hline Cis-Decalin & 0.9984 & \multirow{2}{*}{138.1409} & \multirow{2}{*}{$\mathrm{C} 10 \mathrm{H} 18$} & $99.2 \%$ & AccuStandard \\
\hline Trans-Decalin & 1.008 & & & N/A & $\begin{array}{l}\text { Absolute } \\
\text { Standards }\end{array}$ \\
\hline 1-Methylnaphthalene & 0.9992 & \multirow{2}{*}{142.0782} & \multirow{2}{*}{$\mathrm{C} 11 \mathrm{H} 10$} & $99.6 \%$ & AccuStandard \\
\hline 2-Methylnaphthalene & 0.9888 & & & $98.8 \%$ & AccuStandard \\
\hline 3-Methylbenzothiophene & 1.007 & 148.0347 & C9H8S & N/A & $\begin{array}{l}\text { Absolute } \\
\text { Standards }\end{array}$ \\
\hline Acenaphthylene & 1.000 & 152.0626 & $\mathrm{C} 12 \mathrm{H} 8$ & $100.0 \%$ & AccuStandard \\
\hline 1-Methyldecaline & 1.000 & 152.1565 & $\mathrm{C} 11 \mathrm{H} 20$ & N/A & Chiron \\
\hline Acenaphthene & 1.006 & \multirow{2}{*}{154.0782} & \multirow{2}{*}{$\mathrm{C} 12 \mathrm{H} 10$} & $100.0 \%$ & AccuStandard \\
\hline Biphenyl & 0.9916 & & & $99.0 \%$ & AccuStandard \\
\hline 2,6-Dimethylnaphthalene & 0.9990 & \multirow{2}{*}{156.0939} & \multirow{2}{*}{$\mathrm{C} 12 \mathrm{H} 12$} & $99.9 \%$ & AccuStandard \\
\hline 1,3-Dimethylnaphthalene & 1.003 & & & N/A & $\begin{array}{l}\text { Absolute } \\
\text { Standards } \\
\end{array}$ \\
\hline 2,5-Dimethylbenzothiophene & 1.000 & \multirow{2}{*}{162.0503} & \multirow{2}{*}{$\mathrm{C} 10 \mathrm{H} 10 \mathrm{~S}$} & N/A & Chiron \\
\hline 3,5-Dimethylbenzothiophene & 1.000 & & & $\mathrm{~N} / \mathrm{A}$ & Chiron \\
\hline Fluorene & 1.007 & 166.0782 & $\mathrm{C} 13 \mathrm{H} 10$ & $97.4 \%$ & AccuStandard \\
\hline Carbazole & 0.9884 & 167.0735 & $\mathrm{C} 12 \mathrm{H} 9 \mathrm{~N}$ & $98.6 \%$ & AccuStandard \\
\hline Dibenzofuran & 0.9940 & 168.0575 & $\mathrm{C} 12 \mathrm{H} 8 \mathrm{O}$ & $99.0 \%$ & AccuStandard \\
\hline 2,3,5-Trimethylnaphthalene & 1.000 & 170.1095 & $\mathrm{C} 13 \mathrm{H} 14$ & $94.0 \%$ & AccuStandard \\
\hline Anthracene & 1.009 & \multirow{2}{*}{178.0782} & \multirow{2}{*}{$\mathrm{C} 14 \mathrm{H} 10$} & $100.0 \%$ & AccuStandard \\
\hline Phenanthrene & 0.9908 & & & $99.0 \%$ & AccuStandard \\
\hline 1-Methylfluorene & 1.003 & 180.0939 & $\mathrm{C} 14 \mathrm{H} 12$ & N/A & $\begin{array}{l}\text { Absolute } \\
\text { Standards }\end{array}$ \\
\hline Dibenzothiophene & 0.9838 & 184.0347 & $\mathrm{C} 12 \mathrm{H} 8 \mathrm{~S}$ & $98.3 \%$ & AccuStandard \\
\hline
\end{tabular}




\begin{tabular}{|c|c|c|c|c|c|}
\hline DPNB & 1.027 & 190.1569 & $\mathrm{C} 10 \mathrm{H} 22 \mathrm{O} 3$ & $99.0 \%$ & Sigma \\
\hline 1-Methylphenanthrene & 0.9896 & \multirow{6}{*}{192.0939} & \multirow{6}{*}{$\mathrm{C} 15 \mathrm{H} 12$} & $98.8 \%$ & AccuStandard \\
\hline 2-Methylphenanthrene & 1.002 & & & $97.0 \%$ & AccuStandard \\
\hline 3-Methylphenanthrene & 1.002 & & & $99.3 \%$ & AccuStandard \\
\hline 2-Methylanthracene & 0.9986 & & & $99.7 \%$ & AccuStandard \\
\hline 4-Methylphenanthrene & 0.500 & & & N/A & Chiron \\
\hline 9-Methylphenanthrene & 0.500 & & & N/A & Chiron \\
\hline 4-Methyldibenzothiophene & 0.9850 & \multirow{3}{*}{198.0503} & \multirow{3}{*}{ C13H10S } & $98.1 \%$ & AccuStandard \\
\hline 2-Methyldibenzothiophene & 1.000 & & & $\mathrm{~N} / \mathrm{A}$ & Chiron \\
\hline 1-Methyldibenzothiophene & 0.000 & & & $99.5 \%$ & Chiron \\
\hline Fluoranthene & 1.005 & \multirow{2}{*}{202.0782} & \multirow{2}{*}{$\mathrm{C} 16 \mathrm{H} 10$} & $97.2 \%$ & AccuStandard \\
\hline Pyrene & 1.0028 & & & $99.1 \%$ & AccuStandard \\
\hline $\begin{array}{l}\text { 4,6- } \\
\text { Dimethyldibenzothiophene }\end{array}$ & 1.198 & 212.066 & $\mathrm{C} 14 \mathrm{H} 12 \mathrm{~S}$ & $95.0 \%$ & Acros Organics \\
\hline Benzo(b)fluorene & 0.9842 & 216.0939 & $\mathrm{C} 17 \mathrm{H} 12$ & $98.1 \%$ & AccuStandard \\
\hline Benz[a]anthracene & 1.002 & \multirow{2}{*}{228.0939} & \multirow{2}{*}{$\mathrm{C} 18 \mathrm{H} 12$} & $99.6 \%$ & AccuStandard \\
\hline Chrysene & 0.9962 & & & $98.9 \%$ & AccuStandard \\
\hline Benzo(a)dibenzothiophene & 1.003 & 234.0503 & C16H10S & $100.0 \%$ & AccuStandard \\
\hline Retene & 1.0078 & 234.1409 & C18H18 & $92.5 \%$ & AccuStandard \\
\hline 6-Methylchrysene & 1.002 & 242.1095 & С19H14 & $99 \%$ & $\begin{array}{l}\text { Absolute } \\
\text { Standards }\end{array}$ \\
\hline Benzo[a]pyrene & 0.9960 & \multirow{6}{*}{252.0939} & \multirow{6}{*}{$\mathrm{C} 20 \mathrm{H} 12$} & $99.2 \%$ & AccuStandard \\
\hline Benzo[b]fluoranthene & 1.006 & & & $99.9 \%$ & AccuStandard \\
\hline Benzo[k]fluoranthene & 1.003 & & & $100.0 \%$ & AccuStandard \\
\hline Perylene & 1.003 & & & $100.0 \%$ & AccuStandard \\
\hline Benzo[e]pyrene & 0.9948 & & & $99.4 \%$ & AccuStandard \\
\hline Benzo(a)fluoranthene & 1.002 & & & $99 \%$ & $\begin{array}{l}\text { Absolute } \\
\text { Standards }\end{array}$ \\
\hline Benzo[g,h,i] perylene & 0.9800 & \multirow{2}{*}{276.0939} & \multirow{2}{*}{$\mathrm{C} 22 \mathrm{H} 12$} & $98.0 \%$ & AccuStandard \\
\hline Indeno[1,2,3,-c,d]pyrene & 1.002 & & & $97.1 \%$ & AccuStandard \\
\hline Dibenzo[a,h]anthracene & 0.998 & 278.1096 & $\mathrm{C} 22 \mathrm{H} 14$ & $99.0 \%$ & AccuStandard \\
\hline
\end{tabular}




\begin{tabular}{|c|c|c|c|c|c|}
\hline Hopane & 1.0000 & 412.4069 & $\mathrm{C} 30 \mathrm{H} 52$ & $\mathrm{~N} / \mathrm{A}$ & IRMM \\
\hline \multicolumn{6}{|c|}{ Mixture \#2 - Heteroatoms } \\
\hline Dibenzofuran & 0.982 & 168.0575 & $\mathrm{C} 12 \mathrm{H} 8 \mathrm{O}$ & 98.7 & IRMM \\
\hline $\begin{array}{l}\text { Benzo(b)naphtho(2,3- } \\
\text { d)thiophene }\end{array}$ & 0.961 & 234.0503 & C16H10S & $99 \%$ & Aldrich \\
\hline Acridine & 0.935 & 179.0735 & C13H9N & $97 \%$ & Sigma-Aldrich \\
\hline 7H-Dibenzo(c,g)carbazole & 1.000 & 267.1048 & $\mathrm{C} 20 \mathrm{H} 13 \mathrm{~N}$ & $\mathrm{~N} / \mathrm{A}$ & $\begin{array}{c}\text { SPEX } \\
\text { CertiPrep }\end{array}$ \\
\hline $\operatorname{Dibenz}(\mathrm{a}, \mathrm{h})$ acridine & 1.000 & 279.1048 & $\mathrm{C} 21 \mathrm{H} 13 \mathrm{~N}$ & N/A & $\begin{array}{c}\text { SPEX } \\
\text { CertiPrep } \\
\end{array}$ \\
\hline Hexaphenylbenzene & 1.139 & 534.2347 & $\mathrm{C} 42 \mathrm{H} 30$ & $98 \%$ & Aldrich \\
\hline \multicolumn{6}{|c|}{ Mixture \#3 - PAH Functional Group Series } \\
\hline 1-Methylpyrene & 1.07 & 216.0939 & $\mathrm{C} 17 \mathrm{H} 12$ & $97 \%$ & Sigma \\
\hline 1-Pyrenemethanol & 1.155 & 232.0888 & $\mathrm{C} 17 \mathrm{H} 12 \mathrm{O}$ & $98 \%$ & Aldrich \\
\hline 1-Pyrenecarbaldehyde & 1.065 & 230.0732 & $\mathrm{C} 17 \mathrm{H} 10 \mathrm{O}$ & $98 \%$ & TCI America \\
\hline 1-Acetylpyrene & 1.09 & 244.0888 & $\mathrm{C} 18 \mathrm{H} 12 \mathrm{O}$ & $97 \%$ & Acros Organics \\
\hline 1-Pyrenecarboxylic acid & 1.09 & 246.0681 & $\mathrm{C} 17 \mathrm{H} 10 \mathrm{O} 2$ & $97 \%$ & Aldrich \\
\hline \multicolumn{6}{|c|}{ Mixture \#4 \& 5 - Alkane Functional Group Series } \\
\hline Octadecane & 1.152 & 254.2973 & $\mathrm{C} 18 \mathrm{H} 38$ & $99 \%$ & Acros Organics \\
\hline 1-Octadecanal & 1.125 & 268.2766 & $\mathrm{C} 18 \mathrm{H} 36 \mathrm{O}$ & $99 \%$ & Ultra Scientific \\
\hline 2-Nonadecanone & 1.222 & 282.2923 & $\mathrm{C} 19 \mathrm{H} 38 \mathrm{O}$ & $97 \%$ & Aldrich \\
\hline Stearic acid & 1.269 & 284.2715 & $\mathrm{C} 18 \mathrm{H} 36 \mathrm{O} 2$ & $98 \%$ & Alfa-Aesar \\
\hline Lignocerol & 2.000 & 354.3856 & $\mathrm{C} 12 \mathrm{H} 8 \mathrm{O} 4$ & $99 \%$ & Sigma \\
\hline Lignoceric Acid & 5.000 & 368.3649 & $\mathrm{C} 10 \mathrm{H} 8 \mathrm{O} 2$ & $99 \%$ & Acros Organics \\
\hline \multicolumn{6}{|c|}{ Mixture \#6 - Functional Group Mixture } \\
\hline Phenol & 1.020 & 94.04186 & C6H6O & $99 \%$ & Mallinckrodt \\
\hline 2-Ethylphenol & 1.027 & 122.0732 & $\mathrm{C} 8 \mathrm{H} 10 \mathrm{O}$ & $99 \%$ & Sigma \\
\hline 4-Isopropylphenol & 1.176 & 136.0888 & С9H12O & $98 \%$ & Aldrich \\
\hline 1-Phthalanone & 0.990 & 134.0368 & $\mathrm{C} 8 \mathrm{H} 6 \mathrm{O} 2$ & $99 \%$ & Acros Organics \\
\hline Phthalic acid & 0.999 & 166.0266 & $\mathrm{C} 8 \mathrm{H} 6 \mathrm{O} 4$ & $99 \%$ & Acros Organics \\
\hline Phthalic anhydride & 1.255 & 148.016 & $\mathrm{C} 8 \mathrm{H} 4 \mathrm{O} 3$ & $99 \%$ & Acros Organics \\
\hline
\end{tabular}




\begin{tabular}{|l|c|c|c|c|c|}
\hline Dibenzothiophene & 1.337 & 184.0347 & $\mathrm{C} 12 \mathrm{H} 8 \mathrm{~S}$ & $99 \%$ & Aldrich \\
\hline $\begin{array}{l}\text { 4,6- } \\
\text { Dimethyldibenzothiophene }\end{array}$ & 1.185 & 212.066 & $\mathrm{C} 14 \mathrm{H} 12 \mathrm{~S}$ & $95 \%$ & Acros Organics \\
\hline 2-Naphthaldehyde & 1.010 & 144.0575 & $\mathrm{C} 10 \mathrm{H} 8 \mathrm{O}$ & $98 \%$ & Acros Organics \\
\hline$\gamma$-Heptalactone & 5.00 & 128.0837 & $\mathrm{C} 7 \mathrm{H} 12 \mathrm{O} 2$ & $96 \%$ & Pfaltz \& Bauer \\
\hline$\gamma$-Octalactone & 5.00 & 142.0994 & $\mathrm{C} 8 \mathrm{H} 14 \mathrm{O} 2$ & $95 \%$ & Pfaltz \& Bauer \\
\hline \multicolumn{7}{|c|}{ Mixture \#7 - Polyoxygenated Compounds } \\
\hline \begin{tabular}{l|c|c|c|c|c|c|} 
2,6-Naphthalenedicarboxylic \\
acid
\end{tabular} & 0.93 & 216.0423 & $\mathrm{C} 12 \mathrm{H} 8 \mathrm{O} 4$ & $99 \%$ & Aldrich \\
\hline Anthraquinone & 1.154 & 208.0524 & $\mathrm{C} 14 \mathrm{H} 8 \mathrm{O} 2$ & $97 \%$ & Aldrich \\
\hline 1,5-Dihydroxynaphthalene & 1.11 & 160.0524 & $\mathrm{C} 10 \mathrm{H} 8 \mathrm{O} 2$ & $97 \%$ & Aldrich \\
\hline \multicolumn{7}{|c|}{ Individual Compounds for Matrix Suppression Effects } & \\
\hline Fluorene & 1.285 & 166.0782 & $\mathrm{C} 13 \mathrm{H} 10$ & $98 \%$ & Acros Organics \\
\hline Carbazole & 1.091 & 167.0735 & $\mathrm{C} 12 \mathrm{H} 9 \mathrm{~N}$ & $96 \%$ & Acros Organics \\
\hline Dibenzofuran & 0.982 & 168.0575 & $\mathrm{C} 12 \mathrm{H} 8 \mathrm{O}$ & $98.70 \%$ & IRMM \\
\hline Dibenzothiophene & 1.053 & 184.0347 & $\mathrm{C} 12 \mathrm{H} 8 \mathrm{~S}$ & $99 \%$ & Aldrich \\
\hline
\end{tabular}

Appendix 5. Example of the confirmation of the "tentatively identified" DEET by an mzCloud MS/MS spectral match (95.1\%). Bottom spectrum represents library reference spectrum, while the experimental spectrum is shown on top.

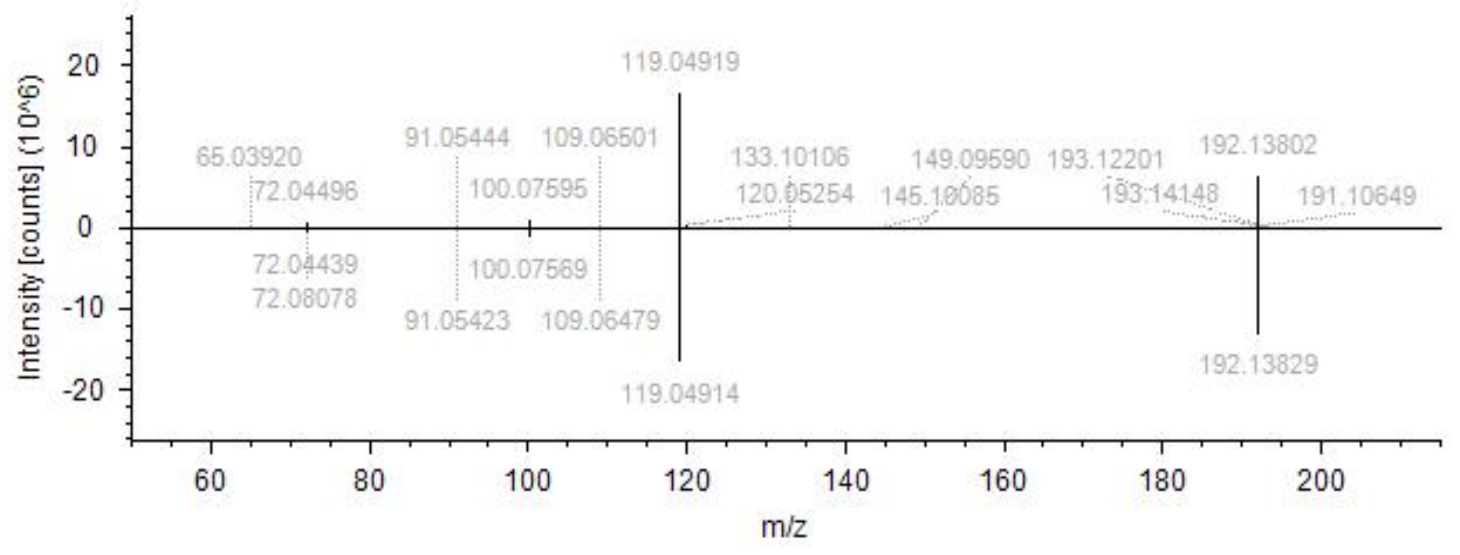


Appendix 6. List of compounds tentatively identified in the grab samples (bolded entries represent compounds only picked up by the non-targeted workflow since they were not included in the suspect list)

\begin{tabular}{|c|c|c|c|}
\hline Compound Name & $\begin{array}{c}\text { Molecular } \\
\text { Weight }\end{array}$ & $\begin{array}{l}\text { Molecular } \\
\text { Formula }\end{array}$ & $\begin{array}{c}\text { mzCloud } \\
\text { Score }(\%)\end{array}$ \\
\hline \multicolumn{4}{|c|}{ Positive Mode Ionization } \\
\hline 2-Amino-1,3,4-octadecanetriol & 317.2924 & $\mathrm{C} 18 \mathrm{H} 39 \mathrm{NO} 3$ & 72.3 \\
\hline 5-Methylbenzotriazole & 133.0639 & C7H7N3 & 93.7 \\
\hline Acridine & 179.0733 & C13H9N & 72.9 \\
\hline Benzotriazole & 119.0484 & C6H5N3 & 96.8 \\
\hline Berberine & 335.1152 & C20H18NO4 & 91.2 \\
\hline Bupivacaine & 288.2196 & $\mathrm{C} 18 \mathrm{H} 28 \mathrm{~N} 2 \mathrm{O}$ & 85.1 \\
\hline Caffeine & 194.0802 & $\mathrm{C} 8 \mathrm{H} 10 \mathrm{~N} 4 \mathrm{O} 2$ & 94.5 \\
\hline Carbamazepine & 236.0946 & $\mathrm{C} 15 \mathrm{H} 12 \mathrm{~N} 2 \mathrm{O}$ & 96.4 \\
\hline Carbendazim & 191.0693 & $\mathrm{C} 9 \mathrm{H} 9 \mathrm{~N} 3 \mathrm{O} 2$ & 83.0 \\
\hline Cetirizine & 388.1547 & $\mathrm{C} 21 \mathrm{H} 25 \mathrm{ClN} 2 \mathrm{O} 3$ & 87.8 \\
\hline Citalopram & 324.1632 & $\mathrm{C} 20 \mathrm{H} 21 \mathrm{FN} 2 \mathrm{O}$ & 89.9 \\
\hline Citroflex 2 & 276.1205 & $\mathrm{C} 20 \mathrm{H} 34 \mathrm{O} 8$ & 84.4 \\
\hline Clindamycin & 424.1791 & $\mathrm{C} 18 \mathrm{H} 33 \mathrm{ClN} 2 \mathrm{O} 5 \mathrm{~S}$ & 84.9 \\
\hline Cotinine & 176.0948 & $\mathrm{C} 10 \mathrm{H} 12 \mathrm{~N} 2 \mathrm{O}$ & 82.7 \\
\hline DEET & 191.1308 & $\mathrm{C} 12 \mathrm{H} 17 \mathrm{NO}$ & 94.6 \\
\hline Desacetyl diltiazem & 372.1503 & $\mathrm{C} 20 \mathrm{H} 24 \mathrm{~N} 2 \mathrm{O} 3 \mathrm{~S}$ & 86.7 \\
\hline Dextrometorphan & 271.1932 & $\mathrm{C} 18 \mathrm{H} 25 \mathrm{NO}$ & 86.3 \\
\hline Doxylamine & 270.1729 & $\mathrm{C} 17 \mathrm{H} 22 \mathrm{~N} 2 \mathrm{O}$ & 78.9 \\
\hline Fluconazole & 306.1035 & $\mathrm{C} 13 \mathrm{H} 12 \mathrm{~F} 2 \mathrm{~N} 6 \mathrm{O}$ & 84.7 \\
\hline Fluridone & 329.1022 & $\mathrm{C} 19 \mathrm{H} 14 \mathrm{~F} 3 \mathrm{NO}$ & 73.0 \\
\hline Galaxolidone & 272.1771 & $\mathrm{C} 18 \mathrm{H} 24 \mathrm{O} 2$ & 93.7 \\
\hline Gential violet & 371.2354 & C25H29N3 & 83.2 \\
\hline Hexamethoxymethyl melamine & 390.2221 & C15H30N6O6 & 72.8 \\
\hline Irbesartan & 428.2319 & $\mathrm{C} 25 \mathrm{H} 28 \mathrm{~N} 6 \mathrm{O}$ & 67.2 \\
\hline Lamotrigine & 255.0075 & $\mathrm{C} 9 \mathrm{H} 7 \mathrm{Cl} 2 \mathrm{~N} 5$ & 85.2 \\
\hline Lidocaine & 234.1729 & $\mathrm{C} 14 \mathrm{H} 22 \mathrm{~N} 2 \mathrm{O}$ & 90.5 \\
\hline
\end{tabular}




\begin{tabular}{|c|c|c|c|}
\hline Losartan & 422.1614 & C22H23CIN6O & 82.7 \\
\hline Memantine & 179.1672 & C12H21N & 90.3 \\
\hline Metoprolol & 267.1830 & $\mathrm{C} 15 \mathrm{H} 25 \mathrm{NO} 3$ & 95.5 \\
\hline Mono(2-ehtylhexyl) phthalate (MEHP) & 278.1512 & $\mathrm{C} 16 \mathrm{H} 22 \mathrm{O} 4$ & 92.6 \\
\hline N,N'-Dicyclohexylurea & 224.1884 & $\mathrm{C} 13 \mathrm{H} 24 \mathrm{~N} 2 \mathrm{O}$ & 98.1 \\
\hline N,N-Diethylethanolamine & 117.1155 & $\mathrm{C} 6 \mathrm{H} 15 \mathrm{NO}$ & 92.6 \\
\hline N,N'-Diphenylguanidine & 211.1108 & $\mathrm{C} 13 \mathrm{H} 13 \mathrm{~N} 3$ & 65.9 \\
\hline N-Ethylamphetamine & 163.1359 & C11H17N & 83.1 \\
\hline O-Desmethyltramadol & 249.1725 & $\mathrm{C} 15 \mathrm{H} 23 \mathrm{NO} 2$ & 69.4 \\
\hline O-Desmethylvenlafaxine & 263.1881 & $\mathrm{C} 16 \mathrm{H} 25 \mathrm{NO} 2$ & 66.9 \\
\hline Oleamide & 281.2714 & $\mathrm{C} 18 \mathrm{H} 35 \mathrm{NO}$ & 89.0 \\
\hline Oxycodone & 315.1465 & $\mathrm{C} 18 \mathrm{H} 21 \mathrm{NO} 4$ & 82.6 \\
\hline Pyroquilon & 173.0840 & $\mathrm{C} 11 \mathrm{H} 11 \mathrm{NO}$ & 71.6 \\
\hline Sulfamethoxazole & 253.0518 & $\mathrm{C} 10 \mathrm{H} 11 \mathrm{~N} 3 \mathrm{O} 3 \mathrm{~S}$ & 75.2 \\
\hline Tributyl phosphate & 266.1642 & $\mathrm{C} 12 \mathrm{H} 27 \mathrm{O} 4 \mathrm{P}$ & 84.8 \\
\hline Trimethoprim & 290.1374 & $\mathrm{C} 14 \mathrm{H} 18 \mathrm{~N} 4 \mathrm{O} 3$ & 95.8 \\
\hline Tris(2-butoxyethyl) phosphate & 398.2425 & C18H39O7P & 83.3 \\
\hline Valsartan & 435.2264 & $\mathrm{C} 24 \mathrm{H} 29 \mathrm{~N} 5 \mathrm{O} 3$ & 82.9 \\
\hline Venlafaxine & 277.2038 & $\mathrm{C} 17 \mathrm{H} 27 \mathrm{NO} 2$ & 80.9 \\
\hline \multicolumn{4}{|c|}{ Negative Mode Ionization } \\
\hline 12-Hydroxydodecanoic acid & 216.17227 & $\mathrm{C} 12 \mathrm{H} 24 \mathrm{O} 3$ & 88.9 \\
\hline 2,4-Bis(2-methylbutan-2-yl)phenol & 234.19821 & $\mathrm{C} 16 \mathrm{H} 26 \mathrm{O}$ & 82.3 \\
\hline 2,5-di-tert-Butylhydroquinone & 222.16194 & $\mathrm{C} 14 \mathrm{H} 22 \mathrm{O} 2$ & 69.7 \\
\hline 2,6-di-tert-Butylphenol & 206.16672 & $\mathrm{C} 14 \mathrm{H} 22 \mathrm{O}$ & 85.4 \\
\hline $\begin{array}{l}\text { 3,5-di-tert-Butyl-4-hydroxybenzyl } \\
\text { alcohol }\end{array}$ & 236.17758 & $\mathrm{C} 15 \mathrm{H} 24 \mathrm{O} 2$ & 77.4 \\
\hline 4-Nitrophenol & 139.02578 & C6H5NO3 & 72.1 \\
\hline Bicalutamide & 430.06175 & C18H14F4N2O4S & 90.3 \\
\hline Dinoterb & 240.07463 & $\mathrm{C} 10 \mathrm{H} 12 \mathrm{~N} 2 \mathrm{O} 5$ & 83.0 \\
\hline Hexadecanoic acid & 286.21502 & $\mathrm{C} 16 \mathrm{H} 32 \mathrm{O} 2$ & 76.7 \\
\hline Linoleic acid & 280.24058 & $\mathrm{C} 18 \mathrm{H} 32 \mathrm{O} 2$ & 69.8 \\
\hline Mycophenolic acid & 320.12645 & $\mathrm{C} 17 \mathrm{H} 20 \mathrm{O} 6$ & 67.4 \\
\hline
\end{tabular}




\begin{tabular}{|l|c|c|c|}
\hline N4-Acetylsulfamethoxazole & $\mathbf{2 9 5 . 0 6 3 4 3}$ & C12H13N3O4S & $\mathbf{8 8 . 8}$ \\
\hline Palmitoleic acid & 254.22484 & C16H30O2 & 85.2 \\
\hline Tretinoin & 300.20962 & C20H28O2 & 90.1 \\
\hline Valsartan & 435.22771 & C24H29N5O3 & 82.4 \\
\hline
\end{tabular}


Appendix 7. Kendrick mass defect plots of the four sampling sites, illustrating the distribution of components
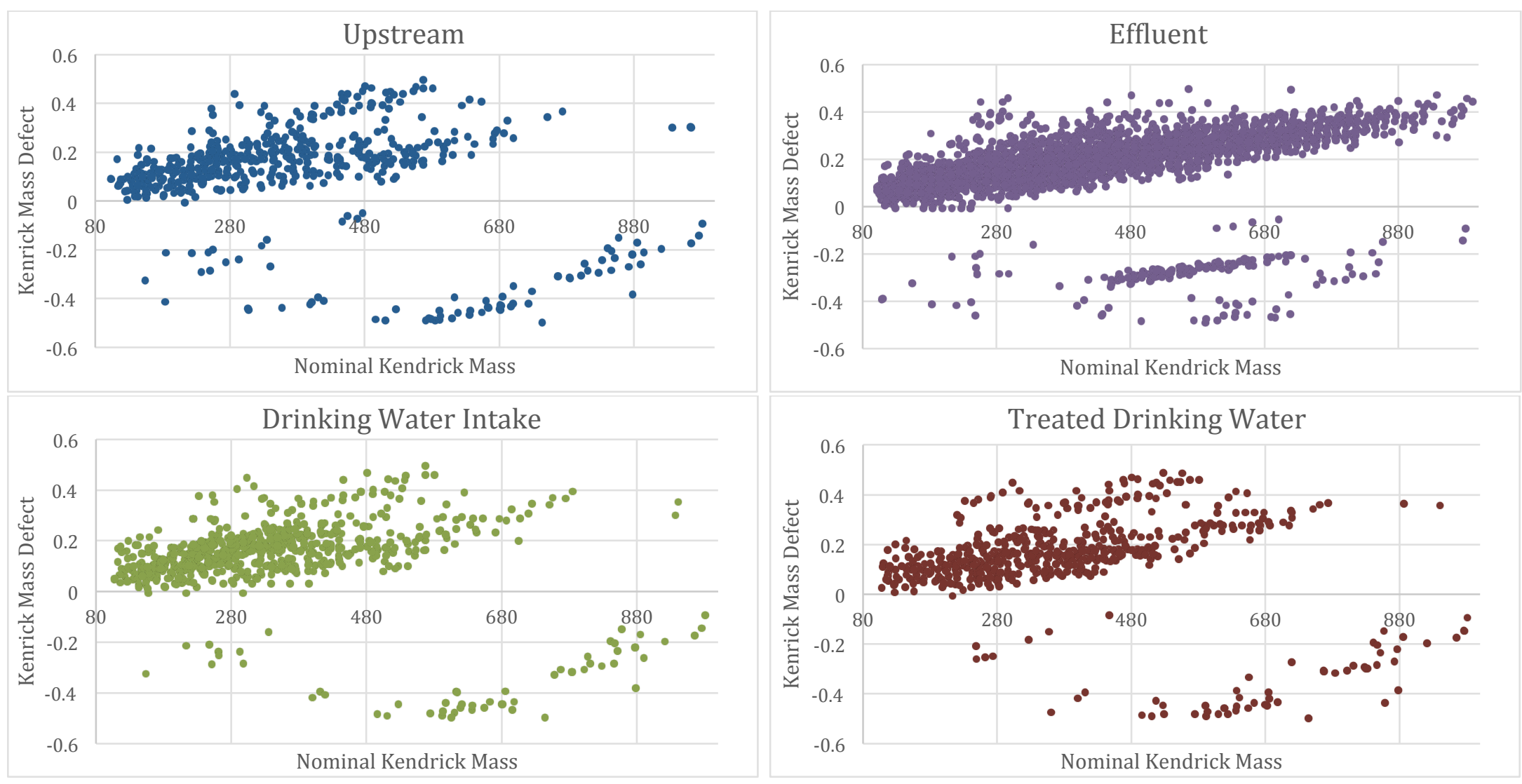
Appendix 8. List of compounds tentatively identified in the POCIS samples (bolded entries represent compounds only picked up in the POCIS samples and not in the grab samples)

\begin{tabular}{|c|c|c|c|}
\hline Compound Name & $\begin{array}{l}\text { Molecular } \\
\text { Weight }\end{array}$ & $\begin{array}{l}\text { Molecular } \\
\text { Formula }\end{array}$ & $\begin{array}{c}\text { mzCloud } \\
\text { Score }(\%)\end{array}$ \\
\hline \multicolumn{4}{|c|}{ Positive Mode Ionization } \\
\hline $\begin{array}{l}\text { 10,11-Dihydro-10,11- } \\
\text { dihydroxycarbamazepine }\end{array}$ & 270.09992 & C15H14N2O3 & 64.7 \\
\hline $\begin{array}{l}\text { 2-Ethylidene-1,5-dimethyl-3,3- } \\
\text { diphenylpyrrolidine (EDDP) }\end{array}$ & 277.18242 & $\mathrm{C} 20 \mathrm{H} 23 \mathrm{~N}$ & 87.0 \\
\hline 5-Methylbenzotriazole & 133.06380 & $\mathrm{C} 7 \mathrm{H} 7 \mathrm{~N} 3$ & 90.7 \\
\hline 5,6-Dimethylbenzimidazole & 146.08417 & C9H10N2 & 62.2 \\
\hline Adenosine & 267.09693 & C10H13N5O4 & 91.0 \\
\hline Anabasine & 162.11554 & C10H14N2 & 93.6 \\
\hline Benzotriazole & 119.04841 & C6H5N3 & 95.6 \\
\hline Bis(2-ethylhexyl) sebacate & 426.37038 & C26H50O4 & 84.1 \\
\hline Carbamazepine & 236.09438 & $\mathrm{C} 15 \mathrm{H} 12 \mathrm{~N} 2 \mathrm{O}$ & 95.0 \\
\hline Carbendazim & 191.06923 & $\mathrm{C} 9 \mathrm{H} 9 \mathrm{~N} 3 \mathrm{O} 2$ & 79.0 \\
\hline Cetirizine & 388.15441 & $\mathrm{C} 21 \mathrm{H} 25 \mathrm{ClN} 2 \mathrm{O} 3$ & 92.0 \\
\hline Choline & 103.10002 & C5H14NO & 85.0 \\
\hline DEET & 191.13071 & $\mathrm{C} 12 \mathrm{H} 17 \mathrm{NO}$ & 94.8 \\
\hline Desacetyl diltiazem & 372.14994 & $\mathrm{C} 20 \mathrm{H} 24 \mathrm{~N} 2 \mathrm{O} 3 \mathrm{~S}$ & 85.6 \\
\hline Diphenhydramine & 255.16176 & C17H21NO & 88.8 \\
\hline Doxylamine & 270.17276 & $\mathrm{C} 17 \mathrm{H} 22 \mathrm{~N} 2 \mathrm{O}$ & 63.4 \\
\hline Escitalopram & 324.16300 & C20H21FN2O & 77.7 \\
\hline Flecainide & 414.13686 & C17H20F6N2O3 & 88.8 \\
\hline Flurandrenolide & 436.22825 & C24H33FO6 & 64.0 \\
\hline Galaxolidone & 272.17701 & $\mathrm{C} 18 \mathrm{H} 24 \mathrm{O} 2$ & 90.6 \\
\hline Hexamethoxymethyl melamine & 390.22167 & C15H30N6O6 & 90.5 \\
\hline Irbesartan & 428.23121 & $\mathrm{C} 25 \mathrm{H} 28 \mathrm{~N} 6 \mathrm{O}$ & 92.9 \\
\hline Isoquinoline & 129.05776 & C9H7N & 78.5 \\
\hline Lamotrigine & 255.00739 & $\mathrm{C} 9 \mathrm{H} 7 \mathrm{Cl} 2 \mathrm{~N} 5$ & 92.4 \\
\hline Lidocaine & 234.17280 & $\mathrm{C} 14 \mathrm{H} 22 \mathrm{~N} 2 \mathrm{O}$ & 86.6 \\
\hline Methylenedioxypyrovalerone (MDPV) & 275.15166 & C16H21NO3 & 70.4 \\
\hline
\end{tabular}




\begin{tabular}{|c|c|c|c|}
\hline Metoprolol & 267.18289 & C15H25NO3 & 93.5 \\
\hline N-Ethylamphetamine & 163.13589 & $\mathrm{C} 11 \mathrm{H} 17 \mathrm{~N}$ & 82.0 \\
\hline N,N'-Dicyclohexylurea & 224.18837 & $\mathrm{C} 13 \mathrm{H} 24 \mathrm{~N} 2 \mathrm{O}$ & 92.2 \\
\hline N,N'-Diphenylguanidine & 211.11065 & $\mathrm{C} 13 \mathrm{H} 13 \mathrm{~N} 3$ & 85.7 \\
\hline Norharman & 168.06851 & C11H8N2 & 66.8 \\
\hline Octadecanamine & 269.30774 & C18H39N & 77.8 \\
\hline Pregnenolone & 316.23945 & C21H32O2 & 68.3 \\
\hline Tetraglyme & 222.14634 & $\mathrm{C} 10 \mathrm{H} 22 \mathrm{O5}$ & 68.7 \\
\hline Tramadol & 263.18802 & C16H25NO2 & 80.5 \\
\hline Trans-3-Hydroxycotinine & 192.09013 & C10H12N2O2 & 82.0 \\
\hline Triethyl phosphate & 182.07056 & C6H15O4P & 80.6 \\
\hline Triphenyl phosphate & 326.06945 & C18H15O4P & 87.6 \\
\hline Tris(2-butoxyethyl) phosphate & 398.24237 & C18H39O7P & 84.6 \\
\hline Ursolic acid & 456.35970 & C30H4803 & 82.0 \\
\hline Venlafaxine & 277.20360 & $\mathrm{C} 17 \mathrm{H} 27 \mathrm{NO} 2$ & 79.6 \\
\hline \multicolumn{4}{|c|}{ Negative Mode Ionization } \\
\hline 1,2-Benzisothiazolin-3-one & 151.0080 & C7H5NOS & 76.2 \\
\hline 2-Naphthalenesulfonic acid & 208.01893 & C10H8SO3 & 81.0 \\
\hline 4-Methylbenzotriazole & 133.06270 & C7H7N3 & $\mathbf{5 2 . 0}$ \\
\hline 4-Nonylphenol & 220.18208 & С15Н24O & 77.7 \\
\hline Myristyl sulfate & 294.18654 & C14H30O4S & 80.3 \\
\hline $\begin{array}{l}\text { Perfluoro-1-hexanesulfonic acid } \\
\text { (PFHxS) }\end{array}$ & 399.94418 & C6HF13O3S & 84.9 \\
\hline
\end{tabular}


VITA

ANNA KATARINA HUBA

2016

Dissertation Evidence Acquisition Fellowship (DEA)

FIU Graduate School

Miami, Florida

2012

B.S., Chemistry

Florida Institute of Technology

Melbourne, Florida

\section{PUBLICATIONS AND PRESENTATIONS}

Anna K. Huba, Susan T. Glassmeyer, Mark A. Mills, and Piero R. Gardinali. Occurrence of Suspect and Non-Target Contaminants in a Linked Surface Water System Influenced by Treated Wastewater. (To be submitted).

Anna K. Huba, Kristina Huba, and Piero R. Gardinali. Understanding the Atmospheric Pressure Ionization of Petroleum Components: the Effect of Size, Structure, and Presence of Heteroatoms. Science of The Total Environment, 568 (2016) 1018-1025.

Anna K. Huba, Piero R. Gardinali. Characterization of a crude oil weathering series by ultra-high resolution mass spectrometry using multiple ionization modes. Science of The Total Environment, 563-564 (2016), 600-610.

Anna K. Huba, Piero R. Gardinali. Occurrence of suspect and non-target contaminants and their transformation products in a linked surface water system influenced by treated wastewater. $7^{\text {th }}$ SETAC World Congress/SETAC North America $37^{\text {th }}$ Annual Meeting, Orlando (FL). November $9^{\text {th }}, 2016$.

Anna K. Huba, Piero R. Gardinali. Detection of contaminants of emerging concern in surface water samples impacted by wastewater using a suspect-target and non-target high-resolution mass spectrometry screening workflow. Nontarget2016, Ascona (Switzerland). May 30 ${ }^{\text {th }}, 2016$.

Anna K. Huba, Piero R. Gardinali. Evaluation of a suspected-target high-resolution mass spectrometry method for the preliminary detection of contaminants of emerging concern in water samples impacted by wastewater. SETAC Europe, Nantes (France). May $25^{\text {th }}$, 2016.

Anna K. Huba, Piero R. Gardinali. Comparison of ionization efficiencies of petroleum model compounds using atmospheric pressure ionization. SETAC North America Meeting, Salt Lake City (UT). November $2^{\text {nd }}, 2015$. 
Anna K. Huba, Piero R. Gardinali. Understanding the atmospheric pressure ionization of petroleum components: the effect of size, structure, and presence of heteroatoms. American Chemical Society National Meeting, Boston (MA). August 16 $6^{\text {th }}, 2015$.

Anna K. Huba, Sudha R. Batchu, Yan Ding, Kathia Sandoval, J. Daniel DeBord, Francisco A. Fernandez-Lima, Piero R. Gardinali. Characterization of Oils Using Comprehensive Mass Spectrometry. Chemistry \& Biochemistry Graduate Student Visitation Day, FIU. March $7^{\text {th }}, 2014$. 